\title{
Experimental and Theoretical Studies of Metal Adsorbates Interacting with Elemental Semiconductor Surfaces
}

Hafiz Muhammad Sohail

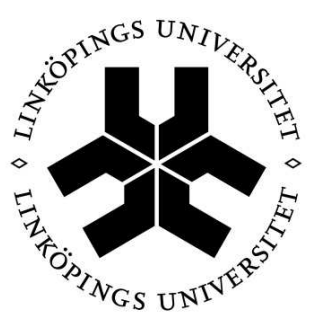

\section{Linköping University}

INSTITUTE OF TECHNOLOGY

Surface and Semiconductor Physics Division

Department of Physics, Chemistry and Biology

Linköping University, SE-581 83 Linköping, Sweden

Linköping 2014 
Cover shows LEED, STM and ARPES images of the $\mathrm{Sn} / \mathrm{Ag} / \mathrm{Ge}(111) 3 \times 3$ surface.

During the course of the research underlying this thesis, Hafiz Muhammad Sohail was enrolled in the graduate school Agora Materiae, a doctoral program within the field of advanced and functional materials at Linköping University, Sweden.

Copyright @ 2014 Hafiz Muhammad Sohail, unless otherwise noted.

All rights reserved.

ISBN: 978-91-7519-399-1

ISSN: 0345-7524

Print by LiU-Tryck, Linköping, Sweden 2014 


\section{Abstract}

Metal adsorbates on semiconductor surfaces have been widely studied over the last few decades. The main interest is focused on various one or two-dimensional structures that exhibit interesting electronic and atomic properties. This thesis focuses on metal adsorbates interacting with the $\mathrm{Si}(111)$ and $\mathrm{Ge}(111)$ surfaces. The main experimental techniques used in the thesis include angle resolved photoelectron spectroscopy (ARPES), core-level spectroscopy, scanning tunneling microscopy (STM), and low energy electron diffraction (LEED). The experimental studies have, in some cases, been complemented by theoretical electronic structure investigations based on density functional theory (DFT).

Silver (Ag), a noble metal, gives rise to several reconstructions on the (111) surfaces of $\mathrm{Si}$ and $\mathrm{Ge}$. The $\mathrm{Ag} / \mathrm{Si}(111) \sqrt{3} \times \sqrt{3}$ surface has been extensively studied, but the $\mathrm{Ag} / \mathrm{Ge}(111)$ $\sqrt{3} \times \sqrt{3}$ surface has not been given similar attention, and there are no detailed experimental nor calculated electronic band structures available in the literature. Thus, a detailed ARPES investigation of the electronic structure of the $\mathrm{Ag} / \mathrm{Ge}(111) \sqrt{3} \times \sqrt{3}$ surface, with nominally 1 monolayer (ML) of $\mathrm{Ag}$, is presented in the thesis together with its atomic structure.

The $\operatorname{Ag} / \operatorname{Si}(111) \sqrt{3} \times \sqrt{3}$ and $\operatorname{Ag} / \operatorname{Ge}(111) \sqrt{3} \times \sqrt{3}$ surfaces were also studied by first principles DFT based calculations (WIEN2k). Two atomic models have been suggested for the $\sqrt{3} \times \sqrt{3}$ surfaces in the literature, i.e., the honeycomb-chained-trimer (HCT) and the in-equivalent trimer (IET) models. Band structure calculations were performed for both models, and comparisons between calculated and experimental surface band structures are presented for the $\mathrm{Si}$ and $\mathrm{Ge}$ cases.

Adding approximately $0.2 \mathrm{ML}$ of $\mathrm{Ag}$ to $\mathrm{Ag} / \mathrm{Ge}(111) \sqrt{3} \times \sqrt{3}$ results in a $6 \times 6$ phase. The electronic structure of the surface is presented in detail. Several new bands appear in the energy region close the Fermi level, which can all be explained by umklapp scattering by reciprocal lattice vectors of the $6 \times 6$ lattice. A metal to semiconductor transition, associated with the $\sqrt{3} \times \sqrt{3}$ to $6 \times 6$ structural change, is explained by gaps opening up where the umklapp scattered bands cross. 
After having established sufficient understanding of the $\operatorname{Ag} / \operatorname{Si}(111) \sqrt{3} \times \sqrt{3}$ and $\mathrm{Ag} / \mathrm{Ge}(111) \sqrt{3} \times \sqrt{3}$ surfaces, they were used as substrates for the formation of binary surface alloys. An amount of $0.45 \mathrm{ML}$ of $\mathrm{Sn}$, in combination with the $\mathrm{Ag}$ of the $\mathrm{Ag} / \mathrm{Ge}(111) \sqrt{3} \times \sqrt{3}$ surface, forms a well-defined $3 \sqrt{3} \times 3 \sqrt{3}$ binary alloy. The surface band structure shows some modifications compared to that of $\mathrm{Ag} / \mathrm{Ge}(111) \sqrt{3} \times \sqrt{3}$ surface. The STM results show clearly the $3 \sqrt{3} \times 3 \sqrt{3}$ periodicity.

A Sn coverage of $0.75 \mathrm{ML}$ on the $\mathrm{Ag} / \mathrm{Ge}(111) \sqrt{3} \times \sqrt{3}$ surface results in a very wellordered $3 \times 3$ surface alloy. This alloy shows a very rich surface band structure in which the upper band exhibits peculiar splits. Two-dimensional constant energy contour data reveal the existence of two rotated contours which is related to the presence of split bands in certain directions. STM images show a hexagonal or a honeycomb structure depending on sample to tip bias.

A similar amount of $\mathrm{Sn}(0.75 \mathrm{ML})$ was also evaporated onto the $\mathrm{Ag} / \mathrm{Si111}) \sqrt{3} \times \sqrt{3}$ surface, with the purpose to form a surface alloy on $\mathrm{Si}(111)$. This resulted in a very well-ordered $\mathrm{Sn} / \mathrm{Ag} / \mathrm{Si}(111) 2 \times 2$ periodicity. The surface shows an interesting free electron like band which crosses the Fermi level. STM images reveal clear, but differently looking, protrusions in the $2 \times 2$ unit cell when comparing empty and filled state images. The atomic structure of the surface alloy was modelled by DFT calculations using structural information provided by the STM images. The modelling resulted in a structure consisting of $\mathrm{Sn}$ and $\mathrm{Ag}$ trimers and a fourth $\mathrm{Ag}$ atom located at the corner of the $2 \times 2$ cell. In addition, the calculated electronic structure based on the proposed model is consistent with experimental results, which verifies the atomic model.

Another combination of metals, 1.33 ML of $\mathrm{Pb}$ and $0.85 \mathrm{ML}$ of In, resulted in the formation of a well-defined $\mathrm{In} / \mathrm{Pb} / \mathrm{Ge}(111) 3 \times 3$ surface alloy. The $3 \times 3$ surface exhibits an interesting band structure where five surface bands were identified of which four cross the Fermi level resulting in a metallic character of the surface. Two-dimensional constant energy data reveal the presence of intricate rotated hexagon like contours which intersect each other along the $\bar{\Gamma}-\bar{K}$ and $\bar{\Gamma}-\bar{M}$ directions of the surface Brillouin zone. The STM results reveal nine bright protrusions per $3 \times 3$ unit cell. 


\section{Populärvetenskaplig sammanfattning}

Avhandlingen handlar om ytors elektron- och atomstruktur. Växelverkan mellan ett material och dess omgivning bestäms av ytans egenskaper, och då främst av dess elektronstruktur vilken bestämmer t.ex. de kemiska och elektriska egenskaperna. En detaljerad bild innefattar kunskap om de kvantmekaniskt tillåtna energitillstånden för elektronerna i materialet. En beskrivning på en nivå med rimlig komplexitet förutsätter ett kristallint material, d.v.s. att atomerna som bygger upp materialet sitter i positioner som kan beskrivas av en enhetscell. För kristallina material kan elektronstrukturen karakteriseras genom att bestämma elektronernas energi $(E)$ som funktion av deras vågvektor $(\bar{k})$ i kristallen. Sambandet mellan E och $\bar{k}$ kallas bandstruktur och utseendet av elektronbanden varierar beroende på vågvektorns riktning i den tredimensionella kristallen. Ytans elektronstruktur skiljer sig från den inuti materialet, dels på grund av att ytatomerna bara har grannar på ena sidan av ytans plan, men också för att ytan är tvådimensionell istället för tredimensionell. Det senare förhållandet gör att elektronernas energier bara beror på en tvådimensionell vågvektor $\left(\bar{k}_{\|}\right)$som är parallell med ytans plan. Elektronstrukturen beskrivs kortfattat som $E\left(\bar{k}_{\|}\right)$. Eftersom atomerna i ytan bara har grannar på ena sidan finns en möjlighet för dem att inta positioner som inte motsvarar lägen innanför ytlagret. En sådan förändring av atomstrukturen kallas för en rekonstruktion. Rekonstruerade ytor är fortfarande kristallina men i två dimensioner. De tvådimensionella enhetscellerna kan variera mycket i form, storlek och i den detaljerade atomstruktur som de beskriver. Som en konsekvens av detta, varierar bandstrukturen och därmed de elektroniska egenskaperna mellan olika rekonstruktioner.

Ytor av enkristallint kisel (Si) och germanium $(\mathrm{Ge})$ har varit föremål för studierna som presenteras i denna avhandling. Båda grundämnena är halvledare vilket innebär att det finns ett energigap mellan fyllda elektrontillstånd i valensbandet och tomma tillstånd i ledningsbandet. Denna egenskap hos det tredimensionella materialet är absolut avgörande för halvledares användning i olika elektroniska komponenter. Vid ytan blir situation emellertid annorlunda. För $\mathrm{Si}$ och Ge karakteriseras en ytas egenskaper av förekomsten av brutna bindningar. Dessa 
motsvarar elektronorbitaler som innehåller en elektron vardera och är riktade ut från ytan. Energierna för dessa elektroner är förhållandevis höga och en reduktion av energin kan åstadkommas genom en rekonstruktion av ytan, d.v.s. atomerna ändrar läge för att skapa nya bindningar och på så sätt åstadkomma en energiminimering. Fundamentala förändringar av elektronstrukturen på ytan, som en övergång från att vara elektriskt ledande till att bli halvledande och vice versa, är konsekvenser av den förändrade periodiciteten.

Förändringar av elektron- och atomstruktur hos (111)-ytor av Si och Ge har varit föremål för experimentella och teoretiska studier i avhandlingen. En (111)-yta karakteriseras av att varje ytatom har en elektronorbital, med en elektron, riktad vinkelrätt ut från den orekonstruerade ytan. Detta förhållande gör att (111)-ytorna av Si och Ge är starkt benägna att ändra sin struktur för att minska den totala energin. De är därför speciellt lämpade för studier av rekonstruktioner som uppstår när främmande atomer adsorberas.

Ag, som är en ädelmetall, ger upphov till en rekonstruktion, bland många andra, som beskrivs av en enhetscell som är $\sqrt{3}$ gånger så stor som enhetscellen för den orekonstruerade ytan längs var och en av de två vektorer som spänner upp cellen. Med gängse beteckningssätt benämns en sådan yta enligt $\mathrm{Ag} / \mathrm{Si}(111) \sqrt{3} \times \sqrt{3}$ och $\mathrm{Ag} / \mathrm{Ge}(111) \sqrt{3} \times \sqrt{3}$, för Si respektive Ge. I avhandlingen presenteras en detaljerad studie av elektronstrukturen uppmätt med hjälp av vinkelberoende fotoemission som resulterar $\mathrm{i}$ en bestämning av den tvådimensionella bandstrukturen, $E\left(\bar{k}_{\|}\right)$. En jämförelse mellan experimentella resultat för $\mathrm{Si}$ och $\mathrm{Ge}$, och mellan experimentella och teoretiska resultat, vilka utgör en del av avhandlingsarbetet, har lett till en mer detaljerad bild av ytornas atom- och elektronstrukturer. Information om atomstrukturer har också erhållits genom avbildning med hjälp av sveptunnelmikroskopi (STM). Den topografiska informationen, i form av bilder med atomär upplösning, har jämförts med simulerade bilder baserade på den beräknade elektronstrukturen. STM har genomgående använts i studierna av de olika ytorna i avhandlingen.

$\mathrm{Ag} / \mathrm{Ge}(111) \sqrt{3} \times \sqrt{3}$ har använts för att studera en övergång från en metallisk till en halvledande elektronstruktur som beror av mängden $\mathrm{Ag}$ på ytan. Genom att addera 0,2 monolager (ML) av Ag till det monolager av Ag som redan finns på ytan, fås en periodicitet som motsvarar en $\mathrm{Ag} / \mathrm{Ge}(111) 6 \times 6$-yta. Resultaten i avhandlingen visar att övergången till en halvledande elektronstrukturen orsakas av ett energigap som uppstår när elektronband korsar varandra. På 6×6-ytan korsar yttillståndsband, med ursprung från $\sqrt{3} \times \sqrt{3}$-ytan, varandra på grund av s.k. Umklappspridning orsakad av den ändrade periodiciteten.

Efter att ha etablerat en tillräcklig kunskap om elektron- och atomstrukturen vad gäller $\mathrm{Ag} / \mathrm{Si}(111) \sqrt{3} \times \sqrt{3}$ och $\mathrm{Ag} / \mathrm{Ge}(111) \sqrt{3} \times \sqrt{3}$, användes dessa ytor som substrat för att bilda binära ytlegeringar. Kombinationer av $\mathrm{Ag}$ och $\mathrm{Sn}$ studerades på både $\mathrm{Ag} / \mathrm{Si}(111) \sqrt{3} \times \sqrt{3}$ och $\mathrm{Ag} / \mathrm{Ge}(111) \sqrt{3} \times \sqrt{3}$ medan In kombinerat med $\mathrm{Pb}$ studerades enbart på $\mathrm{Ag} / \mathrm{Ge}(111) \sqrt{3} \times \sqrt{3}$. Binära ytlegeringar öppnar upp en möjlighet att skapa en rad olika ytbandstrukturer. En avgörande förutsättning är att ytlegeringen är periodisk, d.v.s. är kristallin i två dimensioner. Studien innefattar följande välordnade ytlegeringar, $\mathrm{Sn} / \mathrm{Ag} / \mathrm{Ge}(111) 3 \sqrt{3} \times 3 \sqrt{3}$, $\mathrm{Sn} / \mathrm{Ag} / \mathrm{Ge}(111) 3 \times 3, \mathrm{In} / \mathrm{Pb} / \mathrm{Ge}(111) 3 \times 3$ och $\mathrm{Sn} / \mathrm{Ag} / \mathrm{Si}(111) 2 \times 2 . \mathrm{Sn} / \mathrm{Ag} / \mathrm{Ge}(111) 3 \sqrt{3} \times 3 \sqrt{3}$ med 
0,45 ML av Sn uppvisade en liten förändring av elektronstrukturen medan den för $\mathrm{Sn} / \mathrm{Ag} / \mathrm{Ge}(111) 3 \times 3$, med $0,75 \mathrm{ML}$ av $\mathrm{Sn}$, var helt förändrad med oväntade uppsplittringar av elektronbanden. Som ett annat exempel kan nämnas att $0,75 \mathrm{ML}$ av Sn i kombination med $1 \mathrm{ML}$ av $\mathrm{Ag}$ resulterade i den extremt välordnade ytlegeringen $\mathrm{Sn} / \mathrm{Ag} / \mathrm{Si}(111) 2 \times 2$ med en mycket enkel ytbandstruktur. Elektronerna följer huvudsakligen den bandstruktur som gäller för s.k. frielektroner i två dimensioner. 


\section{Dedicated to}

My Father and Mother 


\section{Preface}

The PhD work in the present thesis has been performed during the years $2009-2013$ at the Department of Physics, Chemistry and Biology (IFM), Linköping University, Sweden. Within the Surface and Semiconductor Physics division, there is a variable temperature, ultra-high vacuum, scanning tunneling microscope from Omicron (VT-UHV STM). The microscope has been used in all STM studies presented in the thesis. The major part of the research work, which consists of angle resolved photoelectron spectroscopy, has been performed at beamline I4 on the MAX-III storage ring at the MAX-lab synchrotron radiation facility in Lund, Sweden. In some papers, density functional theory based calculations (WIEN2k) have also been included, which were performed on a local computer cluster within the Surface and Semiconductor Physics division. The first chapter of the thesis gives a brief description of the field of the present research. In chapter two, surface structure is summarized briefly. Chapter three describes experimental and theoretical methods used in the present work. Chapter 4 gives a brief introduction to the atomic and electronic structures of the clean Si and Ge surfaces and the last chapter five gives a summary of the included papers. The cover page shows LEED, STM and constant energy contour images of the $\mathrm{Sn} / \mathrm{Ag} / \mathrm{Ge}(111) 3 \times 3$ surface, to give a flavor of the research presented in the thesis.

Hafiz Muhammad Sohail

Linköping, February 2014 


\section{List of the included papers}

Paper I

Electronic and atomic structures of the Ag induced $\sqrt{3} \times \sqrt{3}$ superstructure on $\mathrm{Ge}(111)$

Hafiz M. Sohail and R. I. G. Uhrberg

Accepted for publication in Surface Science.

\section{Paper II}

First principles study of electronic and atomic structures of the $\sqrt{3} \times \sqrt{3}$ superstructures induced by $\mathrm{Ag}$ on $\mathrm{Si}(111)$ and $\mathrm{Ge}(111)$

Hafiz M. Sohail, P. E. J. Eriksson, J. R. Osiecki, and R. I. G. Uhrberg

Manuscript

Paper III

Origin of the metal to semiconductor transition associated with the $\sqrt{3} \times \sqrt{3}$ and $6 \times 6$ surfaces of $\mathrm{Ag} / \mathrm{Ge}(111)$

Hafiz M. Sohail and R. I. G. Uhrberg

Manuscript

\section{Paper IV}

Electronic and atomic structures of a Sn induced $3 \sqrt{3} \times 3 \sqrt{3}$ superstructure on the $\mathrm{Ag} / \mathrm{Ge}(111)$ $\sqrt{3} \times \sqrt{3}$ surface

Hafiz M. Sohail and R. I. G. Uhrberg

Manuscript 


\section{Paper V}

Electronic and atomic structures of a $3 \times 3$ surface formed by a binary $\mathrm{Sn} / \mathrm{Ag}$ overlayer on the Ge(111)c(2×8) surface: ARPES, LEED and STM studies

Hafiz M. Sohail, J. R. Osiecki, and R. I. G. Uhrberg

Phys. Rev. B 85, 205409 (2012).

\section{Paper VI}

Experimental evidence of a highly ordered two-dimensional $\mathrm{Sn} / \mathrm{Ag}$ alloy on $\mathrm{Si}(111)$

Jacek R. Osiecki, Hafiz M. Sohail, P. E. J. Eriksson, and R. I. G. Uhrberg

Phys. Rev. Lett. 109, 057601 (2012).

\section{Paper VII}

Experimental studies of an $\mathrm{In} / \mathrm{Pb}$ binary surface alloy on $\mathrm{Ge}(111)$

Hafiz M. Sohail and R. I. G. Uhrberg

Manuscript 


\section{My contributions to the papers}

\section{Paper I}

Performed all experimental work, analyzed the data, wrote the first version of the manuscript, and prepared the final version of the paper together with my supervisor.

\section{Paper II}

Performed all theoretical calculations with some help from the co-authors, analyzed the data, wrote the first version of the manuscript and prepared the final version of the paper together with my supervisor.

\section{Paper III}

Performed all work, analyzed the data, wrote the first version of the manuscript, and prepared the final version of the paper together my supervisor.

\section{Paper IV}

Performed all experimental work, analyzed the data, wrote the first version of the manuscript and prepared the final version of the paper together with my supervisor.

\section{Paper V}

Performed all experimental work, analyzed the data, wrote the first version of the manuscript and prepared the final version of the paper together with my supervisor.

\section{Paper VI}

Participated in all experimental work, was involved in the calculations at the beginning, and read the final version of the manuscript. 


\section{Paper VII}

Performed all experimental work, analyzed the data, wrote the first version of the manuscript and prepared the final version of the paper together with my supervisor.

NB:- All experimental work at MAX-lab was performed in the presence of my supervisor, which allowed for continuous discussions of results and the progress of the experiments during the intense beam times. 


\section{Paper not included in the thesis}

\section{Paper I}

Broken symmetry induced band splitting in the $\mathrm{Ag}_{2} \mathrm{Ge}$ surface alloy on $\mathrm{Ag}(111)$

W. Wang, Hafiz M. Sohail, Jacek R. Osiecki, and R. I. G. Uhrberg

Accepted for publication in PRB. 


\section{Acknowledgements}

After a long journey of more than six years since I came to Sweden in Aug. 2007, now the time has come to conclude my studies and research. For that I am extremely happy and grateful to many of the individuals who have made important contributions to my successful journey.

My deepest thanks and appreciation goes to my supervisor Prof. Roger Uhrberg. Thank you very much for offering me the opportunity to do $\mathrm{PhD}$ studies in surface and semiconductor physics group. I am very much thankful to your kind behavior throughout the studies. Thanks for the valuable time we spent at MAX-lab with lots of discussions and the time during travelling by car to MAX-lab and back. I got the chance to learn many things related to curriculum and extra curriculum, and I am extremely grateful for all of this. My thanks also go to your wife Karin for having nice discussions at your summer house and at other occasions as well.

I would like to thank my co-supervisor Prof. Leif Johansson, for being so nice throughout the time I spent here in Sweden. Especially during my MS studies at the department your endless support was extremely encouraging for me and I could finish my MS studies before the time.

I am thankful to my mentor Prof. Per Jensen for keeping an eye on my study plans and for being so polite.

I would like to acknowledge the importance of my colleague and friend Dr. Jacek Osiecki, for the great time we spent together at the department. A big thank you for introducing me to the scanning tunneling microscope (STM), the magic instrument! I am also grateful for helping me to use the software that you wrote for analyzing the ARPES data.

I am thankful to Dr. Johan Eriksson for guiding me during the DFT calculations using the WIEN2k simulation package for band structure calculations. 
I am thankful to the beamline I4 staff at MAX-lab, especially Dr. Johan Adell and Dr. T. Balasubramanian, for technical support at the beamline and for all the discussions and nice talks that we had. I got the chance to learn a lot from you, and I am grateful for that.

For the administration work, I am thankful to our group secretary Kerstin Vestin for the help to solve all my administrative issues.

I would like to thank Ulf Frykman for the help regarding computer and networking issues.

Thanks to all other members of the division. Also members of the whole department (IFM), for creating such a nice work and research place.

Last but not the least, I would like to present my deepest thanks and love to all my family members, my father, mother, all sisters, all brothers, all brothers in law, brother's wife (bhabi) and all nephews and nieces. You are all valuable to me, without your support it would be difficult to live abroad and study. So I am so much thankful to you all for your endless support, love and encouragements throughout the time of my stay in Sweden.

I am extremely grateful to my wife, for the love, support and for the best time that we have shared together so far. I would like to wish you All the BEST for the successful completion of your PhD thesis in coming months.

I am thankful to all my friends in Pakistan, in Sweden (especially at the department, IFM), and different parts of the world, you have really made my life joyful.

I would like to acknowledge the importance of many well-wishers, colleagues and students in Pakistan and here in Linköping for your positive attitude towards me. I present a bunch of thanks to you all.

Hafiz Muhammad Sohail

Linköping, February 2014 


$\begin{array}{ll}\text { ARPES } & \text { angle resolved photoelectron spectroscopy } \\ \text { BZ } & \text { Brillouin zone } \\ \text { CB } & \text { conduction band } \\ \text { CLS } & \text { core level spectroscopy } \\ \text { DFT } & \text { density functional theory } \\ \text { EF }_{\text {F }} & \text { Fermi level } \\ \text { ED } & \text { electron diffraction } \\ \text { GGA } & \text { generalized gradient approximation } \\ \text { LEED } & \text { low energy electron diffraction } \\ \text { LAPW } & \text { linearized augmented plane wave } \\ \text { LDA } & \text { local density approximation } \\ \text { LDOS } & \text { local density of states } \\ \text { LT } & \text { low temperature } \\ \text { ML } & \text { monolayer } \\ \text { PES } & \text { photoelectron spectroscopy } \\ \text { RT } & \text { room temperature } \\ \text { SBZ } & \text { surface Brillouin zone } \\ \text { STM } & \text { scanning tunneling microscopy } \\ \text { SCF } & \text { self-consistent field } \\ \text { UHV } & \text { ultra high vacuum } \\ \text { UPS } & \text { ultraviolet photoelectron spectroscopy } \\ \text { VB } & \text { valence band } \\ \text { VT } & \text { variable temperature } \\ \text { XPS } & \text { x-ray photoelectron spectroscopy }\end{array}$




\section{Contents}

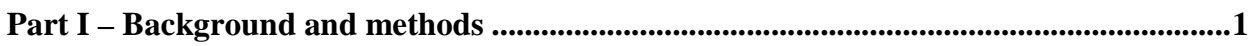

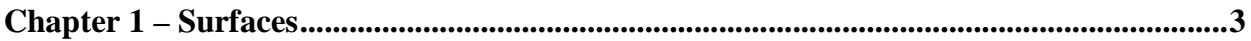

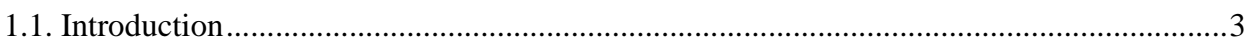

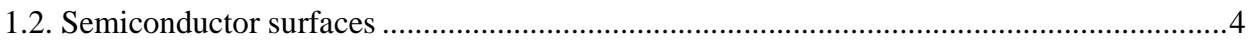

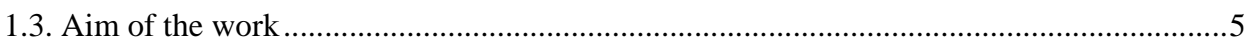

Chapter 2 - Crystal and surface structures ....................................................................................7

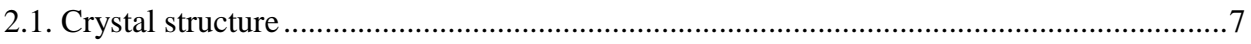

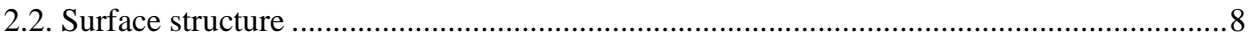

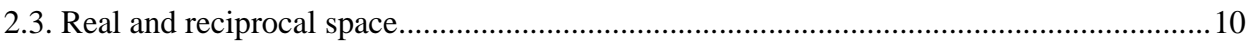

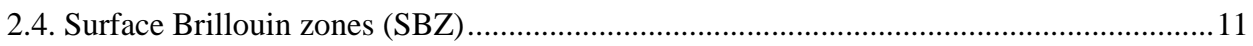

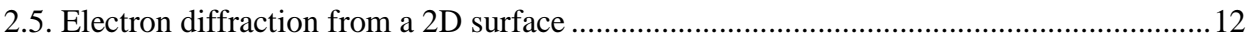

Chapter 3 - Surface characterization methods.................................................................15

A: Experimental methods........................................................................................................15

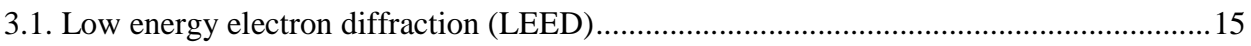

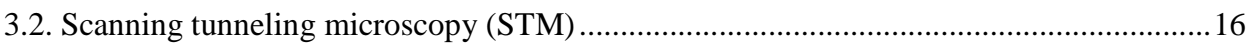

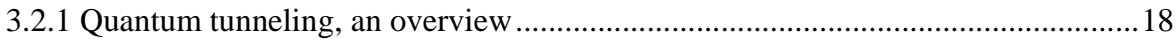

3.2.2 Tersoff-Hamann model for tunneling current .................................................... 19

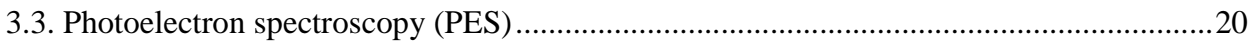

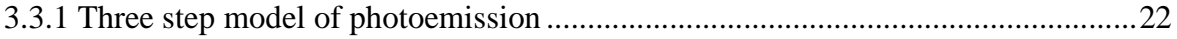

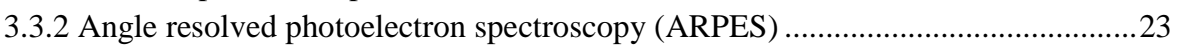

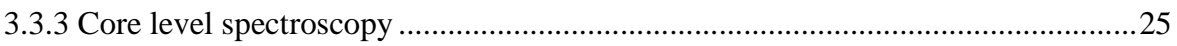

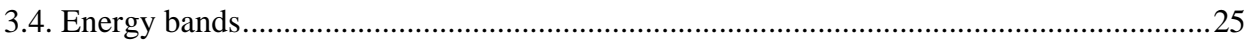

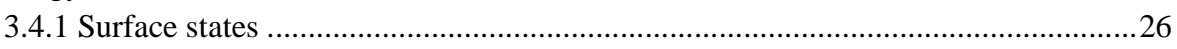

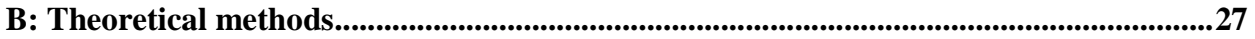




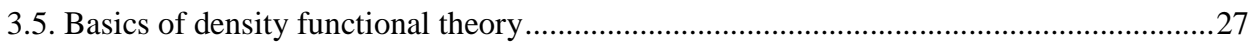

3.5.1 WIEN2k software for electronic structure calculations ........................................28

3.5.2 Structure formation and its geometry in WIEN2k ...........................................28

Chapter 4 - Atomic and electronic structures of semiconductor surfaces ........................31

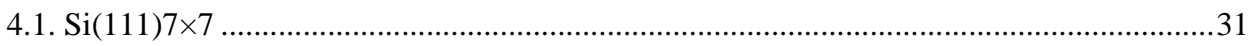

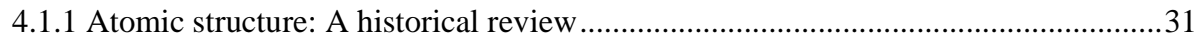

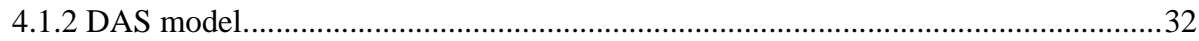

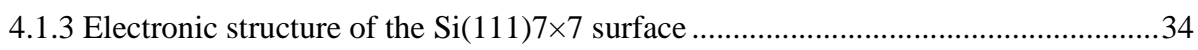

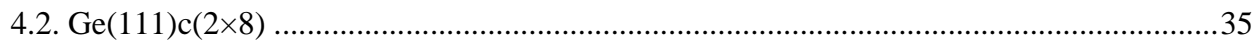

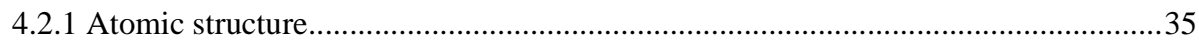

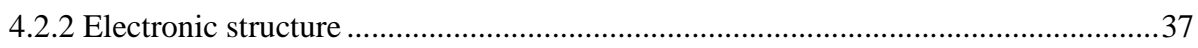

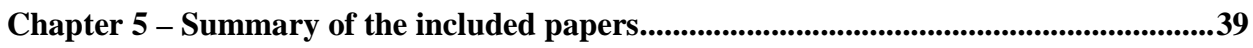

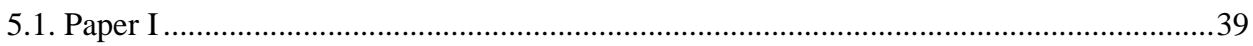

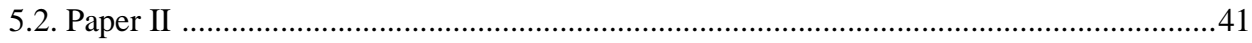

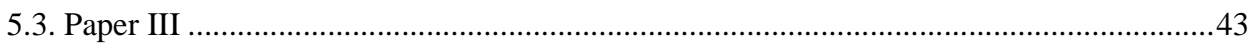

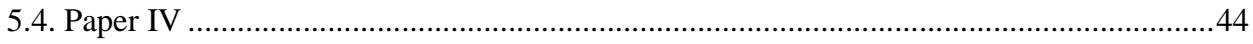

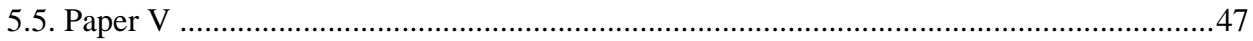

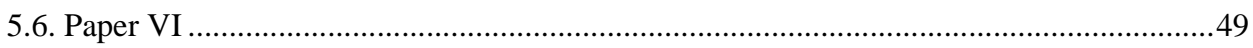

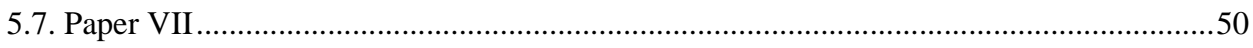

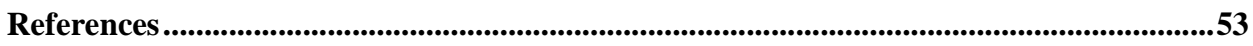

Part II - Included papers ...................................................................................................................57 


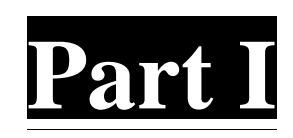

Background and methods 


\section{Chapter 1}

Surfaces

\subsection{Introduction}

Every solid object ends at its surface, where atoms are exposed to various species of the atmosphere. Before the 1960s, a layer with a thickness of about $100 \mathrm{~nm}$ was considered to constitute the surface of a solid [1,2]. With time, as the surface techniques have become more sensitive, the definition has been reconsidered and a surface is in most cases defined as just a few atomic layers [2]. At ambient conditions, surfaces are more or less oxidized and will therefore not have well-defined electronic properties. In order to study fundamental electronic properties one needs solids that are quite well defined. This requirement is fulfilled by single crystals of high purity. Further, it is important to know what atomic species are residing on the surface and their arrangement. For this reason, surfaces must be atomically clean which can be achieved by various evaporation techniques or by ion bombardment under ultra-high vacuum (UHV) conditions, usually at a base pressure of $10^{-10}$ Torr [1]. Even when a surface is prepared under well-defined conditions, there are irregularities such as terraces, atomic steps and kinks on atomically clean surfaces. In addition, vacancies and adatoms are other kinds of defects. Moreover, there is another very important type of modification that is produced by the introduction of foreign atoms on a surface which affects the whole two-dimensional (2D) structure of the surface resulting in new periodicities.

Surfaces are produced in a particular crystallographic direction in various ways. The surface formation may result in various modifications of the outermost atomic layers forming the surface. If the positions of atoms in the top layer do not deviate from their bulk equilibrium positions, the solid is said to be bulk terminated, as shown in Fig. 1.1(a). A small deviation from the simple bulk termination is shown in Fig. 1.1(b), where the topmost layer of atoms has found a new equilibrium position in the z-direction. This change is known as relaxation. Both outward and inward relaxations of the outer layer are possible. In the simplest case of relaxation, the in plane symmetry of the atomic arrangement remains the same as in the bulk. In the more general case, atoms in a few layers close to the surface will move in xyz directions to find new equilibrium 
positions. Such a surface constitutes a new structure which always has different periodicity compared to that of the bulk terminated solid. This extreme modification is known as surface reconstruction. As an example, a reconstruction limited to the upper layer corresponding to a doubling of the lattice constant is shown by Fig. 1.1(c). In addition, a surface reconstruction process modifies the symmetry at the surface and in the near surface region, which strongly affects the surface related properties, such as optical, chemical and electronic properties. Changes of these properties, when going from a situation with a 3D periodic potential as in the bulk of the solid to the $2 \mathrm{D}$ potential of the surface, is of major physical interest. Further, an obvious property of a surface is the lack of nearest neighbors on one side which results in missing chemical bonds that will strongly affect the chemical and electrical properties. In the field of surface physics, various reconstructed surfaces either on metals or semiconductors have been widely studied during the last few decades. The work in this thesis is concentrated on metal induced reconstructions on silicon and germanium surfaces.

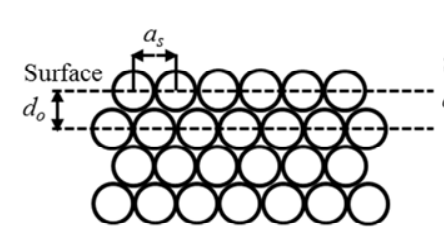

(a) Bulk terminated

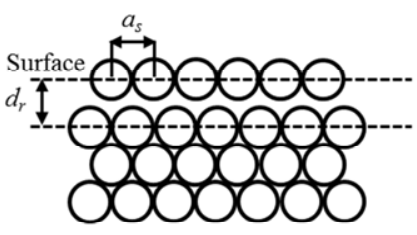

(b) Simple relaxation

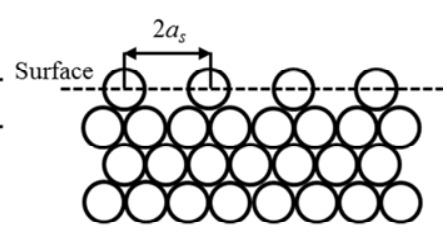

(c) Reconstruction

Figure 1.1 Schematic drawing of disturbances produced during surface formation. Three distinct cases are shown. (a) Bulk termination, where the surface atoms are still in bulk positions, (b) A simple outward relaxation of the surface layer (the relaxation could also be inward) and (c) An extreme case of modification leading to a reconstruction of the surface with a periodicity that is different from that of the bulk. [From ref. 2, modified]

\subsection{Semiconductor surfaces}

Surfaces of the elemental semiconductors, $\mathrm{Si}$ and $\mathrm{Ge}$, reconstruct into new atomic arrangements when they are created. The formation of new bonds, from those that are broken when the surface is created, is the main driving force for reconstruction. Semiconductor surfaces can be produced along crystallographic planes in many ways, but along the (111) plane they are produced by cleavage or by cutting a crystal into thin slices, typically in the form of wafers. The wafers are then polished to create mirror like surfaces. Along the (111) plane, the surface contains dangling bonds that are perpendicular to the plane. These dangling bonds contain one electron each, but can accommodate two electrons with opposite spins. To lower the free energy of the surface it reconstructs into structures which have lower surface energy and fewer dangling bonds. Due to the presence of dangling bonds on (111) surfaces of semiconductors, they are very reactive and interact with atoms and molecules impinging on the surface. As a consequence, they quickly oxidize when exposed to air. Another important consequence of a reconstruction is the formation of new surface states which result from new bonds between surface atoms and between surface and second layer atoms. Several reconstructions have been identified on these surfaces which 
include reconstructions on clean surfaces, mostly depending on annealing conditions, and reconstructions induced by metallic adsorbates [3-24].

\subsection{Aim of the work}

Semiconductor surfaces have been investigated since the late 1950's, when a LEED pattern of $\operatorname{Si}(111) 7 \times 7$ was obtained for the first time. Since then, clean surfaces and those modified by metal adsorbates, are subject to a continuing interest from many research groups world-wide. The aim of this work was to explore new 2D structures formed by either a single metal or a combination of two metals on the $\mathrm{Si}(111)$ and $\mathrm{Ge}(111)$ surfaces. In the beginning of the present work, the $\mathrm{Ag} / \mathrm{Ge}(111) \sqrt{3} \times \sqrt{3}$ surface is thoroughly characterized. This surface is then used as a substrate to form new surface structures induced by various metal adsorbates. The effects on the atomic and electronic structure due to the combined adsorption of two metal species have not been much investigated. The lack of electronic and atomic structure studies of such surfaces motivated a detailed study by the experimental and theoretical methods used in this thesis work. Several well-ordered binary surface alloys were produced and thoroughly characterized. These new alloys were formed by $\mathrm{Sn} / \mathrm{Ag}$ and $\mathrm{In} / \mathrm{Pb}$ combinations. The successful preparation of wellordered binary surface alloys inspires to further studies of various combinations of elements to form new $2 \mathrm{D}$ systems on semiconductor surfaces. 


\section{Chapter 2}

\section{Crystal and surface structure}

\subsection{Crystal structure}

The elemental semiconductors silicon $(\mathrm{Si})$ and germanium $(\mathrm{Ge})$ both crystalize in the diamond structure with a bulk lattice constant $\left(a_{0}\right)$ of 5.43 and $5.65 \AA$, respectively [25]. The diamond structure can be described as a combination of two fcc lattices displaced with respect to each other by $1 / 4$ of the space diagonal [25]. Each atom of a diamond lattice has four nearest neighbors. Figure 2.1 shows the diamond structure together with a (111) plane.

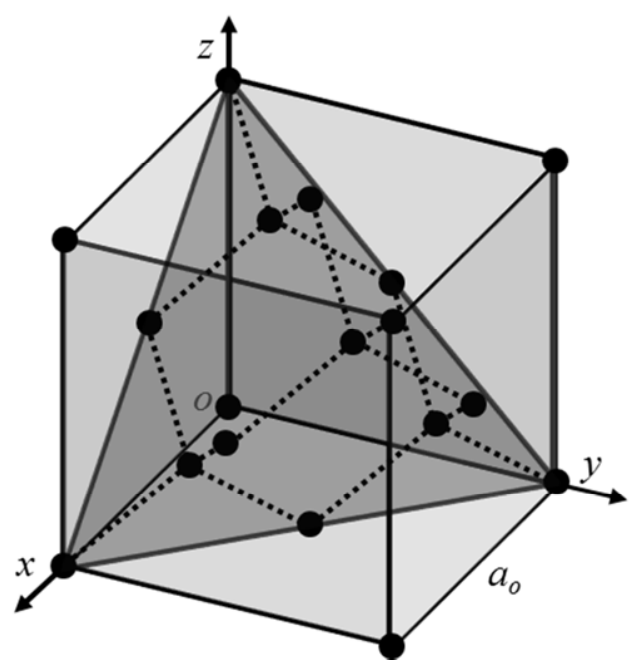

Figure 2.1 Conventional unit cell of the diamond structure. Each atom is fourfold coordinated. The dashed lines show the orientations of the covalent bonds between the $\mathrm{Si}(\mathrm{Ge})$ atoms formed by $\mathrm{sp}_{3}$ hybridized orbitals. A (111) plane of the crystal is shown by the shaded triangle. $a_{o}$ is the bulk lattice constant. 


\subsection{Surface structure}

Clean (111) surface of $\mathrm{Si}$ or Ge can be produced by cleaving bulk crystals in UHV. These surfaces have broken bonds pointing away from the surface containing one electron each. Figure 2.2 shows a hypothetical unreconstructed (111) surface represented by the open circles, whereas the positions of the second layer atoms are shown by the black circles. A $1 \times 1$ unit cell is also shown.

a) Top view

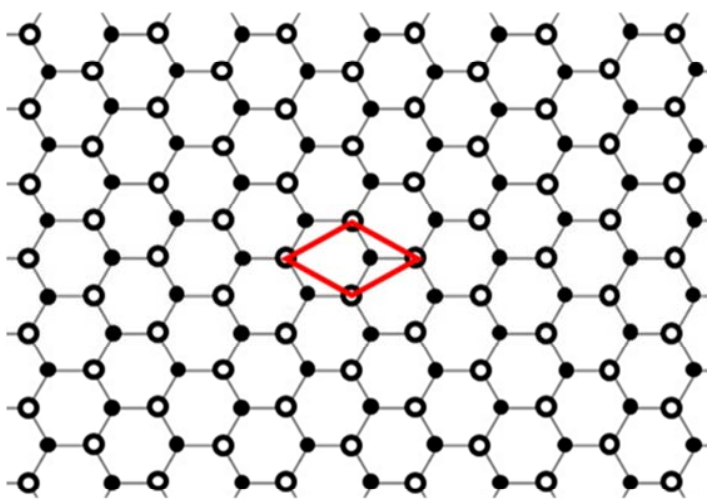

b) Side view

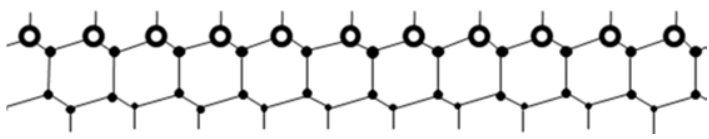

Figure 2.2 Schematic drawing of an unreconstructed (111) surface of the diamond structure. Top layer atoms (open circles) and second layer atoms (black circles) are shown in the top view in (a), together with a $1 \times 1$ unit cell. The broken bonds on the top layer atoms are indicated in the side view in (b).

In contrast to the bulk, the surface has just a $2 \mathrm{D}$ translational symmetry. A $2 \mathrm{D}$ translational vector can be defined as:

$$
\bar{V}=m \bar{a}_{1}+n \bar{a}_{2}
$$

where $m, n$ are positive or negative integers and $\bar{a}_{1}, \bar{a}_{2}$ are primitive lattice vectors of the surface lattice. By combing various values of the $m, n$ integers, one can reach any lattice point of the surface using the translational vector (2.1). Any periodic 2D surface structure can be described by one out of the five so called Bravais lattices, shown in Fig. 2.3. 


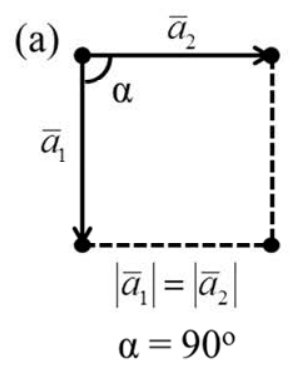

Square

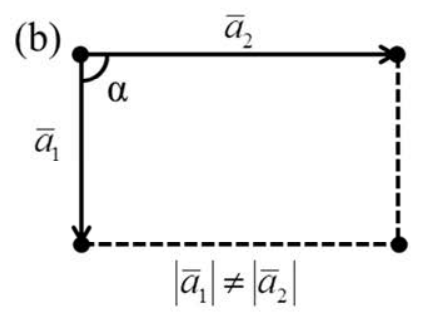

$\alpha=90^{\circ}$

Rectangular

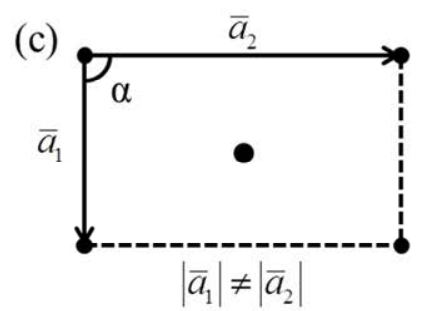

$\alpha=90^{\circ}$

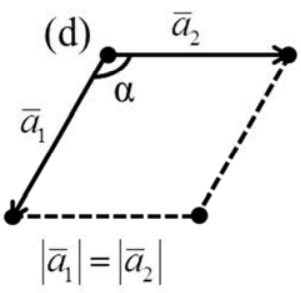

$\alpha=120^{\circ}$

Hexagonal

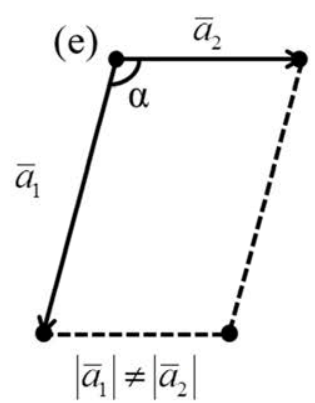

$\alpha \neq 90^{\circ}$

Oblique

Figure 2.3 The five Bravais lattices of 2D periodic structures. The hexagonal lattice (d) describes the (111) surface of the diamond structure.

If the atomic positions of a surface, that terminates the bulk crystal, are the same as before the surface was formed, it is referred to as an ideal or unreconstructed surface. If the primitive cell of the ideal surface is described by $\bar{a}_{1}$ and $\bar{a}_{2}$, then a reconstructed surface can be described the primitive vectors $m \bar{a}_{1}$ and $n \bar{a}_{2}$, where $(m, n)$ are integers. The reconstructed primitive cell will have an area that is $m \times n$ larger than that of the unreconstructed surface. The nomenclature used to describe the surface periodicity and the orientation of the primitive cell is:

$$
E(h k l) m \times n-\phi
$$

where $h k l$ are the Miller indices of the surface plane and $\phi$ is the angle used to describe the rotation of the primitive vectors of the reconstructed surface with respect to those of the ideal, unreconstructed, surface. If $\phi$ is non-zero $\mathrm{m}, \mathrm{n}$ can take non-integer values as in the case of a rotated $\sqrt{3} \times \sqrt{3}-30^{\circ}$ unit cell. In this case the rotated primitive vectors are $\sqrt{3}$ longer than those of the unreconstructed surface. 


\subsection{Real and reciprocal space}

In real space a $2 \mathrm{D}$ Bravais lattice is represented by the primitive vectors $\bar{a}_{1}$ and $\bar{a}_{2}$, which are described in Cartesian coordinates as:

$$
\begin{aligned}
& \bar{a}_{1}=r_{11} \hat{x}+r_{12} \hat{y} \\
& \bar{a}_{2}=r_{21} \hat{x}+r_{22} \hat{y}
\end{aligned}
$$

The area $A$ of the primitive unit cell in real space is given by:

$$
A=\left|\bar{a}_{1} \times \bar{a}_{2}\right|
$$

The primitive vectors in reciprocal space, denoted $\bar{b}_{1}$ and $\bar{b}_{2}$, are related to the primitive vectors in real space by the following equations:

$$
\begin{gathered}
\bar{a}_{i} \cdot \bar{b}_{j}=2 \pi \delta_{i j} \\
\delta_{i j}=1 \text { if } i=j \text { then } \bar{a}_{1} \cdot \bar{b}_{1}=2 \pi \\
\delta_{i j}=0 \text { if } i \neq j \text { then } \bar{a}_{1} \cdot \bar{b}_{2}=0
\end{gathered}
$$

where, $\bar{a}_{i}$ and $\bar{b}_{j}$ are primitive vectors in real and reciprocal space, respectively.

Using $\hat{z}$ as the unit vector along the surface normal, the primitive vectors in reciprocal space can be derived from the expressions that are used in three dimensions:

$$
\bar{b}_{1}=2 \pi \frac{\bar{a}_{2} \times \hat{z}}{\left|\bar{a}_{1} \times \bar{a}_{2}\right|} \text { and } \bar{b}_{2}=2 \pi \frac{\hat{z} \times \bar{a}_{1}}{\left|\bar{a}_{1} \times \bar{a}_{2}\right|}
$$

The vectors $\bar{b}_{1}$ and $\bar{b}_{2}$ define the reciprocal space through the translational vectors given as:

$$
\bar{g}_{h k}=h \bar{b}_{1}+k \bar{b}_{2}
$$

where $h$ and $k$ are integers.

The relationship between real and reciprocal lattices, and their primitive vectors for the $2 \mathrm{D}$ hexagonal lattice, which applies to the (111) surface, are shown in Fig. 2.4. 


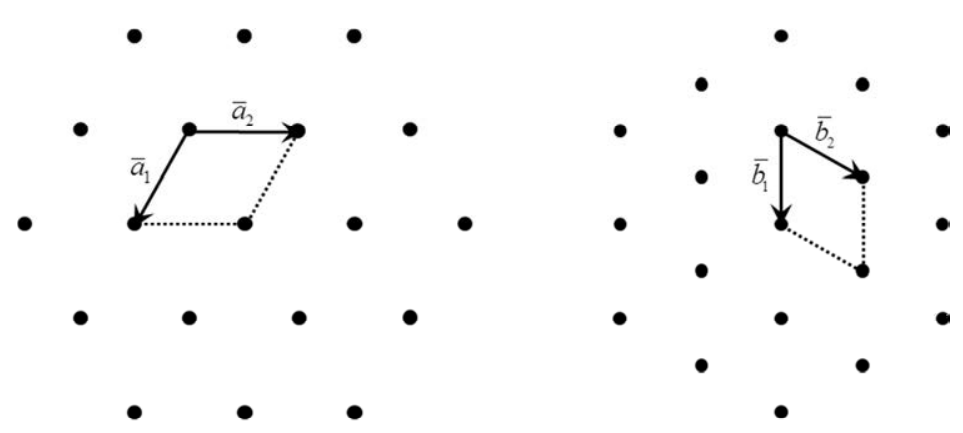

(a)

(b)

Figure 2.4 (a) 2D hexagonal surface lattice in real space and primitive lattice vectors (b) Reciprocal lattice and primitive vectors corresponding to the real lattice in (a).

\subsection{Surface Brillouin zones (SBZ)}

A primitive cell can be constructed in many ways. In reciprocal space it is convenient to use a primitive cell that is constructed in accordance with the Wigner-Seitz procedure used in real space. In reciprocal space such a primitive cell is called a Brillouin zone (BZ). The construction is illustrated in 2D in Fig. 2.5(a) by the dotted lines drawn at half the distance between two neighboring lattice points. The hexagon enclosed by the lines is the surface Brillouin zone (SBZ) which constitutes a primitive cell in reciprocal space.

Three neighboring SBZs are shown in Fig. 2.5(b) following a periodic zone scheme. High symmetry directions and symmetry points $(\bar{\Gamma}, \bar{K}$ and $\bar{M})$ have been included in the figure.

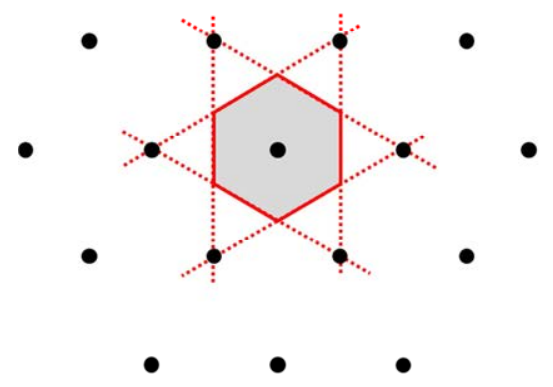

(a)

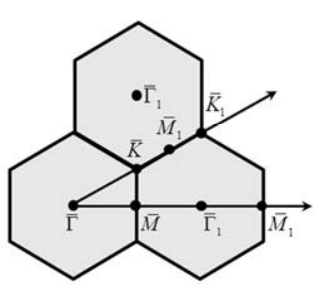

(b)

Figure 2.5 (a) Illustration of the construction of the $1^{\text {st }}$ surface Brillouin zone in reciprocal space for a hexagonal lattice. (b) A few surface Brillouin zones are drawn in the periodic zone scheme, and the commonly used labels of high symmetry points have been introduced. 


\subsection{Electron diffraction from a 2D surface}

Diffraction from a 2D surface differs from that of diffraction in 3D, the reason being the lack of periodicity along the surface normal. One can regard a surface as a single isolated plane of the bulk where all the other planes, both above and below that particular plane, have been moved to plus and minus infinity, respectively. Distances in real and reciprocal space are inversely proportional and when the plane separation increases in real space, the distance between reciprocal lattice points would decrease along lines perpendicular to the surface plane. Eventually, when the separation between the reciprocal lattice points has become infinitesimally small, they form reciprocal lattice rods that are perpendicular to the surface plane. This leads to a relaxation of the diffraction condition compared to the 3D case and diffraction occurs at all energies. This can be understood from the Ewald construction which provides a geometrical illustration of the diffraction condition.

The energy of the incident electron beam is given as:

$$
\begin{aligned}
E & =\frac{\hbar^{2} k^{2}}{2 m} \\
& k=\frac{2 \pi}{\lambda}
\end{aligned}
$$

or one can get the wave length of the electron beam by the expression:

$$
\lambda=\hbar \pi \sqrt{\frac{2}{m E}}
$$

In the case of a 2D surface, the diffraction can be described as a in $3 \mathrm{D}$, if the reciprocal lattice is represented by the periodic arrangement of reciprocal lattice rods labeled by the $2 \mathrm{D}$ Miller indices $(h k)$, see Fig. 2.6.

In Fig. 2.6, an Ewald sphere (circle) is drawn together with the reciprocal lattice corresponding to a square lattice in real space. The lattice constant in real space is $a_{s}$ and $2 \pi / a_{s}$ in reciprocal space. A beam of electrons with a wave vector $\bar{k}_{o}$ is incident normal to the surface. This geometry is normally used in low energy electron diffraction experiments described in the next chapter.

The diffraction conditions in the 2D case are [2]:

$$
\begin{gathered}
\bar{k}_{\|}^{\prime}=\bar{k}_{o \|}+\bar{g}_{h k} \\
\left|\bar{k}^{\prime}\right|=\left|\bar{k}_{o}\right|
\end{gathered}
$$

where $\bar{k}_{\|}^{\prime}$ and $\bar{k}_{o \|}$ represent the components of the $\bar{k}^{\prime}$ and $\bar{k}_{o}$ wave vectors which are parallel to the surface. 
The incident beam diffracts with an angle of $2 \theta_{i}$ (where, $\left.i=1,2,3, \ldots . .10\right)$. There are ten beams of electrons that are elastically scattered, of which five are backscattered as shown by the solid arrows, while the other five are diffracted in directions through the surface, shown as dotted arrows. The diffracted beams are denoted as $\bar{k}_{i}^{\prime}$. Diffraction of the incident beam with a wave vector, $\bar{k}_{o}$, will only occur at the points where the reciprocal lattice rods are intersected by the Ewald sphere (circle), see Fig. 2.6. At these points, the difference between $\bar{k}_{o}$ and $\bar{k}_{i}^{\prime}$ is given by $\Delta \bar{k}$, where $\Delta \bar{k}$ is a reciprocal lattice vector. The general, three dimensional diffraction condition is thus fulfilled. Since the 2D lattice of a surface is represented by reciprocal lattice rods the diffraction condition will be fulfilled more frequently than for a 3D crystal which is represented by points in reciprocal space.

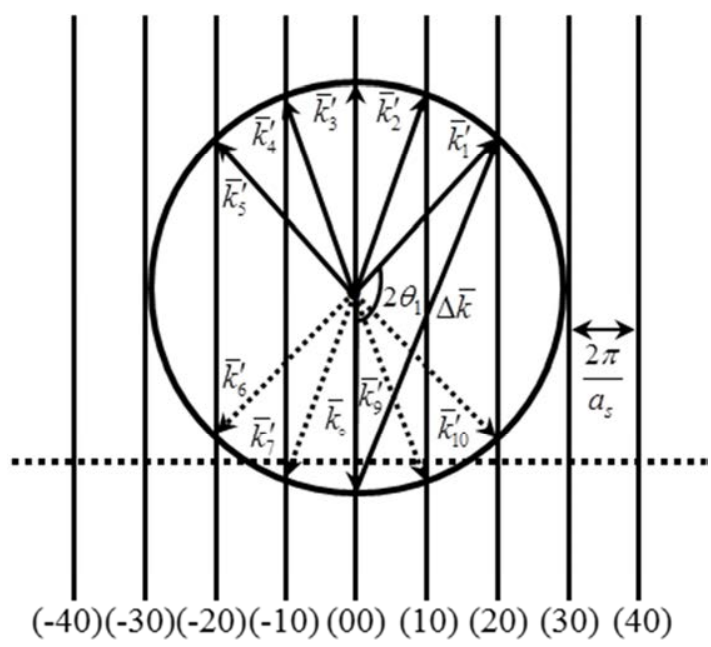

Reciprocal lattice rods with Miller indices

Figure 2.6 One dimensional view of diffraction from a surface represented by a square lattice. An Ewald sphere (circle) and the reciprocal lattice rods have been drawn. The incident beam of wave vector $\bar{k}_{o}$ is parallel to the surface normal. Diffracted beams $\bar{k}_{i}^{\prime}$ make an angle of $2 \theta_{i}$ with respect to the incident beam. 


\section{Chapter 3}

\section{Surface characterization methods}

\section{A. Experimental methods:}

\subsection{Low energy electron diffraction (LEED)}

In 1927 Davisson and Germer used electrons to perform diffraction experiments which proved the dual nature of particles. Since then, electron diffraction is considered as a powerful technique to characterize crystals and their surfaces. Electrons with energies of less than $1000 \mathrm{eV}$ are mainly scattered from the first few atomic layers due to a high scattering cross section at these energies and are therefore used to investigate atomic arrangement at surfaces.

Consider a beam of electrons of energy $E$ as in eq. (2.8) with a wave vector $\bar{k}_{o}$ incident on a single crystal surface as shown in Fig. 3.1. The incident beam is diffracted from the surface as explained by the Ewald construction, shown in Fig. 2.6. In a LEED experiment only the backscattered beams are analyzed.

The experimental setup for LEED is shown in Fig. 3.1. The surface of a single crystal sample is facing the electron gun. To avoid charging, the sample has to be grounded. There are three meshes, with a spherical curvature, indicated by the dotted curves labeled $m_{1}, m_{2}$ and $m_{3}$. The mesh $m_{3}$ that is closest to the sample and the electron gun are both grounded to create a field free region for the backscattered electrons. Meshes $m_{1}$ and $m_{2}$ act as a high pass filter allowing the elastically scattered electrons to pass through but stopping the in-elastically scattered ones. The potential $V_{T}$ (tunable voltage) is adjusted to optimize the suppression of the in-elastically scattered electrons, which would otherwise give rise to a diffuse background in the diffraction pattern resulting in a lower contrast. 

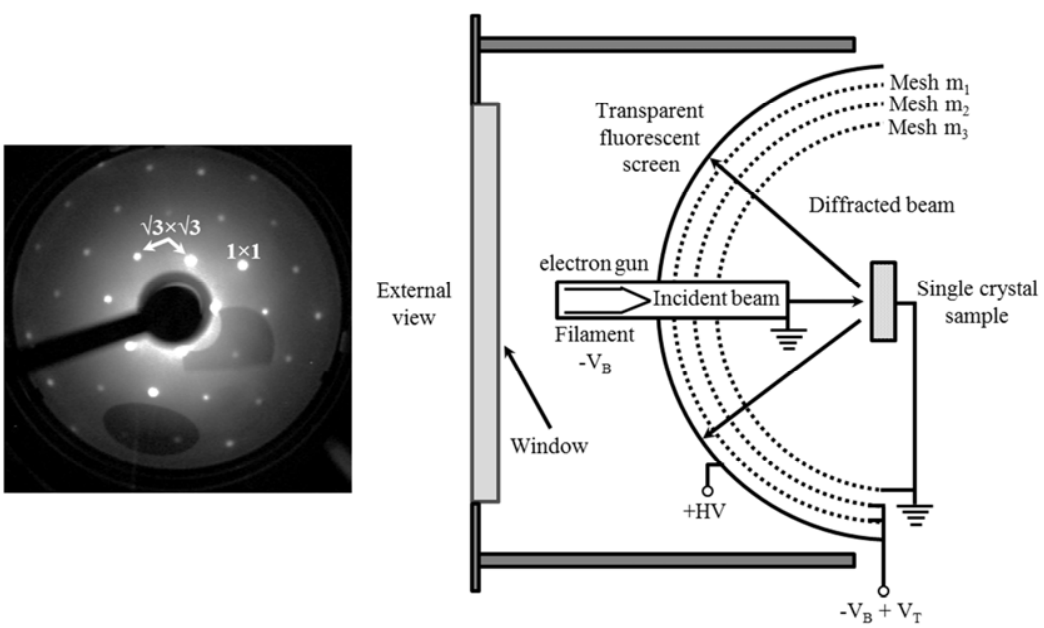

Figure 3.1 Schematic drawing of the low energy electron diffraction (LEED) optics. A beam of electrons, with a well-defined energy hits the surface of a single crystal sample. The diffracted beams give rise to a pattern of bright spots on the transparent fluorescent screen. A typical LEED pattern, obtained at electron energy of $65 \mathrm{eV}$, from a $\mathrm{Ag} / \mathrm{Ge}(111) \sqrt{3} \times \sqrt{3}$ surface is shown as captured by a CCD camera.

A high positive voltage (typically $4-6 \mathrm{kV}$ ) is applied to the screen in order to accelerate the electrons to give them sufficient energy to excite the fluorescent screen. The diffraction pattern appears as a set of bright spots as exemplified in Fig. 3.1 by the photo from a study of the $\mathrm{Ag} / \mathrm{Ge}(111) \sqrt{3} \times \sqrt{3}$ surface. The 2D diffraction pattern is an image of the reciprocal lattice of the surface. The LEED optics is mounted on the vacuum chamber with a window through which the diffraction pattern can be viewed by eye or recorded by a camera.

\subsection{Scanning tunneling microscopy (STM)}

Scanning tunneling microscopy (STM) is a powerful technique that provides microscopy in real space to observe atomically resolved structures. The technique was invented by Binnig and Rohrer in 1981 [26]. Their work was recognized in 1986 when they were awarded the noble prize.

An STM instrument consists of a sharp conducting tip which is attached to a scanner that is made of a piezoelectric material which makes very small motions of the tip in the $x, y$ and $z$ directions possible. A common design of the scanner is based on a tube made of the piezoelectric material. The tube scanner is mounted on a stage that provides coarse motion to bring the tip close to the sample, while the $z$ motion of the tube scanner provides a fine approach to get the tip very close to the sample surface, i.e., within the tunneling range. Fig. 3.2 shows a block diagram of an STM. When a bias voltage is applied between the tip and the sample separated by a very small distance $d<1 \mathrm{~nm}$, then the wave functions of the tip and the sample start to overlap and electrons can tunnel through the vacuum barrier in accordance with quantum mechanics. In this way, a tunneling current in the range of typically $0.1 \mathrm{nA}-100 \mathrm{nA}$ is achieved. The scanner is connected to feedback electronics and its motion is controlled according to the specified mode of 
data acquisition. Typically, the input to the feedback electronics is the tunneling current, which is exponentially dependent on the distance $d$, and the outputs are voltages that are supplied to the scanner. The feedback electronics is computer controlled.

If the STM is used in the constant current mode, the feedback electronics is set to keep the tunneling current constant. This means that the tip will have to move up and down as it is scanned in $x$ and $y$ in order to follow the corrugation (or topography) of the surface. The variation in $V_{z}$, which drives the $z$-motion of the scanner, is recorded and converted into an image representing the topography of the surface. A typical STM image consists of bright and dark features corresponding to protrusions and depressions, see the STM image of $\mathrm{Ge}(111) \mathrm{c}(2 \times 8)$ in the "display monitor" in Fig. 3.2. In this case the bright features correspond to Ge atoms.

In constant height mode, the tip is kept at a certain height above the surface and the feedback electronics is turned off. In this case the tunneling current is not constant during the scan. Thus, the variation in the tunneling current is recorded which gives rise to another kind of image of the surface.

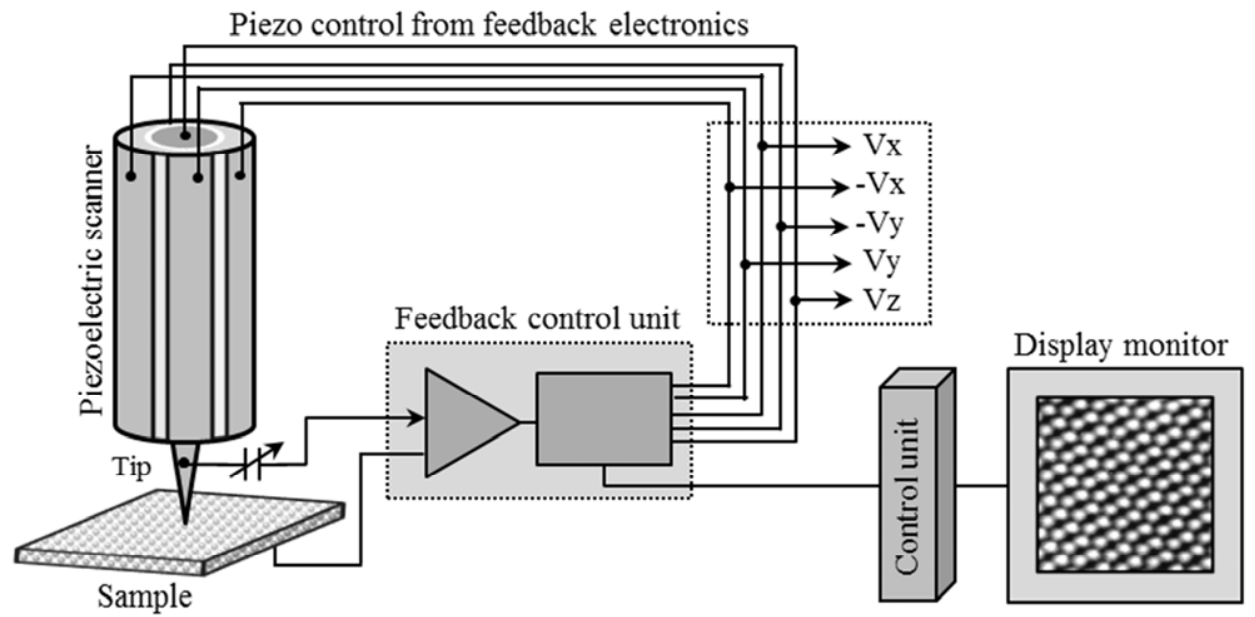

Figure 3.2 Block diagram of the basic components of a scanning tunneling microscope (STM). The piezoelectric tube scanner is the critical part of the microscope since it moves the tip very precisely in the $\mathrm{x}, \mathrm{y}$ and $\mathrm{z}$ directions. In constant current mode the feedback circuit provides the required voltages to the tube scanner in order to keep the tunneling current constant.

If the sample is positively biased with respect to the tip, electrons will tunnel from the tip to the sample. More precisely, electrons from the filled states which are below the Fermi level of the tip will contribute to the tunneling current and flow to the empty states above the Fermi level of the sample. In this case the tunneling current depends on filled states of the tip, empty states of the sample and the probability of electron tunneling through the vacuum gap. Conversely, if the sample is negatively biased electrons will flow from filled states of the sample to empty states of the tip. STM images are usually obtained with both types of bias to obtain as much information as possible about the surface structure. Depending on the electronic structure of a surface, filled and empty state images may look quite similar, but in other cases they can be very different. 


\subsubsection{Quantum tunneling, an overview}

In classical mechanics there is no concept of tunneling through the vacuum gap. If a particle does not have the energy required to overcome the barrier, it cannot be transmitted through it. In contrast, according to quantum mechanics, a particle can tunnel through a barrier even if it has an energy $E$ less than the barrier height $\varphi$, i.e., $\varphi>E$, see Fig. 3.3. The wave function $\psi$ of the particle decays exponentially in the forbidden vacuum gap as given by the equation [27]:

$$
\psi(d)=\psi(0) \exp -\frac{\sqrt{2 m(\varphi-E)}}{\hbar} d
$$

where, $m$ is the mass of the particle, $E$ is the energy, $\varphi$ is the barrier height, and $\hbar=h / 2 \pi$, where $h=6.625 \times 10^{-34} \mathrm{Js}$, is the Planck constant.

There are barrier heights on each side of one dimensional tunneling junction, one for the sample and one for the tip, as shown in Fig. 3.3. The effective barrier height $\varphi$ can be expressed as:

$$
\varphi=\frac{\varphi_{S}}{2}+\frac{\varphi_{T}}{2}+\frac{e V}{2}-E
$$

where $\varphi_{S}$ and $\varphi_{T}$, are the barrier heights seen by sample and tip, respectively The wave functions of the tip and the sample overlap in the classically forbidden gap region which is represented here as a vacuum gap region. The tunneling current $I_{T}$ is proportional to the gap voltage $V$ and density of states of the sample $\rho_{S}\left(E_{F}\right)$. Moreover, it is also exponentially dependent on the distance $d$ between the tip and the sample as shown by the relation [27]:

$$
I_{T} \alpha V \rho_{S}\left(E_{F}\right) \exp -2 \frac{\sqrt{2 m(\varphi-E)}}{\hbar} d
$$

Equation (3.3) implies that the current is strongly dependent on $d$ due to the exponential function. 


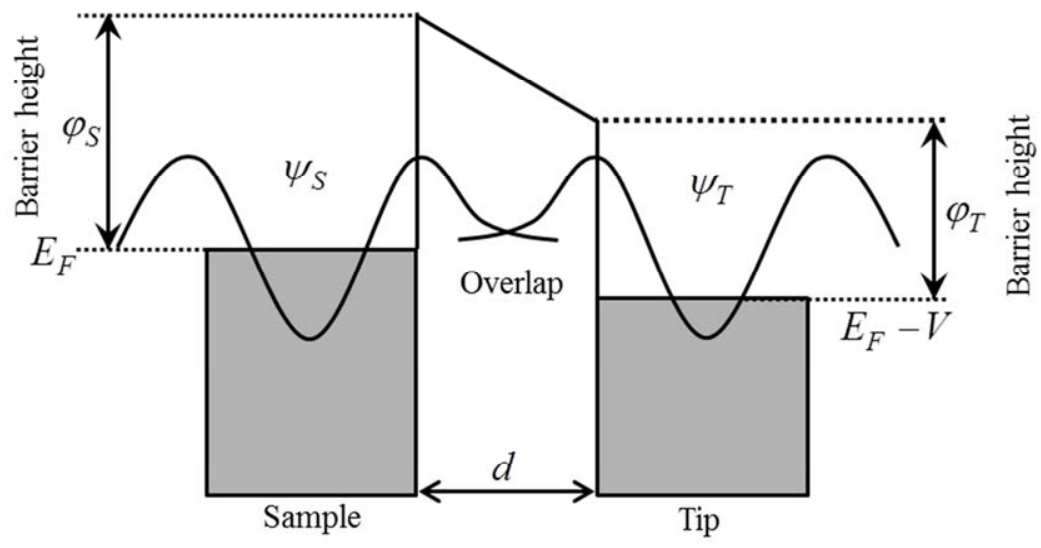

Figure 3.3 Schematic representation of one dimensional tunneling. Electronic wave functions of the sample and the tip overlap in the gap region. $\varphi_{S}$ and $\varphi_{T}$ represent the barrier height for sample and tip, respectively. The wave functions decay exponentially in the gap region. [From ref. 27, modified]

\subsubsection{Tersoff-Hamann model for tunneling current}

The Tersoff-Hamann model [28,29] explains the validity of equation (3.3) for 3D tunneling in which it was assumed that the tip wave function is considered to be a spherical s-wave function and the density of states of the sample is considered to be the local density of states (LDOS) at the Fermi energy.

In the Tersoff-Hamann model, the tunneling current between two metallic electrodes, having a potential difference and separated by an insulator (or vacuum gap), is described by [27-29]:

$$
I_{T}=\frac{4 \pi e}{\hbar} \int_{-\infty}^{+\infty}\left[f\left(E_{F}-e V+\varepsilon\right)-f\left(E_{F}+\varepsilon\right)\right] \rho_{S}\left(E_{F}-e V+\varepsilon\right) \rho_{T}\left(E_{F}+\varepsilon\right) M^{2} d \varepsilon
$$

where, $f(E)$ is the Fermi function defined as:

$$
f(E)=\frac{1}{1+e^{\left(E-E_{F}\right) / k_{B} T}}
$$

$\mathcal{E}$ is a variable used for the integration, $\rho_{T}\left(\rho_{S}\right)$ is the density of states of the tip (sample), $M$ is the tunneling matrix element defined by Bardeen which has the form $[27,30]$ :

$$
M=\frac{\hbar}{2 m} \int_{\text {sufface }}\left(\psi_{S}^{*} \frac{\partial \psi_{T}}{\partial d}-\psi_{S} \frac{\partial \psi_{T}^{*}}{\partial d}\right) d S
$$


where, sample and tip wave functions are $\psi_{S}$ and $\psi_{T}$, respectively. The surface integral in equation (3.6) is evaluated to determine the matrix element. For small bias voltages, the tunneling current in equation (3.4) simplifies to [27]:

$$
I_{T}=\frac{4 \pi e}{\hbar} \int_{0}^{e V} \rho_{S}\left(E_{F}-e V+\varepsilon\right) \rho_{T}\left(E_{F}+\varepsilon\right) M^{2} d \varepsilon
$$

Assuming that the density of states of the tip is constant, the tunneling current will only depend on the LDOS of the sample, i.e., $\rho_{S}\left(E_{F}\right)$ [27]:

$$
I_{T} \alpha V \rho_{S}\left(E_{F}-e V\right)
$$

Equation (3.8) is known as the Tersoff-Hamann model.

\subsection{Photoelectron spectroscopy (PES)}

A non-destructive technique which is suitable for surface studies involving analysis of photoelectron energies is known as photoelectron spectroscopy (PES). Photoelectrons are emitted from the sample when excited by photons of sufficient energy, i.e., the excited electrons must to overcome the work function barrier. The electrons may originate from both valence and core states depending on the photon energy. Photoelectrons are collected and analyzed by an electron energy analyzer that measures the kinetic energy of the emitted electrons. Depending on the energy of the incident photons, the technique is referred to as ultraviolet photoelectron spectroscopy (UPS) (5-100 eV), soft x-ray photoelectron spectroscopy (SXPS) (100-1000 eV) and $\mathrm{x}$-ray photoelectron spectroscopy (XPS) (>1000 eV) [31]. In UPS studies performed with a lab source, a helium discharge lamp emitting 21.2 and $40.8 \mathrm{eV}$ photons is commonly used. These energies are mainly used to probe the valence states of the sample since only a few core-level states can be reached with these rather low energies. In case of XPS, the standard lab sources utilizes the aluminum $K_{\alpha}$ emission at an energy of $1487 \mathrm{eV}$ or the magnesium $K_{\alpha}$ emission at $1254 \mathrm{eV}$. These photon energies are sufficient to result in emission of core electrons from many elements. Synchrotron radiation is another source of photons. It has the advantage that it is tunable over wide a range of energies. Further the intensity is usually several orders of magnitude larger than ordinary lab sources. Schematic diagrams of the photoemission processes in the case of UPS and XPS are shown in Fig. 3.4. 

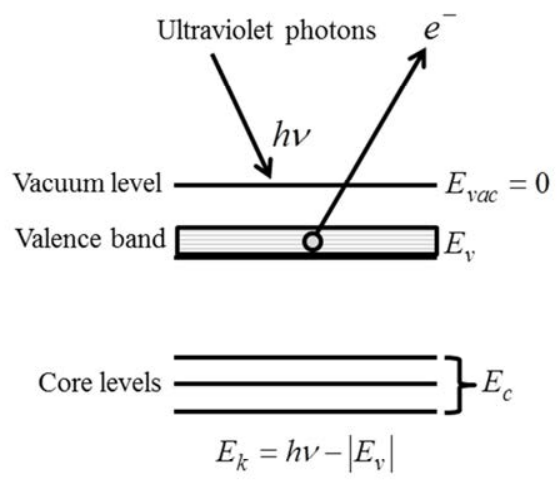

(a) UPS

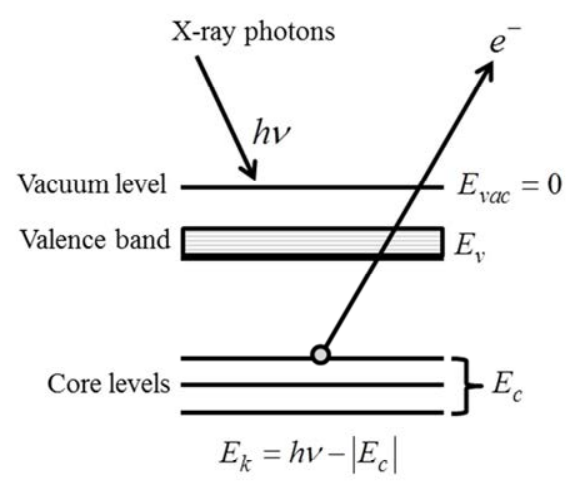

(b) XPS

Figure 3.4 Schematic energy level diagrams of photoelectron spectroscopy in the photon energy ranges corresponding to (a) UPS and (b) XPS. $E_{k}$ is the kinetic energy of the emitted electrons in vacuum.

In the photoemission process, the conservation laws for the energy and momentum are:

$$
\begin{aligned}
& E_{p h}=E_{f}-E_{i} \\
& \bar{k}_{p h}=\bar{k}_{f}-\bar{k}_{i}
\end{aligned}
$$

The kinetic energy of the photoelectron, $E_{k}$, is determined by:

$$
E_{k}=h v-\varphi-E_{B}
$$

where, $\varphi$ is the work function of the sample surface and $E_{B}$ is the binding energy relative to the Fermi level. In equation (3.9), $E_{f}=E_{k}+\varphi$ and $E_{i}=E_{B}$. The small recoil energy of the atoms ejecting the photoelectrons is neglected.

Figure 3.5 shows energy levels and the corresponding energy distribution of emitted photoelectrons. Both valence and core levels are shown. If a photon of energy $h v$ excites core electrons with a binding energy of $E_{B}$ into vacuum, the corresponding spectrum will appear at the higher binding energy part (lower kinetic energy part) of the energy distribution plot. Electrons, which are excited from the valence band, will result in a spectrum close to the Fermi level $\left(E_{F}\right)$, as shown in Fig. 3.5. The kinetic energy of the photoelectron with respect to the vacuum level is given by equation (3.10). 


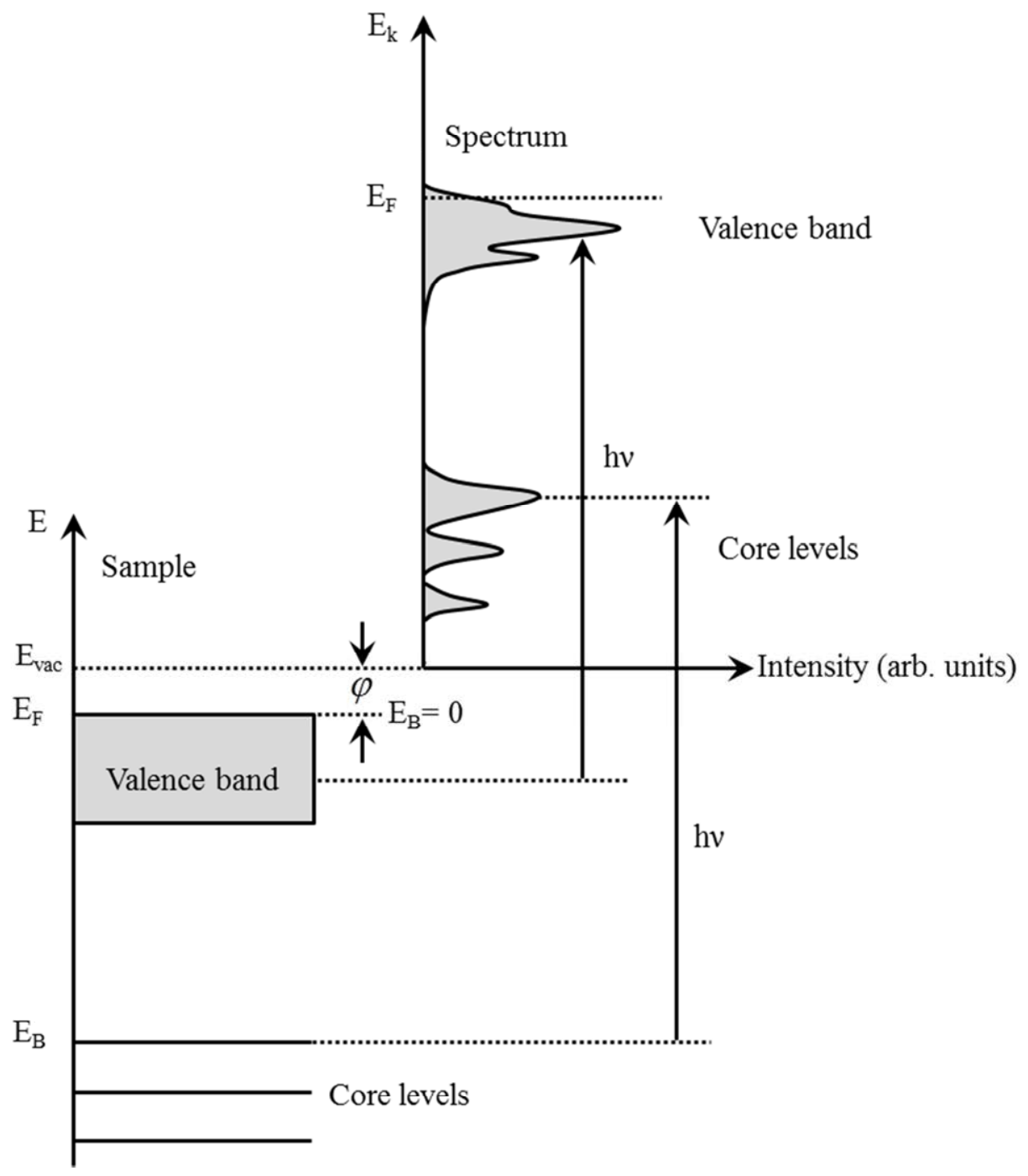

Figure 3.5 Schematic diagram of the photoemission process. Electrons can be emitted from both core and valence levels to the vacuum. A schematic spectrum is drawn showing both core level and valence band contributions to the emission intensity.

\subsubsection{Three step model of photoemission}

A three step model is used to describe photoelectron emission in a simplified way.

In the first step, a photon of energy $h v$ is absorbed by an electron which is excited from the initial state to a final state inside the sample. The first step depends on the probability of 
excitation of the electron by the incoming photon, which depends on the initial and final state wave functions and the vector potential of incident photon.

In the second step, the excited electron is transported to the surface. During this step, the electron may encounter elastic and inelastic collisions. Elastic collisions result in photoelectron diffraction whereas inelastically scattered electrons result from collisions with phonons, electrons and from plasmon excitations. These processes can reduce the energy of the photoelectrons by a few meV up to several $\mathrm{eV}$. Photoelectron spectra typically show a high background at low kinetic energy as a result of multiple inelastic scattering events. Finally, in the third step the electrons escape into the vacuum by overcoming the potential barrier of the surface.

In a quantum mechanical description, photoemission is a one-step process but the three step model is often used for simplicity to describe the photoemission process.

\subsubsection{Angle resolved photoelectron spectroscopy (ARPES)}

Angle resolved photoelectron spectroscopy is a powerful technique which allows for a study of energy versus momentum dependent electronic structures of solids. The process is similar to PES but here the electron momentum is also determined. The geometry of a typical ARPES experiment is shown in Fig. 3.6.

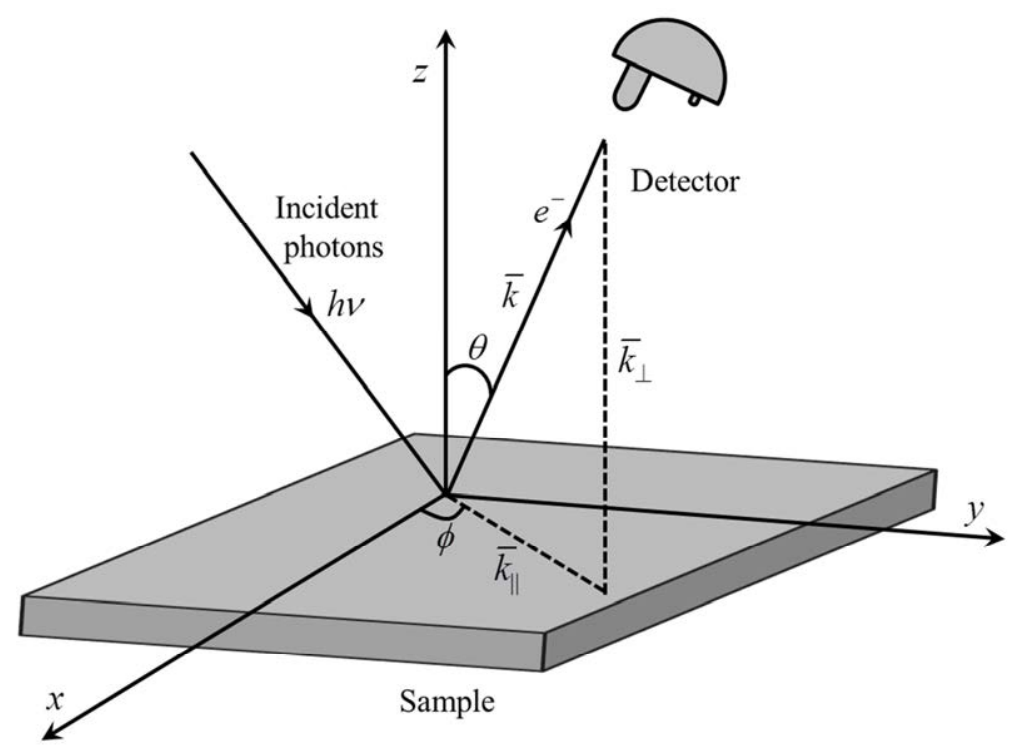

Figure 3.6 Geometry of an ARPES experiment. Incoming photons of energy $h v$ cause emission of electrons. The emitted photoelectrons are analyzed in various directions specified by the emission angle $\theta$ and azimuthal angle $\phi$. From the kinetic energy of an electron one can determine the wave vector $\bar{k}$. The projection of $\bar{k}$ on the surface plane, $\bar{k}_{\|}$, and the kinetic energy $E_{k}$ are most important results of an ARPES experiment. From these data one can construct a two dimensional band structure that gives a complete description of surface bands. 
An electrostatic electron energy analyzer is used to collect electrons at a certain emission angle or within a range of emission angles. The latter situation is the case for the modern analyzers which map the emitted electrons onto a $2 \mathrm{D}$ detector (energy vs emission angle). Images of the $2 \mathrm{D}$ detector are recorded by a CCD camera.

The momentum of the photoelectron is determined by the kinetic energy equation:

$$
\begin{aligned}
& E_{k}=\frac{p^{2}}{2 m} \Rightarrow p=\sqrt{2 m E_{k}} \\
& p=\hbar k=\sqrt{2 m E_{k}} \Rightarrow k=\frac{\sqrt{2 m E_{k}}}{\hbar}
\end{aligned}
$$

where, $k$ is the magnitude of the wave vector of the photoelectron.

In Fig. 3.6 the wave vector $\bar{k}$ is decomposed into parallel and perpendicular components, thus, according to equation (3.11), the kinetic energy of the photoelectron is:

$$
E_{k}=\frac{\hbar^{2} \bar{k}^{2}}{2 m}=\frac{\hbar^{2}\left(\bar{k}_{\|}^{2}+\bar{k}_{\perp}^{2}\right)}{2 m}
$$

The parallel and perpendicular components of the wave vector $\bar{k}$ are defined by $\bar{k}_{\|}=\bar{k}_{x}+\bar{k}_{y}$ and $\bar{k}_{\perp}=\bar{k}_{z}$, respectively, and by:

$$
\begin{aligned}
& k_{x}=\frac{\sqrt{2 m E_{k}}}{\hbar} \sin \theta \cos \phi \\
& k_{y}=\frac{\sqrt{2 m E_{k}}}{\hbar} \sin \theta \sin \phi \\
& k_{z}=\frac{\sqrt{2 m E_{k}}}{\hbar} \cos \theta
\end{aligned}
$$

Thus, $k_{\|}$and $k_{\perp}$ components are simply given by:

$$
\begin{aligned}
& k_{\|}=|\bar{k}| \sin \theta=\frac{\sqrt{2 m E_{k}}}{\hbar} \sin \theta=0.512 \sqrt{E_{k}} \sin \theta \\
& k_{\perp}=|\bar{k}| \cos \theta=\frac{\sqrt{2 m E_{k}}}{\hbar} \cos \theta=0.512 \sqrt{E_{k}} \cos \theta
\end{aligned}
$$

The parallel component of the wave vector, using equation (3.14) gives a complete dispersion relation $E\left(\bar{k}_{\|}\right)$, i.e., the dependence of binding energy $\mathrm{E}_{\mathrm{B}}$ on the momentum $\bar{k}_{\|}$of the electrons of a $2 \mathrm{D}$ periodic arrangement of atoms such as the surface of crystalline material. The parallel 
component of the wave vector, $\bar{k}_{\|}$, is conserved for an emitted electron except for a possible addition of a surface reciprocal lattice vector $\bar{g}_{\|}$, i.e.,

$$
\bar{k}_{\|, \text {outside }}=\bar{k}_{\|, \text {inside }}+\bar{g}_{\|}
$$

The addition of $\bar{g}_{\|}$results in diffraction of the emitted electrons, which is also referred to as umklapp scattering when surface bands are discussed.

The perpendicular component, $\bar{k}_{\perp}$, is not conserved due to the sudden change in the potential along the $z$-axis. When a photoelectron escapes from the sample it will lose an energy corresponding to the work function which leads to a decrease of the kinetic energy. The corresponding decrease in $\bar{k}$ is accounted for by a decrease of $\bar{k}_{\perp}$.

\subsubsection{Core level spectroscopy}

The inner electrons of an atom, that do not form bonds with neighboring atoms, occupy energy levels (core levels) that are unique for each element. As a consequence, photoelectron spectra of core level electrons provide chemical and compositional information about the solid [32]. A core level spectrum obtained from a clean and well-ordered surface of a crystalline sample has a well specified line shape. Thus, a deviation in the line shape of such a core level spectrum may indicate a degraded quality caused by some contamination. For instance, in the present study the Si $2 p$ core level spectrum was obtained in order to check the quality of the $\operatorname{Si}(111) 7 \times 7$ surface before deposition of other atomic species. Similarly, the quality of the $\mathrm{Ge}(111) \mathrm{c}(2 \times 8)$ surface was checked by measuring the Ge $3 d$ core level. The $2 p$ and $3 d$ core level spectra of the $7 \times 7$ and $c(2 \times 8)$ surfaces, respectively, have complicated line shapes even when the surfaces are atomically clean. Both surfaces have complicated structures (see Figs. 4.1 and 4.4) with atoms in different positions with slightly different binding energies of the core levels. To extract structural and chemical information, the core level spectrum is decomposed into the various components that constitute the complete spectrum. The components that are used in the case of semiconductors have a line shape that corresponds to convolutions of Gaussian and Lorentzian functions. The number of components, their binding energies and magnitudes, provide structural and chemical information of the solid crystal and its surface.

\subsection{Energy bands}

Energy bands are formed by the valence electrons when atoms are brought together to form a solid. The wave functions of the valence electrons will start to overlap resulting in a set of energy levels that form a valence band (VB). In a crystalline material, i.e., a material with a periodic potential, the electron states are not just characterized by the energy, but also the wave vector $\bar{k}$ is essential to specify the available states. In a 3D solid an energy band is described by $E(\bar{k})$. Several such bands constitute valence band structure. For semiconductors there is a forbidden energy gap separating the occupied levels of the valence band and unoccupied conduction band 
(CB) levels. This band gap is 1.11 and $0.67 \mathrm{eV}$ for $\mathrm{Si}$ and $\mathrm{Ge}$, respectively. A surface of a single crystal is also crystalline but in $2 \mathrm{D}$. The electronic structure of such a surface can be described by $E\left(\bar{k}_{\|}\right)$, where $\bar{k}_{\|}$is a wave vector in the surface plane. This, so called, surface band structure has been in the focus of all studies included in the thesis. In particular, changes in the surface band structure due to metal induced changes of the atomic structure have been studied. The new periodicities of the top layers give rise to new surface bands that are measured using ARPES, described in the earlier section.

\subsubsection{Surface states}

In the bulk of a crystalline solid there is a three-dimensional periodic potential, but at the surface it is periodic in two dimensions due to the lack of periodicity in the direction normal to the surface. In the latter case, travelling wave solutions to the Schrödinger equation which are within the projected bulk band gap are defined as surface states. The wave functions of the surface states decay exponentially into the bulk and are thereby strongly confined to the surface layer. The electronic structure due to the surface states can have a large influence on basic properties, such as chemical reactivity, semiconducting/metallic character, and phase transitions. In contrast to surface states, there are, so called, surface resonances that overlap with the projected bulk band structure, but has enhanced amplitude at the surface. In the general case, the two-dimensional surface band structure $E\left(k_{\|}\right)$will extend throughout the SBZ. In the region where the surface band is located in the gap of the projected bulk bands, it is regarded as a true surface band while it has the character of a surface resonance when it is overlapping with the projected bulk bands.

A few examples of surface states and their origins:

1. The potential at the surface, which is different from that of the bulk, results in surface states on simple unreconstructed surfaces, i.e., a bulk terminated crystal.

2. Relaxations of the surface layer(s).

3. Reconstructions of a surface that change the $2 \mathrm{D}$ periodicity, either on clean surfaces or induced by adsorbed species.

4. Structural irregularities, for instance step edges, domain boundaries, point defects, dislocations, etc.

5. Impurities absorbed on the surface. 


\section{B. Theoretical method:}

\subsection{Basics of density functional theory}

Density functional theory is a quantum mechanical theory that provides methods to solve the Schrödinger equation of many body systems. It was formulated in 1964 by Hohenberg and Kohn [33] in the form of two theorems which can be applied to any system of many interacting particles with an external potential $V_{e x t}(\bar{r})$. The Hohenberg and Kohn theorems state that:

1) For an interacting system of particles the $V_{\text {ext }}(\bar{r})$ can be found (except for a constant) from the ground state density $n_{0}(\bar{r})$.

2) A universal energy functional $E[n]$ is defined based on the ground state density of the interacting particles $n_{0}(\bar{r})$ which is consistent with the external potential $V_{e x t}(\bar{r})$.

These theorems do not provide any procedure how to construct the functionals for interacting many body systems.

In 1965, Kohn and Sham [35] presented a method to approximate the functionals of the ground state for many electron systems. They suggested a way to treat the many body system as independent single particles by assuming the ground state density of the interacting system to be equivalent to that of the assumed non-interacting system, where all interactions of the many body system are included in the exchange and correlation energy functional of density, $E_{x c}[n]$.

The exchange correlation energy functional $E_{x c}[n]$ is defined as [34]:

$$
E_{x c}[n]=\int n(\bar{r}) \varepsilon_{x c}([n], \bar{r}) d \bar{r}
$$

where $\varepsilon_{x c}([n], \bar{r})$ is the exchange correlation energy density, i.e., energy per electron at a point $\bar{r}$ which depends only on the density $n$.

\section{Approximation to the exchange correlation:}

There are two main approximations used for the exchange correlation energy functional $E_{x c}[n]$.

\section{1) Local density approximation (LDA)}

Kohn and Sham regarded the solid as a homogeneous electron gas, it means that the exchange and correlation are only effective locally and thus can be approximated locally. The approximation to $E_{x c}[n]$ is known as local density approximation, (LDA). It is defined by the integral [34]:

$$
E_{x c}^{L D A}[n]=\int n(\bar{r}) \varepsilon_{x c}^{\mathrm{hom}}(n) d^{3} r
$$




\section{2) Generalized gradient approximations (GGAs)}

Generalized gradient approximations provide an advancement over LDA in which the generalized gradient expansion, i.e., the gradient of the density $|\nabla n(\bar{r})|$ and $n(\bar{r})$ are included in the expression for the exchange correlation energy. Thus the generalized form of integral (3.18) is [34]:

$$
E_{x c}^{G G A}[n]=\int n(r) \varepsilon_{x c}(n(\bar{r}),|\nabla n(\bar{r})|) d^{3} r
$$

\subsubsection{WIEN2k software for electronic structure calculations}

All theoretical calculations in the thesis were performed using the WIEN2k software package [36], which is based on a linearized augmented plane wave (LAPW) method within density functional theory (DFT). The LAPW method provides a way to solve the Kohn-Sham equation for the total energy and ground state density of a many body system. LAPW divides the unit cell into non-overlapping spheres and an interstitial region. WIEN2k uses both LDA and GGA approximations of the exchange correlation energy functional $E_{x c}[n]$. For GGAs, Perdew, Burke and Ernzerhof (PBE) 96, was used [37].

\subsubsection{Structure formation and its geometry in WIEN2k}

A slab of twenty layers, having inversion symmetry, was used for the theoretical calculations in the present work. The slab had a vertical size of $30 \AA$ and was separated by a $35 \AA$ wide vacuum gap with respect to the next slab. An example of the structure is shown in Fig. 3.7. Initially, the structure with inversion symmetry was subjected to force minimization in which the outermost four layers and the adatom layers, on each side of the slab, were allowed to relax until the Hellmann-Feynman forces on each atom was reduced to $\approx 0.04 \mathrm{eV} / \AA$. Then the relaxed structure was converted to a structure without inversion symmetry having ten atomic layers, where the dangling bonds of the bottom layer are hydrogen terminated, see Fig. 3.8. The structure was subjected to the self-consistent field (SCF) cycles during which energy convergence occurs after many iterations. Further, band structure calculations were performed using the defined k-path along the high symmetry lines of the SBZ. The band structure in Fig. 3.7(b) is obtained along the $\bar{M}-\bar{\Gamma}-\bar{K}-\bar{M}$ path of the $\sqrt{3} \times \sqrt{3}$ SBZ. Due to the inversion symmetry of the structure the bands are split into two as a result of interaction between states on the opposite sides of the slab. The split is quite small but it can be noticed for the upper occupied band along $\bar{\Gamma}-\bar{K}$. In Fig. 3.8(b) the band structure along the $\bar{M}-\bar{\Gamma}-\bar{K}-\bar{M}$ path of $\sqrt{3} \times \sqrt{3}$ SBZ is shown obtained from the asymmetric structure shown in Fig. 3.8(a). With hydrogen termination on one side of the slab, the cause of the band split is removed and the band structure consists just of a set of single bands, see Fig. 3.8(b). 


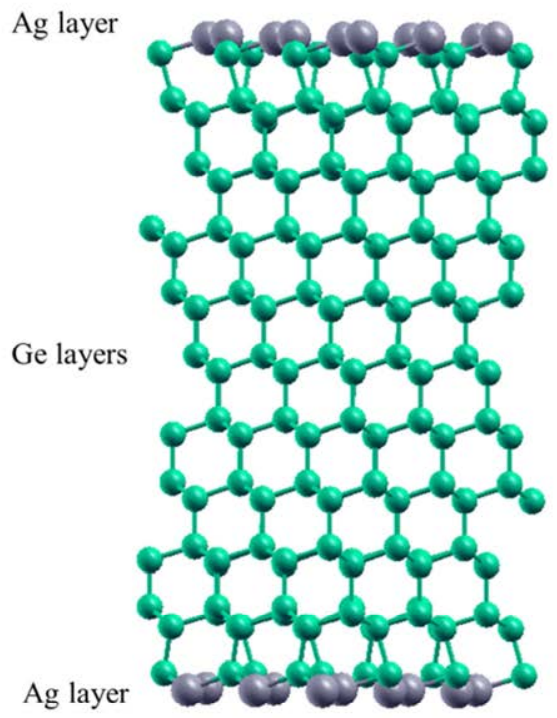

b) $\mathrm{Ag} / \mathrm{Ge}(111) \sqrt{ } 3 \times \sqrt{3}$-band structure

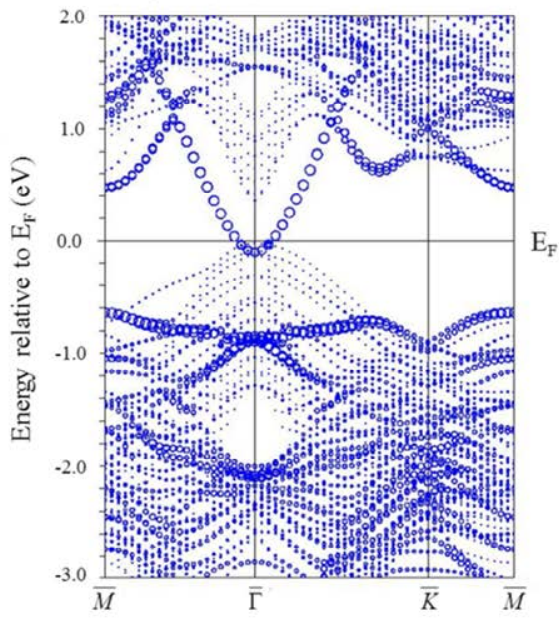

a) Inversion symmetric slab

Figure 3.7 (a) Symmetric slab consisting of twenty layers showing inversion symmetry. (b) The corresponding band structure of the slab.

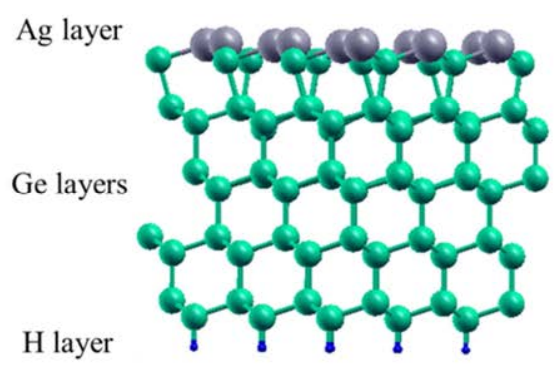

a) Asymmetric - H-terminated slab b) $\mathrm{Ag} / \mathrm{Ge}(111) \sqrt{3} \times \sqrt{3}$-band structure

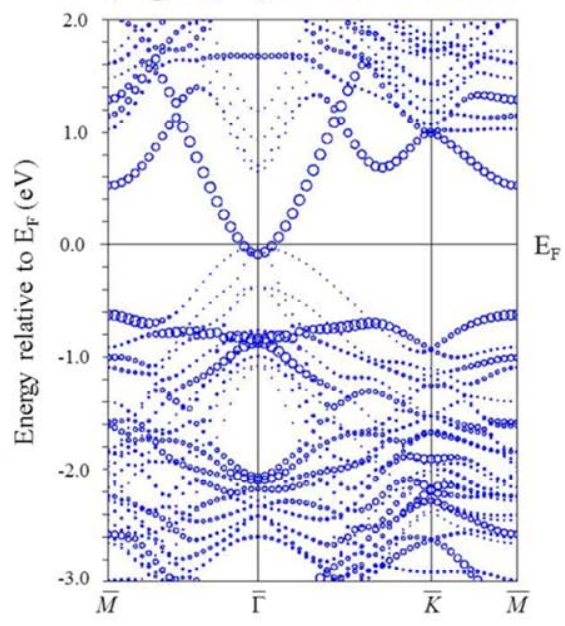

Figure 3.8 (a) Asymmetric slab with no inversion symmetry consisting ten layers, where the bottom layer is Hterminated. (b) Band structure obtained using the asymmetric structure in (a). 


\section{Chapter 4}

\section{Atomic and electronic structures of semiconductor surfaces}

Low index surfaces, (001), (011), and (111) of Si and Ge have been extensively studied after the 1970's, including studies of clean surfaces as well as surfaces modified by metallic adsorbates [3$24,38-42]$. In this chapter, the electronic and atomic structures of the clean $\operatorname{Si}(111) 7 \times 7$ and $\mathrm{Ge}(111) \mathrm{c}(2 \times 8)$ surfaces are summarized.

\section{1 $\mathrm{Si}(111) 7 \times 7$}

\subsubsection{Atomic structure: A historical review}

In 1959, the $\mathrm{Si}(111)$ surface was discovered to have an atomic structure different from a simple surface structure as that of bulk termination when the $7 \times 7$ reconstruction was observed by electron diffraction by Farnsworth et al. [43]. There were many suggestions about the atomic structure of the $7 \times 7$ reconstruction, but early studies were unable to solve the structure. For instance, according to some reports the $7 \times 7$ structure was believed to be the result of carbon and/or chlorine contamination. These atoms were supposed to be located a few atomic layers below the surface. However, the existence of buried atoms could not be verified by Auger electron spectroscopy (AES), secondary ion mass spectroscopy (SIMS) or by other techniques. Therefore, it was believed that the $7 \times 7$ reconstruction is a property of the clean $\operatorname{Si}(111)$ surface. The $\operatorname{Si}(111) 7 \times 7$ reconstruction was first observed in real space using the scanning tunneling microscope (STM) invented by Binnig and Rohrer [26]. STM images typically show twelve atomically resolved features per $7 \times 7$ unit cell. The $7 \times 7$ surface was also studied by many other groups around the world. The most important contribution regarding the $7 \times 7$ surface was reported in 1984 by Takayanagi et al. [44]. They produced a very thin Si(111) sample and used transmission high energy electron diffraction (THEED) to obtain an electron diffraction pattern from $\operatorname{Si}(111) 7 \times 7$. Moreover, $x$-ray diffraction was also used together with information obtained from electron diffraction to predict an atomic model of the $\operatorname{Si}(111) 7 \times 7$ surface. The resulting atomic model of the surface is known as the dimer-adatom-stacking fault (DAS) model, which is now well accepted. 


\subsubsection{DAS model}

The DAS model, shown in Fig. 4.1, shows the arrangement of atoms in the outermost layers, i.e., the positions of adatoms, rest atoms, dimers and the stacking sequence of the atoms in the top few layers. In Fig. 4.1(a), black dots represent 12 adatoms in the top layer of the surface. These adatoms have four valence electrons each. One of these electrons occupies a dangling bond orbital which is directed away from the surface, parallel to the surface normal. The other three valence electrons make bonds with the second layer atoms. These bonds are known as back bonds. In the second layer, there are two kinds of atoms as shown by open and gray circles of the same size. The atoms represented by open circles have no dangling bonds, since all valence electrons are taking part in bonds with other $\mathrm{Si}$ atoms. The other atoms (in gray) located at the center of the triangles formed by neighboring adatoms, labeled $A$ (left side) and $B$ (right side), are called rest atoms, see Fig. 4.1(a). The rest atoms have one electron in a dangling bond orbital pointing away from surface into the vacuum. Therefore, the six rest atoms also contribute 6 dangling bonds. Each corner hole of the unit cell, surrounded by 6 adatoms, contains one atom situated at the 4th layer. This atom has one valence electron in a dangling bond state directed into the vacuum. Each corner hole of $7 \times 7$ unit cell is shared by four neighboring $7 \times 7$ cells, thus the four corner holes will actually contribute only one dangling bond per $7 \times 7$ cell. In total the $7 \times 7$ cell contains 19 dangling bonds, (12 adatoms, 6 rest atoms, and one corner hole). The adatoms and rest atoms are not located at the same level as shown by the DAS model, see Fig. 4.1, resulting in different dangling bond energies. A charge transfer takes place from adatom states to rest atom and corner hole states. The result of the charge transfer is that out of the initial 19 dangling bond electrons, only 5 electrons remain in dangling bonds, i.e., dangling bonds of the adatoms. This number is odd number which indicates that the $7 \times 7$ surface is metallic, which is also the case. Another important characteristic of the $7 \times 7$ structure is the existence of dimers. There are three dimers at each side of the two triangles forming the $7 \times 7$ unit cell. Out of these, three dimers are entirely inside the cell, see Fig. 4.1(a). In other words, the $7 \times 7$ cell contains a total of 9 dimers. Lastly, a very important aspect of the $7 \times 7$ structure is the stacking fault which appears in one half of the unit cell, but not in the other half. The consequence of this fault is that the fourth layer atoms are not visible in a top view of the left side of the model (i.e., the faulted side) in contrast to the right side (i.e., unfaulted side), see the small black dots in Fig. 4.1(a). This is due to the difference in the stacking sequence of atoms in the top four layers, see Fig. 4.1(b) and focus on the bond sequences marked wyz and xyz. The DAS model is the accepted model for the $\operatorname{Si}(111) 7 \times 7$ surface as it has been verified by many techniques, such as STM, high energy electron diffraction, low energy electron diffraction, x-ray diffraction and by theoretical calculations $[27,45,46]$. 


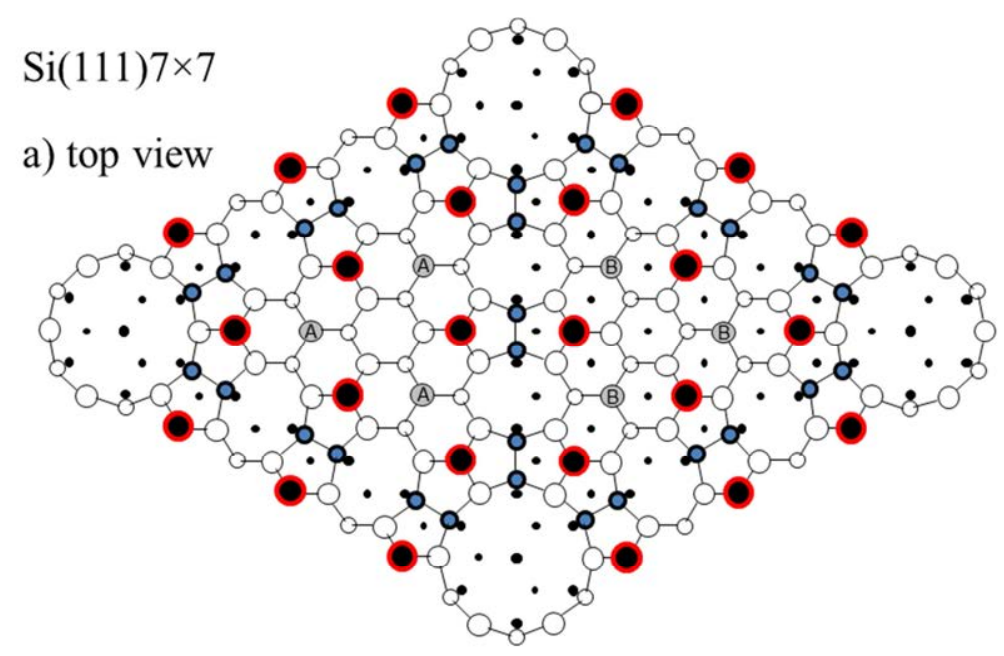

b) side view

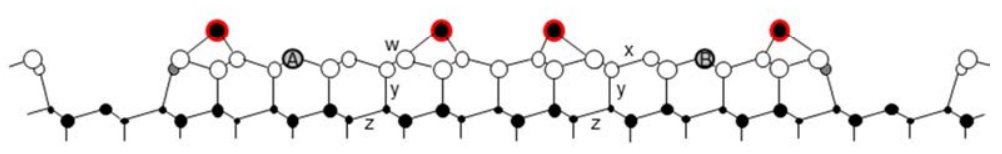

Figure 4.1 Schematic drawing of the DAS model of the $\mathrm{Si}(111) 7 \times 7$ surface, showing a top view in (a) and a side view in (b). Takayanagi et al. [44].

In practice, the $7 \times 7$ reconstruction is produced from a polished $\mathrm{Si}(111)$ wafer which is first degreased $e x$-situ by chemicals and cleaned in-situ by heat treatment. First, the sample is out gassed for a few hours so that adsorbed species leave the surface. To produce the $7 \times 7$ surface, annealing is done up to $1250{ }^{\circ} \mathrm{C}$ in steps. Initially, the sample is heated slowly to $950{ }^{\circ} \mathrm{C}$ and then rapidly up to $1250{ }^{\circ} \mathrm{C}$, and after a few seconds the temperature is reduced back to $950{ }^{\circ} \mathrm{C}$. Finally, the sample is slowly cooled down to room temperature (RT). These steps are repeated a few times to form a well-ordered $7 \times 7$ reconstruction, which can be verified by low energy electron diffraction (LEED) or by scanning tunneling microscopy (STM). $\operatorname{Si}(111) 7 \times 7$ is very reactive since it has 5 electrons in dangling bond states, per $7 \times 7$ cell, which are ready to make bonds with atomic and molecular species.

Figure 4.2(a) shows a LEED pattern of the $\operatorname{Si}(111) 7 \times 7$ surface obtained at an electron energy of $70 \mathrm{eV}$. The sharp spots highlighted by white circles are the $1 \times 1$ spots, while the small spots in between the $1 \times 1$ spots originate from the $7 \times 7$ reconstruction. The distance between $7 \times 7$ spots is $1 / 7$ of the distance between of $1 \times 1$ spots. The sharp spots of the LEED pattern are indicative of a well-ordered structure of the $7 \times 7$ surface which is usually the case if the proper cleaning procedure is followed.

In Fig. 4.2(b) and 4.2(c), empty and filled state STM images obtained at RT using a sample to tip biased of $( \pm 1.5 \mathrm{~V})$ are shown, respectively. A $7 \times 7$ unit cell has been superimposed on the images. 
There are 12 bright blobs per unit cell that represent Si adatoms as described by the DAS model. Figures 4.2(b) and 4.2(c) represent slightly different appearances but both are explained by the DAS model as both show 12 bright blobs per $7 \times 7$ unit cell. However, the brightness level differs between the two halves of the unit cell in Fig. 4.2(c). The faulted side looks brighter than the unfaulted side, which is due to a difference in the charge transfer between the two halves of the $7 \times 7$ unit cell. Moreover, at certain tip to sample biases it is possible to observe the rest atoms, marked in light gray in Fig. 4.1(a). Having a closer look at the STM image in Fig. 4.2(c) one can also identify the rest atoms.
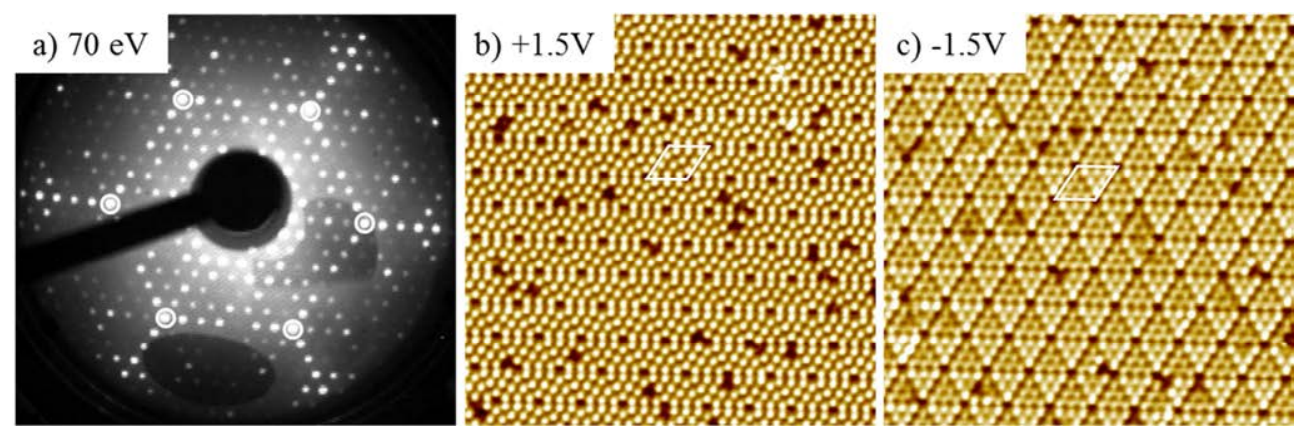

Figure 4.2 (a) LEED image of the $\mathrm{Si}(111) 7 \times 7$ surface. (b) and (c) show empty and filled state STM images of the surface. The images have a size of $30 \times 30 \mathrm{~nm}^{2}$ and were obtained at a sample to tip bias of $\pm 1.5 \mathrm{~V}$, respectively.

\subsubsection{Electronic structure of the $\operatorname{Si}(111) 7 \times 7$ surface}

The electronic structure of the $\mathrm{Si}(111) 7 \times 7$ surface, measured at RT by angle resolved photoelectron spectroscopy at beamline I4 at MAX-lab, is shown in Fig. 4.3. A photon energy of $30 \mathrm{eV}$ was used to obtain the electronic structure along the $\bar{\Gamma}-\bar{K}-\bar{M}$ and $\bar{\Gamma}-\bar{M}-\bar{\Gamma}$ high symmetry lines of the $1 \times 1$ SBZ. Figures 4.3 (a) and 4.3 (c) show the intensity variation of the photoemitted electrons as function of energy and $k_{\|}$along the symmetry lines. Figures $4.3(\mathrm{~b})$ and 4.3(d), show the second derivative along the energy axis of the intensity maps in (a) and (c), respectively. The second derivative approach is useful since it makes also weak but well-defined features visible. As a result, more features of the electronic structure can be seen in a single image. The dotted curves in Fig. 4.3 show the upper edge of the projected bulk bands. Two surface states, $S_{1}$ and $S_{2}$, at $\sim-0.4 \mathrm{eV}$ and $\sim-0.9 \mathrm{eV}$ are clearly seen in Figs. 4.3(b) and 4.3(d). The $\mathrm{S}_{1}$ state at $\sim-0.4 \mathrm{eV}$ is attributed to the dangling bond state of the adatoms [47]. $\mathrm{S}_{1}$ has a characteristic intensity variation showing an increased intensity half way to the $1 \times 1 \mathrm{SBZ}$ boundary. The $\mathrm{S}_{2}$ state at $\sim-0.9 \mathrm{eV}$ corresponds to the doubly occupied dangling bond orbitals on the rest atoms [47]. There are two more states reported in the literature [48]. One of the states, usually labeled $\mathrm{S}_{3}$, is related to the back bonds, i.e., the bonds between the adatoms and the atoms of the underlying layer. The $S_{3}$ state shows up clearly at $\sim-1.8 \mathrm{eV}$ near the $\bar{K}$-point using a photon energy of $21.2 \mathrm{eV}$, but is hardly visible in the $30 \mathrm{eV}$ data in Fig. 4.3(b). Another surface 
state, $S_{4}$, was identified between the $S_{1}$ and $S_{2}$ states in data obtained at a sample temperature of $55 \mathrm{~K}$ [47]. $\mathrm{S}_{4}$ is not observed in the RT data presented here.

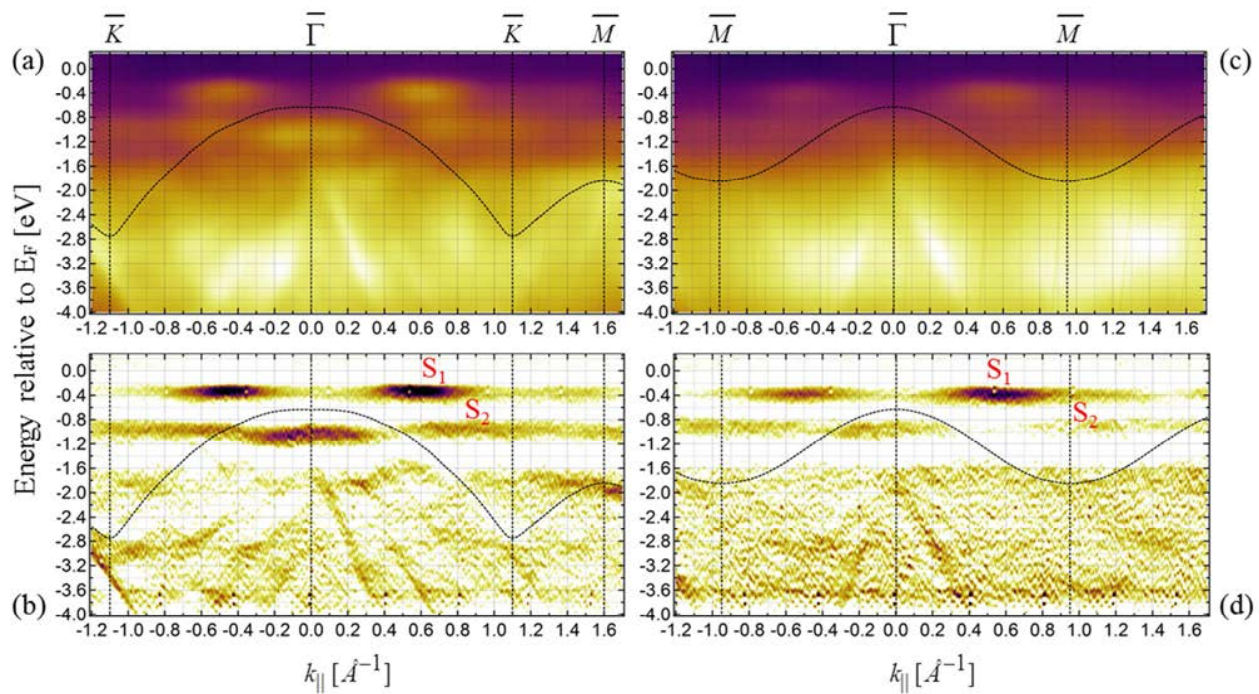

Figure 4.3 (a) and (c) Photoemission intensity as function of energy and $k_{\|}$. The ARPES data from $\operatorname{Si(111)} 7 \times 7$ were obtained along the $\bar{\Gamma}-\bar{K}-\bar{M}$ and $\bar{\Gamma}-\bar{M}-\bar{\Gamma}$ high symmetry lines of the $1 \times 1 \mathrm{SBZ}$ at RT, at a photon energy of $30 \mathrm{eV}$. (b) and (d) Second derivative representations of the intensity data in (a) and (c). The second derivative was obtained along the energy axis.

\section{$4.2 \operatorname{Ge}(111) \mathrm{c}(2 \times 8)$}

\subsubsection{Atomic structure}

The Ge(111) surface, obtained by cleaving, reconstructs into a $\mathrm{c}(2 \times 8)$ periodicity after annealing at $200{ }^{\circ} \mathrm{C}$ [49]. In practice, the $\mathrm{c}(2 \times 8)$ surface is produced from a polished $\mathrm{Ge}(111)$ single crystal wafer, through $\mathrm{Ar}^{+}$ion bombardment (i.e., sputtering) and annealing at typically $\sim 750{ }^{\circ} \mathrm{C}$. This procedure results in a well-ordered $c(2 \times 8)$ reconstruction, which is usually verified by LEED and/or STM. The reconstruction is not similar to that of the $\operatorname{Si}(111) 7 \times 7$ surface. The $c(2 \times 8)$ reconstruction, illustrated by a model in Fig. 4.4, is a rather simple adatom structure without any stacking fault. Ge adatoms occupy $\mathrm{T}_{4}$ sites of an unreconstructed $\mathrm{Ge}(111)$ surface [50,51]. There is $1 / 4$ of a ML of adatoms on the surface, shown by gray circles in Fig. 4.4. They have one empty dangling bond each. Besides the adatoms, there is $1 / 4 \mathrm{ML}$ of rest atoms on the surface, shown as black circles in Fig. 4.4. Each rest atom has a doubly occupied dangling bond. The double occupation of the rest atom dangling bonds is a consequence of an electron transfer from the higher energy adatom dangling bonds to the lower energy rest atom dangling bonds. In this case, all dangling bonds of the rest atoms are fully occupied, while those of the adatoms are empty. The $c(2 \times 8)$ unit cell drawn in Fig. 4.4 shows 4 adatoms and 4 rest atoms per cell. The $c(2 \times 8)$ unit 
cell, shown by the black parallelogram, is traditionally drawn in this form but the atomic structure can also be represented by a c $(4 \times 2)$ and a $(2 \times 2)$ unit cell.

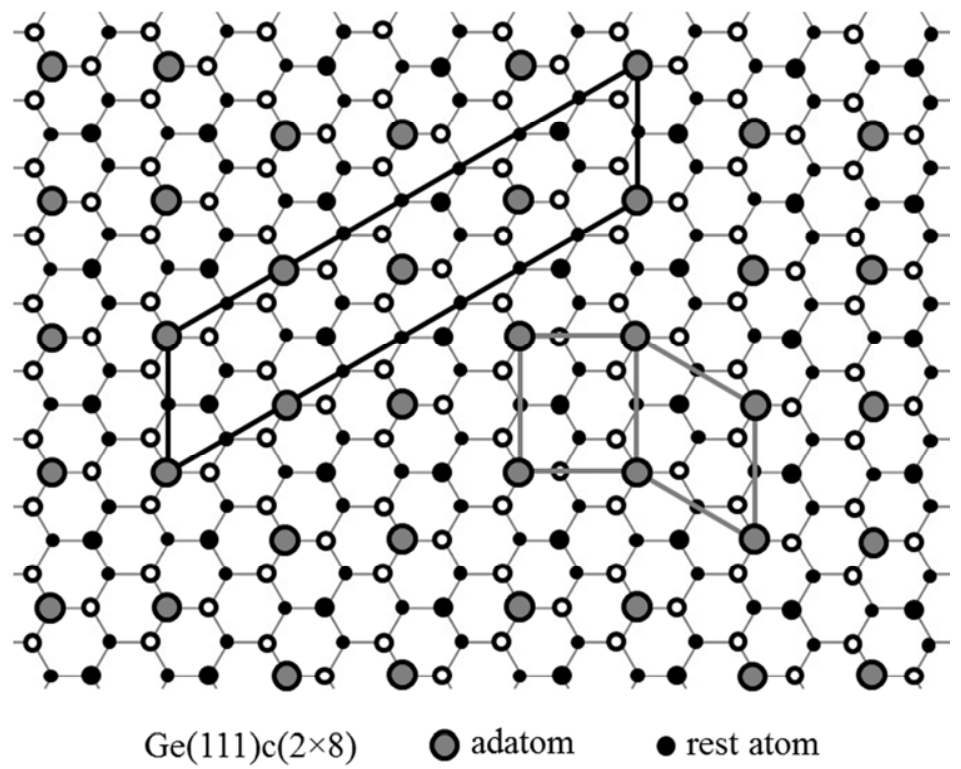

Figure 4.4 Schematic drawing of the adatom model of the $\mathrm{Ge}(111) \mathrm{c}(2 \times 8)$ surface. Gray circles represent Ge adatoms of the topmost layer, whereas the black circles are rest atoms that are part of the first complete layer. The amounts of adatoms and rest atoms correspond to $1 / 4 \mathrm{ML}$ each. A $\mathrm{c}(2 \times 8)$ unit cell is drawn in black and an alternative representation of the structure is illustrated by the $\mathrm{c}(4 \times 2)$ (rectangle) and $(2 \times 2)$ (parallelogram) unit cells drawn by gray lines.

In Fig. 4.5(a) a LEED pattern from the $\operatorname{Ge}(111) \mathrm{c}(2 \times 8)$ surface is shown obtained at an electron energy of $60 \mathrm{eV}$. There are some $\mathrm{c}(2 \times 8)$ spots missing which is due to the structure factor. The sharp $(1 \times 1)$ spots are highlighted by black circles while $c(2 \times 8)$ spots are between the $(1 \times 1)$ spots. Figure 4.5(b) presents an empty state STM image which was obtained at a sample to tip bias of $1.5 \mathrm{~V}$ tunneling at RT. The $\mathrm{c}(2 \times 8)$ unit cell contains four Ge adatoms. Each adatom has an empty dangling bond due to the electron transfer to the dangling bonds of the rest atoms. Thus, the $c(2 \times 8)$ surface does not have any partially occupied dangling bonds and is therefore semiconducting in contrast to the $\operatorname{Si}(111) 7 \times 7$ surface [52]. 

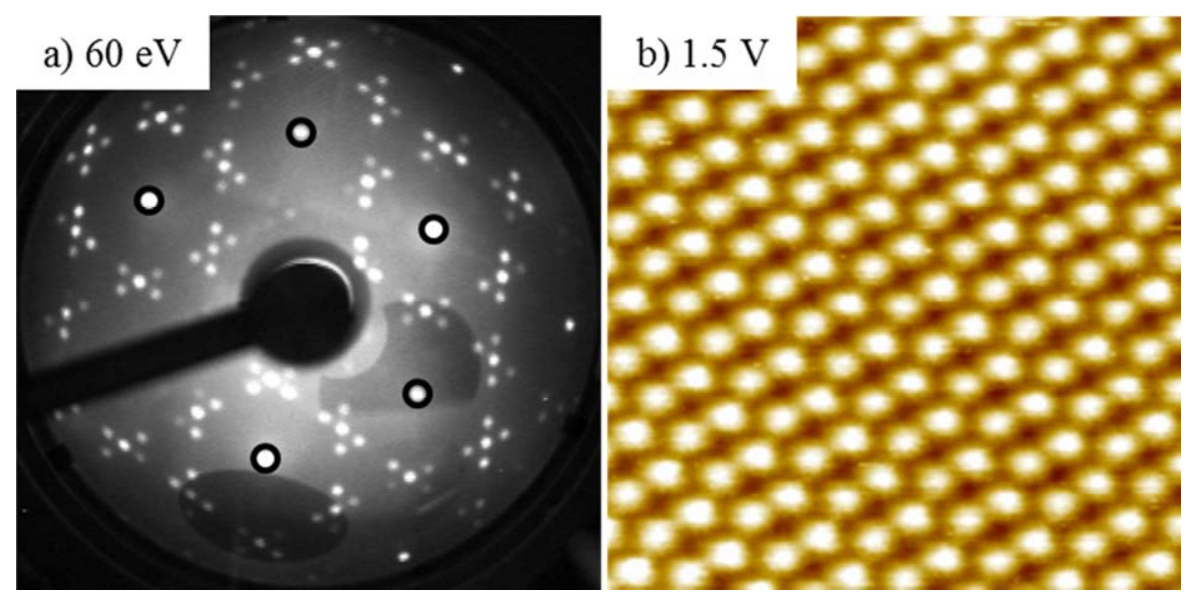

Figure 4.5 (a) LEED pattern of the Ge(111)c(2×8) surface, (b) Empty state STM image of the $c(2 \times 8)$ surface. The size of the image is $10 \times 10 \mathrm{~nm}^{2}$ and it was obtained at a sample to tip bias of $1.5 \mathrm{~V}$.

\subsubsection{Electronic structure}

Figure 4.6 shows the electronic structure of a clean $\mathrm{Ge}(111) \mathrm{c}(2 \times 8)$ surface, measured by ARPES using a photon energy of $30 \mathrm{eV}$ at $100 \mathrm{~K}$. Along the $\bar{\Gamma}-\bar{K}-\bar{M}$ line in Figs. 4.6(a) and 4.6(b), there are four surface bands in the projected bulk gap region denoted as $S_{1}-S_{4}$. At $0.6 \AA^{-1}$, there is only one band, $S_{1}$, at an energy of $-0.8 \mathrm{eV}$, but it splits into two bands $\left(\mathrm{S}_{1}\right.$ and $\left.\mathrm{S}_{2}\right)$ after $0.6 \AA^{-1}$ with a maximum separation of $0.1 \mathrm{eV}$ at $0.75 \AA^{-1}$. At $k_{\|}=0.9 \AA^{-1}$ the bands again become degenerate without any further splitting when approaching the $\bar{K}$-point of the $1 \times 1 \mathrm{SBZ}$. These bands originate from rest atom states, as reported in the literature [52]. There are two more bands $\left(\mathrm{S}_{3}\right.$ and $\left.\mathrm{S}_{4}\right)$ at the $\bar{K}$-point at binding energies of -1.2 and $-1.6 \mathrm{eV}$, respectively. The dispersion of $\mathrm{S}_{3}$ is somewhat difficult to follow but $\mathrm{S}_{4}$ shows weak traces and disperses upward from a minimum at the $\bar{K}$-point. $\mathrm{S}_{4}$ is related to adatom back bonds as reported in [52]. Along $\bar{\Gamma}-\bar{M}-\bar{\Gamma}$ there are two surface bands $\left(S_{1}\right.$ and $\left.S_{2}\right)$ at $0.5 \AA^{-1}$ where they have maximum gap of $0.2 \mathrm{eV}$. The bands are degenerate at $0.4 \AA^{-1}$ and $0.7 \AA^{-1}$ with a binding energy of $\approx-0.6 \mathrm{eV}$ but further out in the positive $k_{\|}$direction the bands become weak. The remaining band, $\mathrm{S}_{5}$, at $-1.0 \mathrm{eV}$ shows a tiny dispersion around $0.7 \AA^{-1}$, and continues upward to overlap with the bulk features, see Figs. 4.6(c) and 4.6(d). 


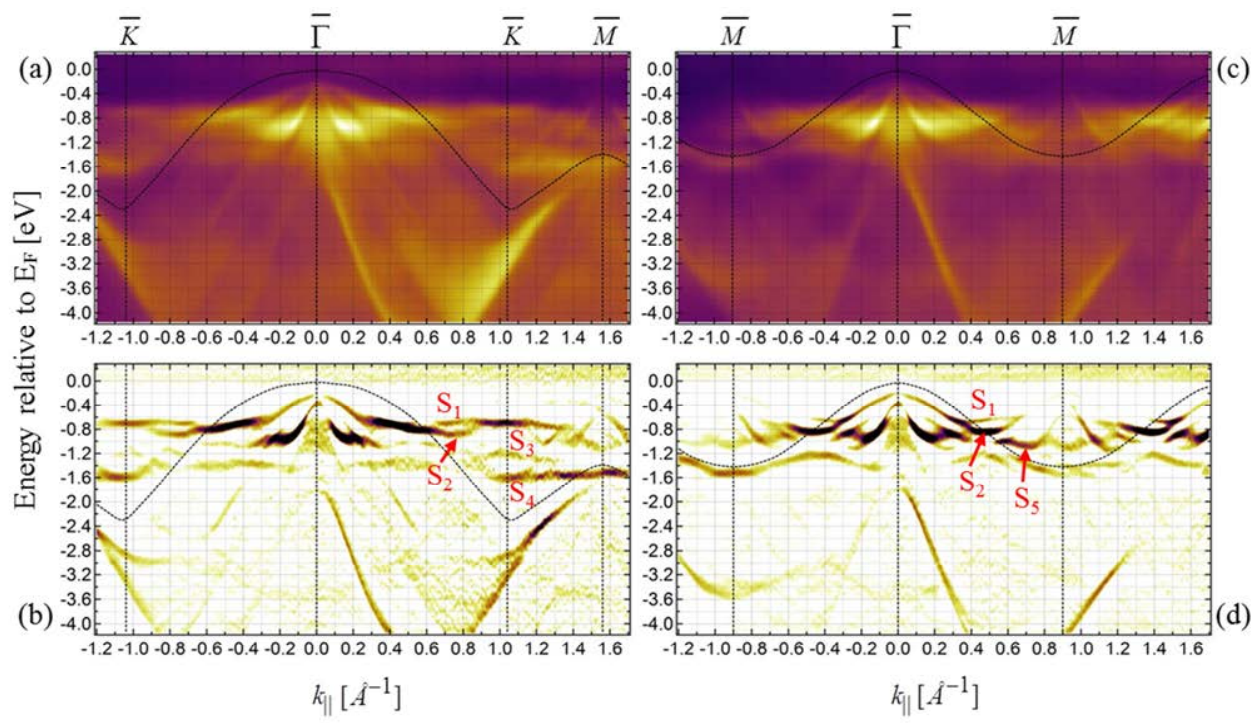

Figure 4.6 (a) and (c) Photoemission intensity as function of energy and $k_{\|}$. The ARPES data from the $\mathrm{Ge}(111) \mathrm{c}(2 \times 8)$ surface were obtained at $100 \mathrm{~K}$ along the $\bar{\Gamma}-\bar{K}-\bar{M}$ and $\bar{\Gamma}-\bar{M}-\bar{\Gamma}$ high symmetry lines of the $1 \times 1$ SBZ, using a photon energy of $30 \mathrm{eV}$. (b) and (d) Second derivative of the ARPES data in (a) and (c), respectively. 


\section{Chapter 5}

\section{Summary of the included papers}

\subsection{Paper I}

Silver is one example of a metal adsorbate that forms several structures on the $\mathrm{Si}(111)$ and Ge(111) surfaces [53-68] which depend on the amount of the adsorbate and annealing conditions. With an amount of $1 \mathrm{ML}, \mathrm{Ag} / \mathrm{Si}(111) \sqrt{3} \times \sqrt{3}$ and $\mathrm{Ag} / \mathrm{Ge}(111) \sqrt{3} \times \sqrt{3}$ superstructures can be formed that have interesting electronic and atomic properties. The $\mathrm{Ag} / \mathrm{Si}(111) \sqrt{3} \times \sqrt{3}$ surface has been extensively studied but for the Ge counterpart, i.e., the $\mathrm{Ag} / \mathrm{Ge}(111) \sqrt{3} \times \sqrt{3}$ surface, detailed electronic structure studies are lacking. In this paper, we present a detailed electronic and atomic structure study of the $\mathrm{Ag} / \mathrm{Ge}(111) \sqrt{3} \times \sqrt{3}$ superstructure prepared with two $\mathrm{Ag}$ coverages, i.e., 0.9 and 1.1 ML. The band structures of the two Ag coverages are investigated at RT and LT (100 $\mathrm{K})$.

Initially, 0.9 and 1.1 ML of $\mathrm{Ag}$ were deposited followed by annealing to $330{ }^{\circ} \mathrm{C}$ which resulted in a well ordered $\mathrm{Ag} / \mathrm{Ge}(111) \sqrt{3} \times \sqrt{3}$ surface, see Fig. 5.1. Figures 5.1(a) and 5.1(b) show LEED patterns for 0.9 and 1.1 ML of Ag, respectively. Figure 5.1(a) exhibits sharp $1 \times 1$ and $\sqrt{3} \times \sqrt{3}$ diffraction spots together with extra spots indicating a $4 \times 4$ periodicity whereas Fig. 5.1(b) only shows strong $1 \times 1$ and $\sqrt{3} \times \sqrt{3}$ diffraction spots. The $4 \times 4$ spots in Fig. 5.1(a) comes from a reconstruction that requires less than $1 \mathrm{ML}$ of $\mathrm{Ag}$ and is therefore expected since the surface was prepared from 0.9 ML of Ag. However, the $\sqrt{3} \times \sqrt{3}$ areas dominate on the surface as indicated by the strong intensity of the $\operatorname{sharp} \sqrt{3} \times \sqrt{3}$ diffraction spots.

In Figs. 5.1(c) and 5.1(d), STM results obtained at sample to tip bias of 0.3 and $1.0 \mathrm{~V}$ are shown, respectively. Both images are obtained at RT tunneling to empty states. Figure 5.1(c) exhibits a honeycomb structure and can be explained by the honeycomb chained triangle model (HCT), whereas Fig. 5.1(d) shows a hexagonal structure which can be accounted for by the inequivalent triangle model (IET). 

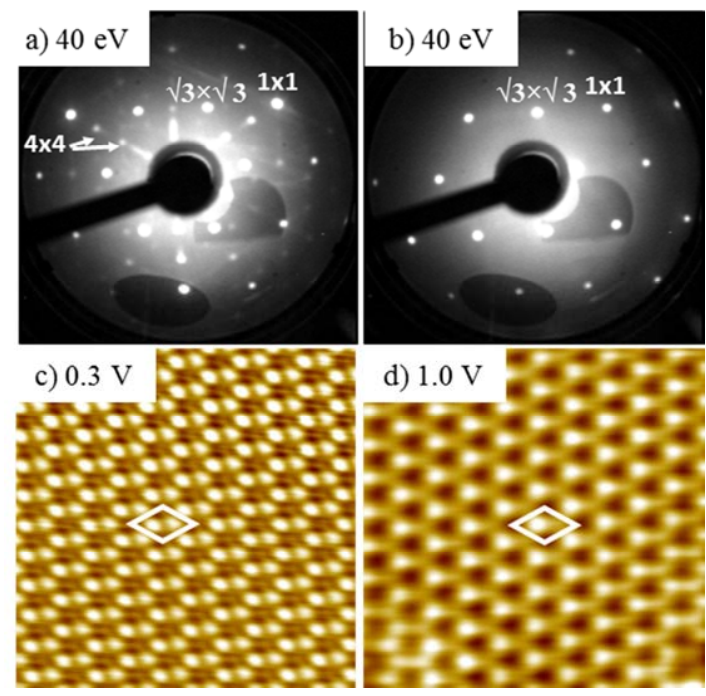

Figure 5.1 (a) and (b) LEED images of the $\mathrm{Ag} / \mathrm{Ge}(111) \sqrt{3} \times \sqrt{3}$ surfaces prepared by 0.9 and $1.1 \mathrm{ML}$ of $\mathrm{Ag}$, respectively. (c) and (d) Empty state STM images of the Ag/Ge(111) $\sqrt{3} \times \sqrt{3}$ surface obtained at a tunneling bias of 0.3 and $1.0 \mathrm{~V}$, respectively. The STM results in (c) and (d) are consistent with HCT and IET models, respectively. The images are $6.4 \times 6.4 \mathrm{~nm}^{2}$ in size and obtained at RT.

The electronic structures of the 0.9 and the $1.1 \mathrm{ML}$ surfaces were investigated by angle resolved photoelectron spectroscopy (ARPES) using a photon energy of $30 \mathrm{eV}$ at RT and LT. An interesting characteristic of the band structure is the $S_{1}$ band that shows different behavior depending on the $\mathrm{Ag}$ amount and temperature. The second derivative of the ARPES data illustrates the dispersion of the $\mathrm{S}_{1}$ band at RT and LT for the 1.1 ML case, see Figs. 5.2(a) and 5.2(b). Figures 5.2(c) and 5.2(d) show the $\mathrm{S}_{1}$ dispersion for the 0.9 ML case.

The depth of the $\mathrm{S}_{1}$ band in Fig. 5.2(a) in the $1.1 \mathrm{ML}$ case is $\approx-0.6 \mathrm{eV}$ at RT which is clearly different from that of the $0.9 \mathrm{ML}$ case in Fig. 5.2(c) which is $\approx-0.25 \mathrm{eV}$ measured at RT. The depth of the band is related to the presence of extra Ag atoms on the surface, expected for the 1.1 ML case. The extra Ag atoms donate their s electrons to the $S_{1}$ band which results in a downward shift. This is a well-known fact that have been observed for the $S_{1}$ band on $\operatorname{Ag} / \operatorname{Si}(111) \sqrt{3} \times \sqrt{3}$ surface, but for $\mathrm{Ag} / \mathrm{Ge}(111) \sqrt{3} \times \sqrt{3}$ surface it is here reported for the first time. In addition, the shape of the band in the 1.1 ML case deviates from a true free electron like parabola of $S_{1}$ for 0.9 ML. The other important feature of the band is related to its behavior at LT $(100 \mathrm{~K})$, where two extra bands within $\approx-0.3 \mathrm{eV}$, denoted $\mathrm{S}_{1 \mathrm{U}}$ and $\mathrm{S}_{1 \mathrm{D}}$ appear, see Fig. 5.2(b). The extra bands are attributed to the surplus $\mathrm{Ag}$ atoms present at RT in the 1.1 ML case. These Ag atoms might be "frozen" into position at specific lattice sites. The behavior of the $S_{1}$ band of $\mathrm{Ag} / \mathrm{Ge}(111) \sqrt{3} \times \sqrt{3}$ has some similarities and differences with the $\mathrm{S}_{1}$ band of $\mathrm{Ag} / \mathrm{Si}(111) \sqrt{3} \times \sqrt{3}$ surface, a detail discussion is found in Ref. [22]. 

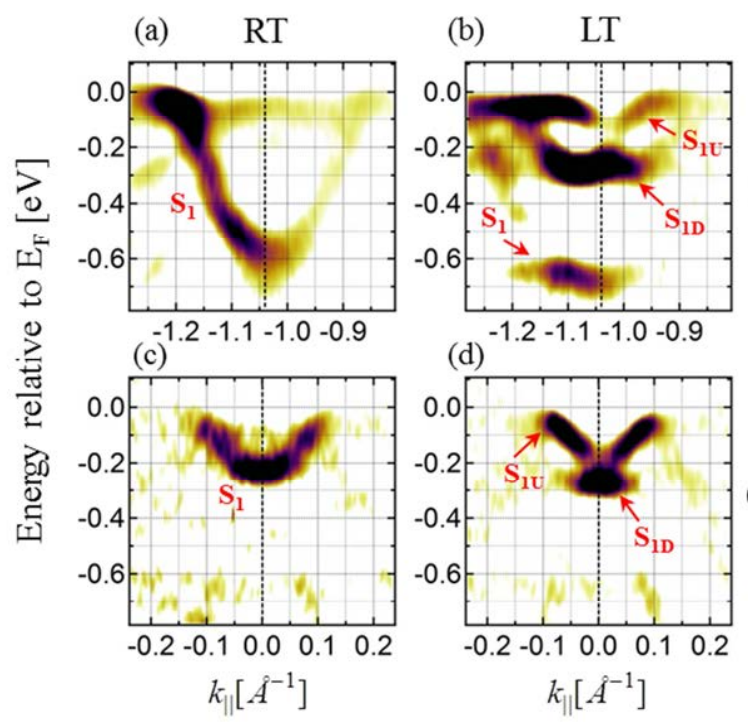

$1.1 \mathrm{ML}$

(d)

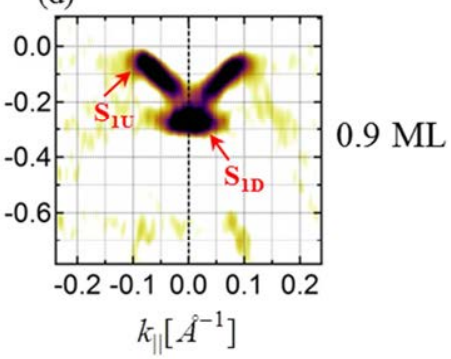

Figure 5.2 (a) - (d) Second derivative of the $S_{1}$ band dispersion for the $\operatorname{Ag} / \mathrm{Ge}(111) \sqrt{3} \times \sqrt{3}$ surface measured at RT ((a) and (c)) and at LT ((b) and (d)). The Ag amount was 1.1 ML ((a) and (b)) and 0.9 ML ((c) and (d)). The ARPES data were obtained at a photon energy of $30 \mathrm{eV}$.

In the $0.9 \mathrm{ML}$ case, the parabolic $\mathrm{S}_{1}$ band changes its shape at LT. It appears to have a V-shape instead of being a true parabola but with almost the same minimum energy. There is a tiny band just below the $\mathrm{V}$-shaped band, at an energy of $-0.3 \mathrm{eV}$, which does not show any dispersion. Beside the interesting behavior of the $S_{1}$ band, there are a total of four bands $\left(S_{1}-S_{4}\right)$ at RT and five bands $\left(S_{1 \mathrm{U}}, S_{1 D}\right.$ and $\left.S_{2}-S_{4}\right)$ at LT which were also discussed in the paper. A discussion of the origin of the $S_{2}$ surface band and the degeneracy of the $S_{3}$ and $S_{4}$ surface bands were also included in the paper [22].

\subsection{Paper II}

The $\sqrt{3} \times \sqrt{3}$ superstructure that is formed by $\mathrm{Ag}$ on either $\mathrm{Si}(111)$ or $\mathrm{Ge}(111)$, is considered as a model system in terms of metal and semiconductor interaction. These surfaces have been studied experimentally but only a few studies are available which present theoretical calculations of the electronic structure of the $\mathrm{Ag} / \mathrm{Si}(111) \sqrt{3} \times \sqrt{3}$ surface [54,60,69-72]. In the case $\mathrm{Ag} / \mathrm{Ge}(111)$ $\sqrt{3} \times \sqrt{3}$, there is a total lack of theoretical results, since there are no reports on the atomic or electronic structures of this surface.

Paper II presents the results of DFT based calculations for both the $\operatorname{Ag} / \operatorname{Si}(111) \sqrt{3} \times \sqrt{3}$ and $\mathrm{Ag} / \mathrm{Ge}(111) \sqrt{3} \times \sqrt{3}$ superstructures. Two atomic models, HCT and IET, were used for the band structure calculations using the GGA and LDA approximations. The band structure for $\mathrm{Ag} / \mathrm{Si}(111) \sqrt{3} \times \sqrt{3}-\mathrm{HCT}$ and $\mathrm{Ag} / \mathrm{Si}(111) \sqrt{3} \times \sqrt{3}$-IET models obtained by GGA are very similar. There is, however, a qualitative difference in energy depth of the free electron like band, $S_{1}$. The 
minimum of this band is slightly below $\mathrm{E}_{\mathrm{F}}$ in the IET case, while it is above $\mathrm{E}_{\mathrm{F}}$ for the HCT model. Moreover, there is an obvious difference when it comes to the gap between the $S_{2}$ and $S_{3}$ bands at the $\bar{K}$-point when the IET model is followed, which is in agreement with the earlier calculations [60]. The band calculations for $\mathrm{Ag} / \mathrm{Ge}(111) \sqrt{3} \times \sqrt{3}-\mathrm{HCT}$ and $\mathrm{Ag} / \mathrm{Ge}(111) \sqrt{3} \times \sqrt{3}-$ IET models resulted in almost similar results with those of the $\mathrm{Ag} / \mathrm{Si}(111) \sqrt{3} \times \sqrt{3}$ surface, except when it comes to the energy minimum of the free electron band. The theoretical $S_{1}$ band is occupied for both $\mathrm{Ag} / \mathrm{Ge}(111) \sqrt{3} \times \sqrt{3}-\mathrm{HCT}$ and $\mathrm{Ag} / \mathrm{Ge}(111) \sqrt{3} \times \sqrt{3}$-IET, which is in contrast to the $\mathrm{Si}$ case. In addition, the depth of the band for the IET structure is significantly larger than that of HCT. Another important consequence is that bands $S_{2}$ and $S_{3}$ are degenerate at the $\bar{K}$-point for both HCT and IET. In the paper, only results from GGA are presented, since the results obtained from LDA do not deviate from those of GGA.

In Fig. 5.3 a comparison is presented between the experimental band structure and that calculated for the $\mathrm{Ag} / \mathrm{Ge}(111) \sqrt{3} \times \sqrt{3}-\mathrm{HCT}$ structure. Figure 5.3(a) shows the experimental band structure along the $\bar{M}-\bar{\Gamma}-\bar{K}-\bar{M}$ path of the $\sqrt{3} \times \sqrt{3}$ surface Brillouin zone. There are six surface bands of which the free electron band $S_{1}$ shows a dispersion down to $\approx-0.3 \mathrm{eV}$. At the $\bar{K}$-point, the $S_{2}$ and $S_{3}$ bands are degenerate whereas at the $\bar{M}$-point the band $S_{2}$ has another branch denoted as $\mathrm{S}_{2}^{\prime}$, which has maximum gap of $\approx 0.4 \mathrm{eV}$ at the $\bar{M}$-point.

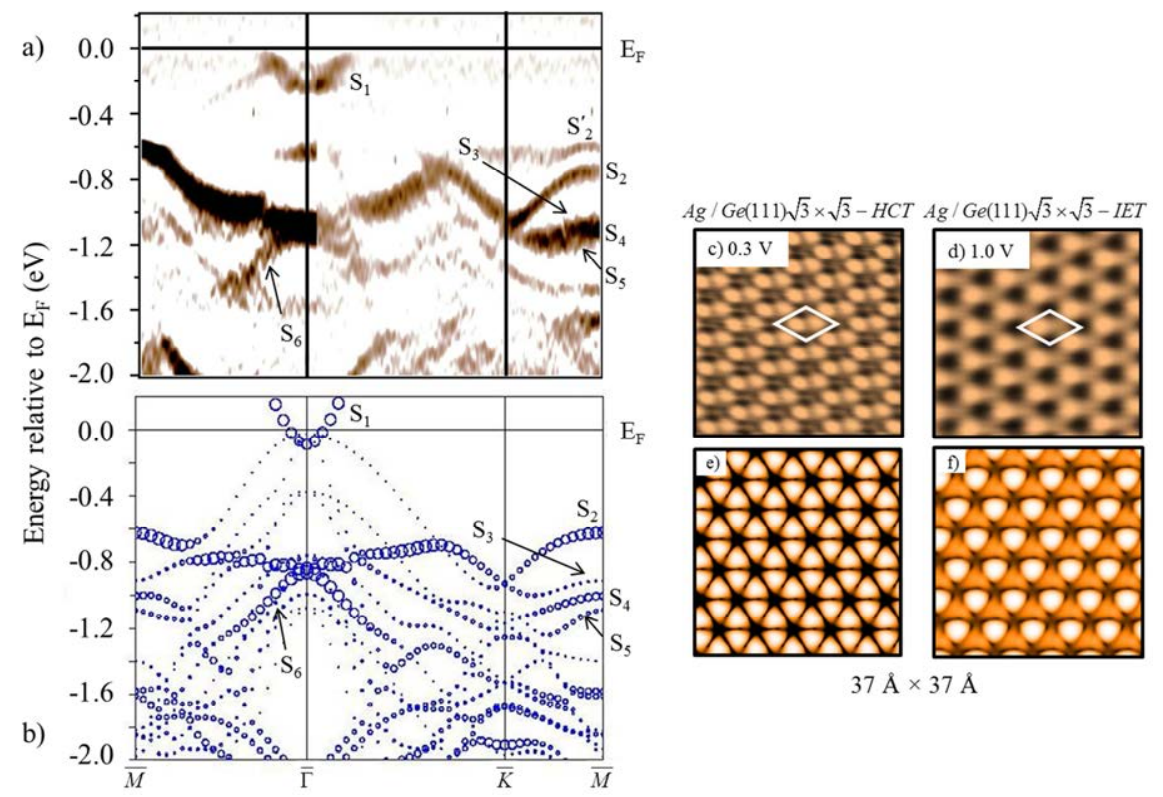

Figure 5.3 (a) Electronic structure of the $\mathrm{Ag} / \mathrm{Ge}(111) \sqrt{3} \times \sqrt{3}$ surface (with $\approx 0.9$ ML of $\mathrm{Ag}$ ) obtained experimentally by ARPES using a photon energy of $30 \mathrm{eV}$ at RT. (b) Calculated band structure based on the HCT model. (c) and (d) Empty state STM images exhibit honeycomb or hexagonal structures depending on the bias. (e) and (f) Empty state simulated STM images based on the HCT and IET models, respectively. (e) Shows a honeycomb structure while (f) exhibits a hexagonal structure. 
The calculated band structure was obtained using a slab consisting of nine Ge layers and a $\mathrm{H}$-layer at the bottom. A top Ag layer was added having HCT structure. The band structure is in agreement with that of the experimental bands. Most of the experimental bands and their dispersions are reproduced by the theoretical band structure. However, the $S^{\prime}{ }_{2}$ band does not appear in the theoretical results, see Fig. 5.3(b). In Figs. 5.3(c) and 5.3(d) STM images are shown obtained at RT tunneling to empty states with sample biases 0.3 and $1.0 \mathrm{~V}$, respectively. Simulated STM images were obtained using the Tersoff-Hamann approach. Empty state simulated STM images based on HCT and IET models were obtained by integrating the local density of states within $0.4 \mathrm{eV}$ above the Fermi energy, in Fig. 5.3(e) and 5.3(f), respectively. The images represent honeycomb and hexagonal structures, respectively.

\subsection{Paper III}

In this study, the $\mathrm{Ag} / \mathrm{Ge}(111) \sqrt{3} \times \sqrt{3}$ surface was used as a substrate onto which $0.2 \mathrm{ML}$ of $\mathrm{Ag}$ was added. This resulted in a $\mathrm{Ag} / \mathrm{Ge}(111) 6 \times 6$ phase without annealing. The surface periodicity was verified by LEED which shows sharp $6 \times 6$ diffraction spots (yellow circles) together with strong $\sqrt{3} \times \sqrt{3}$ spots (red circles), see Fig. 5.4(a). The strong $\sqrt{3} \times \sqrt{3}$ spots indicate that the structure of the substrate remains, and that the added $\mathrm{Ag}$ atoms sit at certain $\sqrt{3} \times \sqrt{3}$ lattice sites to form the $6 \times 6$ phase. An atomic model of the $6 \times 6$ phase is shown in Fig. 5.4(b) derived from earlier STM results $[57,73]$.

a) $60 \mathrm{eV}$

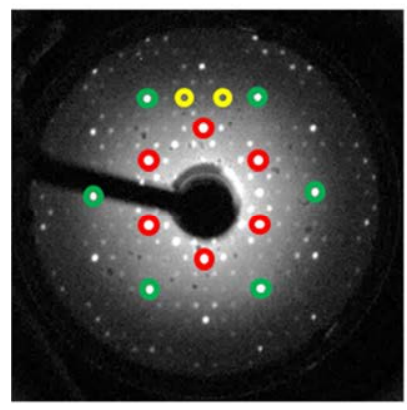

b) $6 \times 6$ model

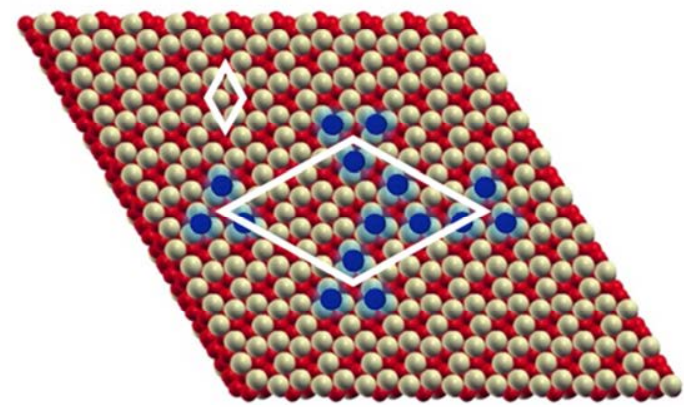

- Ge atoms $\bullet \mathrm{Ag}$ atoms $\bullet \mathrm{Ag}$ adatoms

Figure 5.4 (a) LEED pattern of the $\mathrm{Ag} / \mathrm{Ge}(111) 6 \times 6$ surface showing sharp $1 \times 1, \sqrt{3} \times \sqrt{3}$ and $6 \times 6$ spots indicated by green, red and yellow circles, respectively. (b) Atomic model showing a $6 \times 6$ unit cell which contains six extra Ag atoms (blue circles). The smaller unit cell corresponds to the $\sqrt{3} \times \sqrt{3}$ periodicity of the substrate. It contains three Ag atoms per unit cell.

The electronic structure of the $\mathrm{Ag} / \mathrm{Ge}(111) 6 \times 6$ surface, which was studied in detail, consists of several new bands in addition to those of $\mathrm{Ag} / \mathrm{Ge}(111) \sqrt{3} \times \sqrt{3}$. The band structure is modified especially close to the Fermi level, which is the energy region where the free electron 
band, $S_{1}$, of $\sqrt{3} \times \sqrt{3}$ surface resides. The energy width of the occupied part of $S_{1}$ has increased significantly to $0.85 \mathrm{eV}$. In addition, there are extra bands in the $S_{1}$ region that are due to the $6 \times 6$ phase. The $6 \times 6$ phase provides reciprocal lattice vectors which result in umklapp scattering of the $\mathrm{S}_{1}$ band.

Figure 5.5(a) presents two dimensional constant energy contours obtained from the $\mathrm{Ag} / \mathrm{Ge}(111) 6 \times 6$ surface using synchrotron light with an energy of $30 \mathrm{eV}$. Constant energy data obtained at the Fermi level do not show any features, which suggests that all bands are below the Fermi level and that the $\mathrm{Ag} / \mathrm{Ge}(111) 6 \times 6$ surface is semiconducting. However, at $0.2 \mathrm{eV}$ below $\mathrm{E}_{\mathrm{F}}$ there are several constant energy contours, as shown in Fig. 5.5(a). The top and bottom bright circles are due to the $S_{1}$ band of the $\sqrt{3} \times \sqrt{3}$ surface, where the center of the figure corresponds to the $\bar{\Gamma}$-point of the $\sqrt{3} \times \sqrt{3}$ surface ( $\bar{K}$-point of the $1 \times 1 \mathrm{SBZ}$ ). There are some other weak circles in Fig. 5.5(a) which are highlighted in Fig. 5.5(b) by red circles. These weak circles are due to umklapp scattering. The umklapp circles centered at different $\bar{\Gamma}$-points of the $6 \times 6 \mathrm{SBZs}$ overlap each other which results in a complicated pattern. Figure 5.5(c) is a schematic representation of Fig. 5.5(a) where each circle is centered at a different $\bar{\Gamma}$-point of the periodic $6 \times 6 \mathrm{SBZ}$ scheme. The origins of these umklapp bands are discussed in paper III.
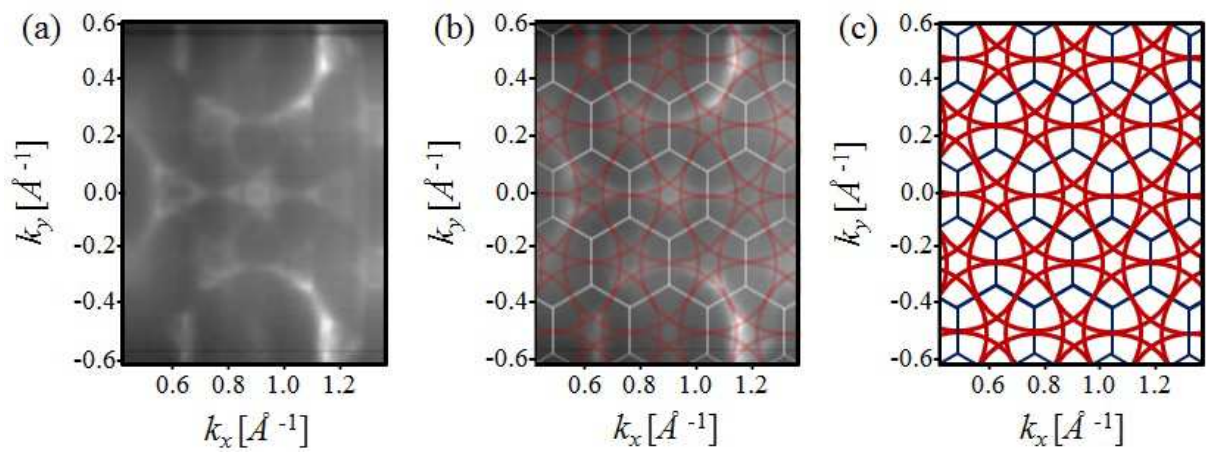

Figure 5.5 (a) Constant energy contours at $0.2 \mathrm{eV}$ below $\mathrm{E}_{\mathrm{F}}$ obtained from the $\mathrm{Ag} / \mathrm{Ge}(111) 6 \times 6$ surface. (b) Umklapp circles from (a) are schematically drawn to highlight the complicated pattern produced by the umklapp scattering (c) Schematic drawing of the constant energy contours at $-0.2 \mathrm{eV}$ in (a) and $6 \times 6 \mathrm{SBZs}$ in a periodic zone scheme.

Another interesting observation is the transition from a metallic $\sqrt{3} \times \sqrt{3}$ surface into semiconducting $6 \times 6$ surface. The umklapp scattering of the $S_{1}$ band results in band crossings at $\approx 0.2 \mathrm{eV}$ between branches centered at neighboring $6 \times 6 \bar{\Gamma}$-points. A gap opens up where the bands cross and the upper edge of the gap is pushed above the Fermi level. As a consequence of this, the electronic structure of the $6 \times 6$ becomes semiconducting.

\subsection{Paper IV}

One aim of the thesis work was to study the combination of two metallic adsorbates interacting with the $\mathrm{Si}(111)$ or $\mathrm{Ge}(111)$ surface instead of just one adsorbate, which has been the topic of most studies so far. Several metal combinations were tried on different surfaces of which the 
$\mathrm{Ag} / \mathrm{Si}(111) \sqrt{3} \times \sqrt{3}$ and $\mathrm{Ag} / \mathrm{Ge}(111) \sqrt{3} \times \sqrt{3}$ surfaces turned out to be very suitable substrates. These surfaces were also initially a natural choice since they are well-ordered and the knowledge and understanding about the atomic and electronic structures are well-developed. The $\mathrm{Ag} / \mathrm{Si}(111)$ $\sqrt{3} \times \sqrt{3}$ and $\mathrm{Ag} / \mathrm{Ge}(111) \sqrt{3} \times \sqrt{3}$ surfaces were investigated experimentally and theoretically in the first two papers.

It was found that combinations of $\mathrm{Ag}$ and $\mathrm{Sn}$ form 2D ordered structures on the $\mathrm{Ge}(111)$ surfaces. Several amounts of $\mathrm{Sn}$ on the $\mathrm{Ag} / \mathrm{Ge}(111) \sqrt{3} \times \sqrt{3}$ surface have been investigated. A submonolayer coverage of $\mathrm{Sn}(\approx 0.45 \mathrm{ML})$ on the $\sqrt{3} \times \sqrt{3}$ surface, which has nominally $1 \mathrm{ML}$ of $\mathrm{Ag}$, forms a well-ordered $3 \sqrt{3} \times 3 \sqrt{3}$ superstructure after annealing to $300{ }^{\circ} \mathrm{C}$. The $3 \sqrt{3} \times 3 \sqrt{3}$ surface is very much dependent on the $\mathrm{Sn}$ amount and annealing conditions. If not prepared properly it will switch to another phase. The $\mathrm{Ag} / \mathrm{Ge}(111) \sqrt{3} \times \sqrt{3}$ surface is not destroyed as evidenced by STM which shows that both surfaces are at the same level and the periodicities can be clearly seen. However, the electronic structure of the $\mathrm{Ag} / \mathrm{Ge}(111) \sqrt{3} \times \sqrt{3}$ surface becomes modified as is obvious from the changes in the band structure. The electronic and atomic structures of the surface were investigated in detail [22].

In Fig. 5.6, LEED and STM results obtained for $\mathrm{Sn} / \mathrm{Ag} / \mathrm{Ge}(111) 3 \sqrt{3} \times 3 \sqrt{3}$ surface are shown. Figure 5.6(a) shows a LEED pattern in which strong $1 \times 1$ spots (black circles) and $\sqrt{3} \times \sqrt{3}$ spots (white circles) are present together with rather weak but well defined $3 \sqrt{3} \times 3 \sqrt{3}$ spots between the $\sqrt{3} \times \sqrt{3}$ diffraction spots. This indicates that the $\sqrt{3} \times \sqrt{3}$ surface is not destroyed when the $3 \sqrt{3} \times 3 \sqrt{3}$ periodicity is formed. Figures 5.6(b) and 5.6(c) show empty and filled state STM images of $3 \sqrt{3} \times 3 \sqrt{3}$ superstructure with a sample bias of $\pm 0.3 \mathrm{~V}$, respectively. The surface shows a similar structure tunneling to empty or filled states. There are two periodicities, one with a small unit cell corresponding to a $\sqrt{3} \times \sqrt{3}$ periodicity, while the large one is that of $3 \sqrt{3} \times 3 \sqrt{3}$. A $3 \sqrt{3} \times 3 \sqrt{3}$ unit cell contains nine blobs.
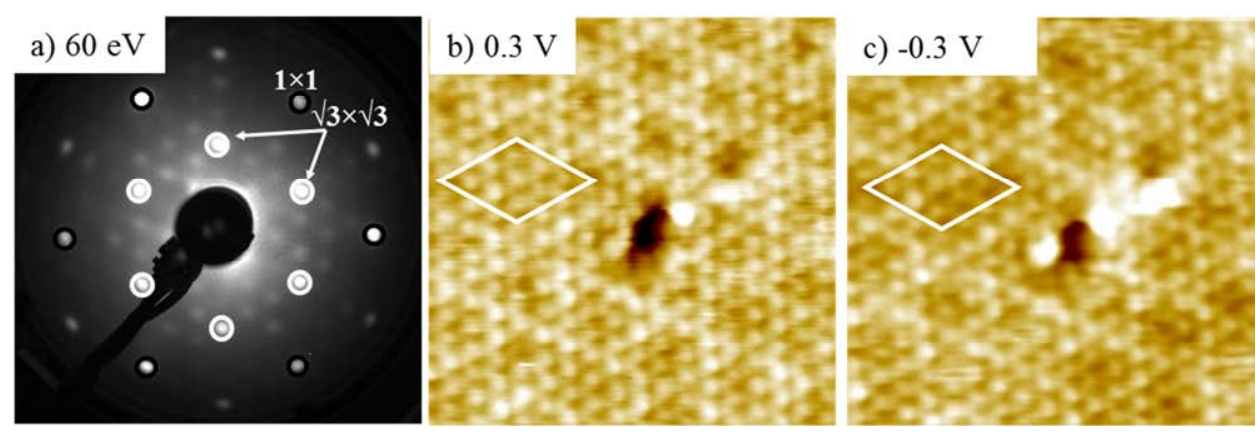

Figure 5.6 (a) LEED pattern of the $\mathrm{Sn} / \mathrm{Ag} / \mathrm{Ge}(111) 3 \sqrt{3} \times 3 \sqrt{3}$ surface showing $1 \times 1$ and $\sqrt{3} \times \sqrt{3}$ diffraction spots in black and white circles, respectively. Whereas $3 \sqrt{3} \times 3 \sqrt{3}$ spots are between the $\sqrt{3} \times \sqrt{3}$ spots. (b) and (c) Empty and filled state STM images $\left(\approx 10 \times 10 \mathrm{~nm}^{2}\right)$ of the $3 \sqrt{3} \times 3 \sqrt{3}$ surface obtained at $\pm 0.3 \mathrm{~V}$, respectively. The parallelograms show $3 \sqrt{3} \times 3 \sqrt{3}$ unit cells which contain nine protrusions. 
Figure 5.7 shows the electronic structure of the $\mathrm{Sn} / \mathrm{Ag} / \mathrm{Ge}(111) 3 \sqrt{3} \times 3 \sqrt{3}$ surface, measured at a photon energy of $30 \mathrm{eV}$. Figure 5.7 (a) shows $\sqrt{3} \times \sqrt{3}$ and $3 \sqrt{3} \times 3 \sqrt{3} \mathrm{SBZs}$ together with the high symmetry points and directions. The experimental band structure in the form of the second derivative is presented along $\bar{\Gamma}-\bar{M}-\bar{\Gamma}$ and $\bar{\Gamma}-\bar{K}-\bar{M}$ of the $3 \sqrt{3} \times 3 \sqrt{3}$ SBZ, in Figs. $5.7(\mathrm{~b})$ and 5.7(c), respectively. The band structure exhibits significant modifications when it comes to the dispersion of the free electron like $S_{1}$ band of the $\sqrt{3} \times \sqrt{3}$ surface, see Fig. 5.7(b). The depth of the band changed drastically, from -0.65 to $-1.0 \mathrm{eV}$, cf. Figs. 5.2(a) and 5.7(b). There are some other bands labeled $S_{2}-S_{7} . S_{6}$ and $S_{7}$ are similar to $S_{2}$ and $S_{3}$ of the $\sqrt{3} \times \sqrt{3}$ surface, see Figs. 5.3(a) and 5.3(b), respectively. At the $\bar{M}_{2}$-point of $3 \sqrt{3} \times 3 \sqrt{3}$ (or $\bar{M}$-point of $\sqrt{3} \times \sqrt{3}$ ) the bands have a maximum gap of $\approx 0.4 \mathrm{eV}$ whereas the bands are degenerate at the $\bar{\Gamma}_{2}$-point of $3 \sqrt{3} \times 3 \sqrt{3}$ (or $\bar{K}$ point of $\sqrt{3} \times \sqrt{3}$ ) in Fig. 5.7(c). There is one obvious difference in the dispersion of the $S_{7}$ band (or $\mathrm{S}_{3}$ bands of $\sqrt{3} \times \sqrt{3}$ surface) which has a maximum at the $\bar{M}$-point of the $\sqrt{3} \times \sqrt{3}$ surface but it shows clear minimum at the $\bar{M}_{2}$-point, cf. Figs. 5.3(a) and 5.7(c). The constant energy contour of the $S_{1}$ band shows a significant difference in shape changing from a circular to a hexagonal contour. In addition, $\mathrm{Sn} 4 d$ and Ge $3 d$ core levels are also discussed. In conclusion, the formation of the $\mathrm{Sn} / \mathrm{Ag} / \mathrm{Ge}(111) 3 \sqrt{3} \times 3 \sqrt{3}$ surface results in a modification of the electronic structure of $\mathrm{Ag} / \mathrm{Ge}(111) \sqrt{3} \times \sqrt{3}$ surface which can be clearly seen from the dispersions of the bands.

(a)

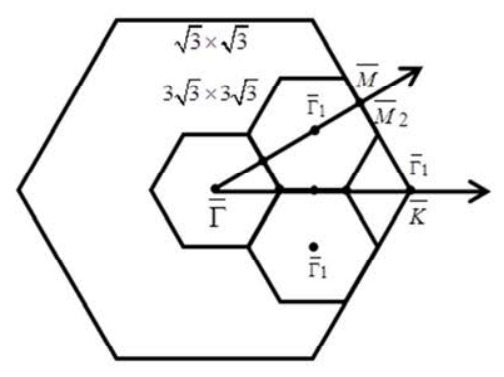

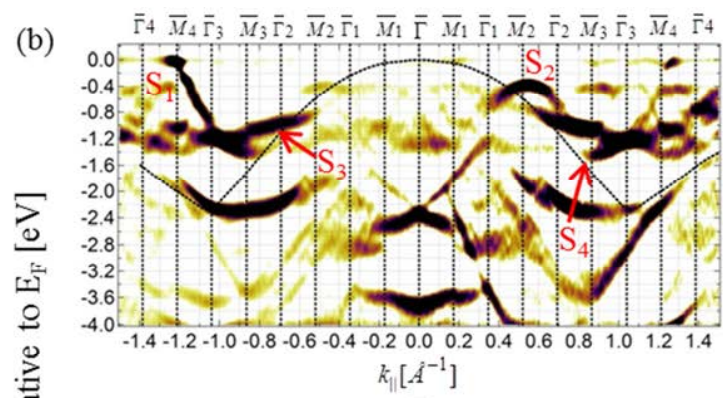

㑊

(c)

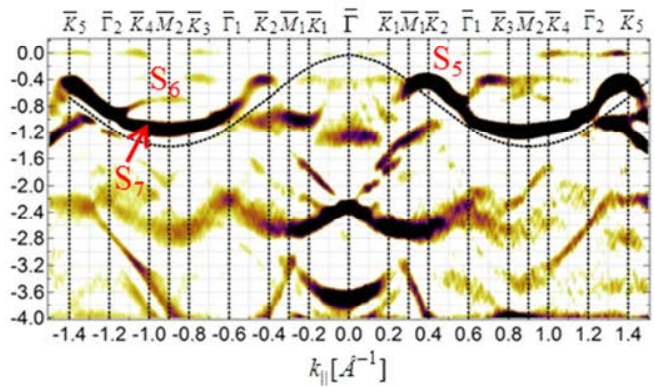

Figure 5.7 (a) $\sqrt{3} \times \sqrt{3}$ and $3 \sqrt{3} \times 3 \sqrt{3}$ SBZs with high symmetry points and directions. (b) and (c) Second derivative of the $\mathrm{Sn} / \mathrm{Ag} / \mathrm{Ge}(111) 3 \sqrt{3} \times 3 \sqrt{3}$ surface band structure along $\bar{\Gamma}-\bar{M}-\bar{\Gamma}$ and $\bar{\Gamma}-\bar{K}-\bar{M}$ directions of the $3 \sqrt{3} \times 3 \sqrt{3} \mathrm{SBZ}$, obtained at a photon energy of $30 \mathrm{eV}$ at LT $(100 \mathrm{~K})$. 


\subsection{Paper V}

In this paper, we investigated a higher coverage of $\mathrm{Sn}(0.75 \mathrm{ML})$ on the $\mathrm{Ag} / \mathrm{Ge}(111) \sqrt{3} \times \sqrt{3}$ surface which resulted, after annealing to $300{ }^{\circ} \mathrm{C}$ for few minutes, in a very well-ordered $\mathrm{Sn} / \mathrm{Ag} / \mathrm{Ge}(111) 3 \times 3$ periodicity.

Figure 5.8(a) shows a LEED pattern of the $3 \times 3$ surface with sharp diffraction spots which is an indication of a well-ordered periodicity of the surface alloy. In Fig. 5.8(b) a Sn $4 d$ core level spectrum obtained at a photon energy of $80 \mathrm{eV}$ is shown. The spectrum is fitted by two components. The main component, $\mathrm{C}_{1}$, constitutes $84 \%$ of total $\mathrm{Sn} 4 d$ intensity, whereas the other component, $\mathrm{C}_{2}$, corresponds to only $16 \%$. The sharpness of the main component indicates that most of the $\mathrm{Sn}$ atoms are located at well-ordered sites of the $\mathrm{Sn} / \mathrm{Ag} / \mathrm{Ge}(111) 3 \times 3$ surface. However, it is difficult to predict the origin of the $\mathrm{C}_{2}$ component. The Gaussian width is quite large $(0.5 \mathrm{eV})$ which suggests that it might be related to $\mathrm{Sn}$ atoms that occupy sites with a significant disorder and not originating from $\mathrm{Sn}$ atoms that are part of $\mathrm{Sn} / \mathrm{Ag} / \mathrm{Ge}(111) 3 \times 3$ surface itself.
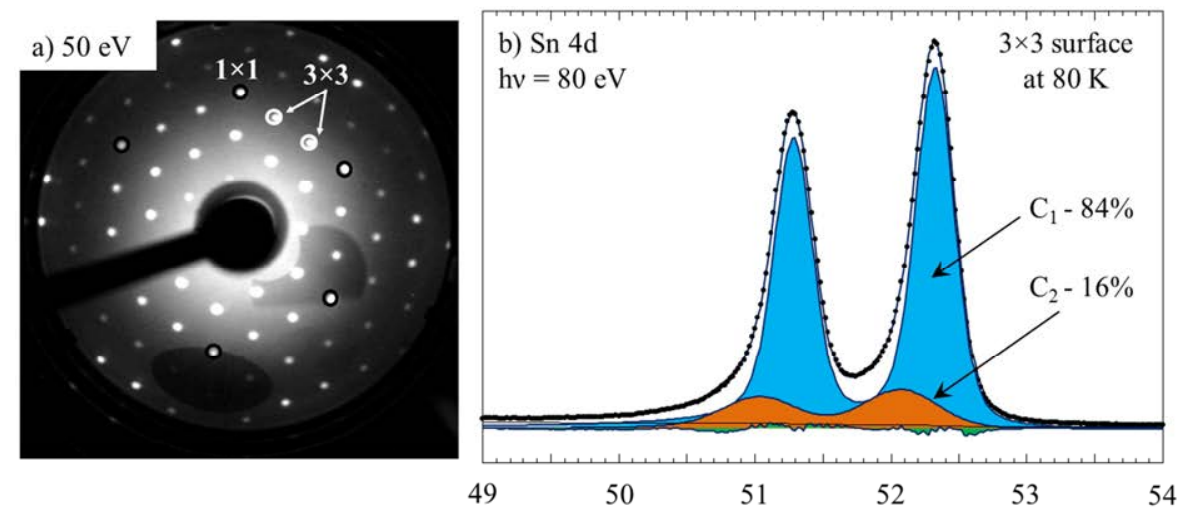

Figure 5.8 (a) LEED pattern of the $\mathrm{Sn} / \mathrm{Ag} / \mathrm{Ge}(111) 3 \times 3$ surface, showing sharp $3 \times 3$ and $1 \times 1$ spots marked by white and black circles, respectively. (b) Sn $4 d$ core level spectrum measured at a photon energy of $80 \mathrm{eV}$ at $80 \mathrm{~K}$. The spectrum is fitted with two components which constitute $84 \%$ and $16 \%$ of the intensity, respectively.

The electronic structure is shown in Fig. 5.9, measured using synchrotron light with an energy of $30 \mathrm{eV}$, In Fig. 5.9(a), constant energy contours at $0.1 \mathrm{eV}$ below $\mathrm{E}_{\mathrm{F}}$ are shown for the $\mathrm{Sn} / \mathrm{Ag} / \mathrm{Ge}(111) 3 \times 3$ surface. There are two triangular features rotated by some angle with respect to each other located at each $\bar{K}$-point of $3 \times 3 \mathrm{SBZ}$ while at the $\bar{\Gamma}$-point the contours are rather complicated. The $3 \times 3 \mathrm{SBZ}$ is drawn together with the high symmetry points and directions. Figures 5.9(b) and 5.9(c) show vertical cuts along the $\bar{\Gamma}-\bar{K}$ and $\bar{\Gamma}-\bar{M}$ directions of $3 \times 3 \mathrm{SBZ}$. The interesting features of the band structure is the upper band $S_{1}$ that shows almost a linear dispersion down to $\approx 0.40 \mathrm{eV}$ below $\mathrm{E}_{\mathrm{F}}$ at the $\bar{\Gamma}$-point $(\approx 0.30 \mathrm{eV}$ at the $\bar{K}$-point). The band shows splits along the $\bar{\Gamma}-\bar{M}$ line that could be explained by the constant energy contours. The shapes of the contours reveal that the split is due to the complicated rotated shapes of the contours centered 
at the $\bar{\Gamma}$-point. Along the $\bar{\Gamma}-\bar{K}$ line the contours are cut through the crossing point and no split is therefore observed along this line, see Fig. 5.9(a). In paper $\mathrm{V}$, the $\mathrm{Sn} / \mathrm{Ag} / \mathrm{Ge}(111) 3 \times 3$ surface alloy has been discussed in detail. There are a total of six surface bands, labeled $\mathrm{S}_{1}-\mathrm{S}_{6}$, along the $\bar{\Gamma}-\bar{K}$ and $\bar{\Gamma}-\bar{M}$ directions which all follow the $3 \times 3$ periodicity, while another three bands $\left(\mathrm{A}_{1}-\right.$ $\mathrm{A}_{3}$ ) are surface bands related to a $1 \times 1$ periodicity.
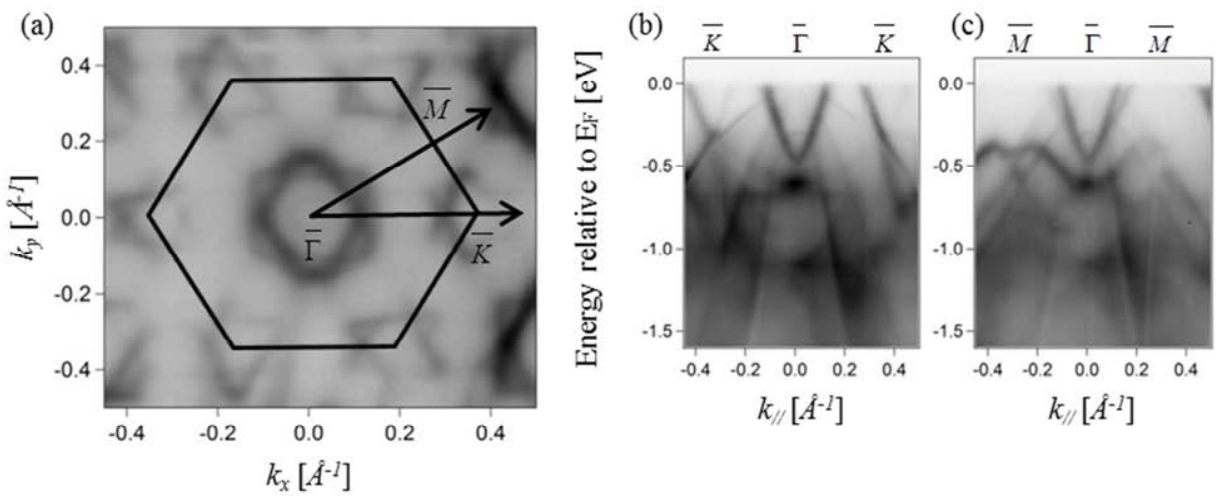

Figure 5.9 (a) Constant energy contours at $0.1 \mathrm{eV}$ below $\mathrm{E}_{\mathrm{F}}$ for the $\mathrm{Sn} / \mathrm{Ag} / \mathrm{Ge}(111) 3 \times 3$ surface, obtained at $30 \mathrm{eV}$. (b) and (c) Cuts along the energy axis along the $\bar{\Gamma}-\bar{K}$ and $\bar{\Gamma}-\bar{M}$ high symmetry lines of the $3 \times 3$ SBZ. The upper band shows a split only along the $\bar{\Gamma}-\bar{M}$ line which is due to the shape of the contours along that line.

Figure 5.10 shows $\mathrm{STM}$ results obtained at low temperature $(\approx 40 \mathrm{~K})$ for the $\mathrm{Sn} / \mathrm{Ag} / \mathrm{Ge}(111) 3 \times 3$ surface. Figure $5.10(\mathrm{a})$ is a filled state image at $-1.5 \mathrm{~V}$ which shows a hexagonal structure with one big protrusion per $3 \times 3$ unit cell. In contrast, the empty state STM image in Fig. 5.10(b) obtained at $1.5 \mathrm{~V}$ exhibits a honeycomb structure. The $3 \times 3$ unit cell in this image contains two blobs.
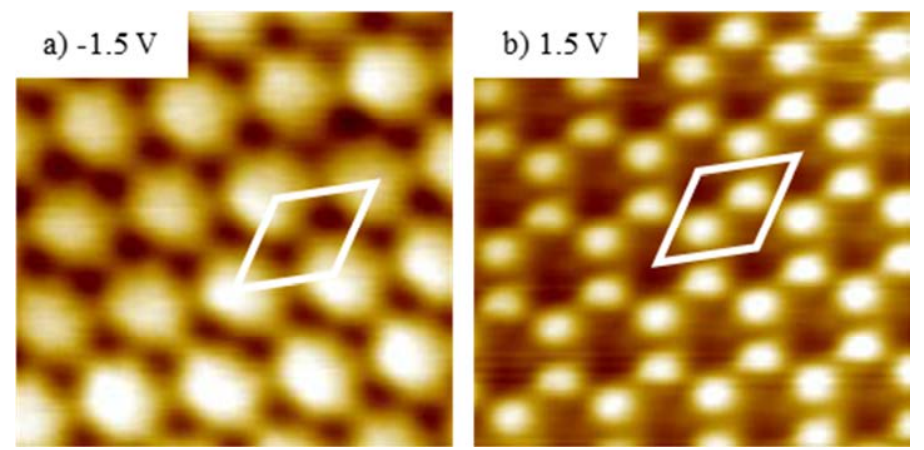

Figure 5.10 (a) and (b) Filled and empty state STM images $\left(\approx 5 \times 5 \mathrm{~nm}^{2}\right)$ obtained at $\pm 1.5 \mathrm{~V}$ at $\approx 40 \mathrm{~K}$ from the $\mathrm{Sn} / \mathrm{Ag} / \mathrm{Ge}(111) 3 \times 3$ surface. The images show essentially a hexagonal and a honeycomb arrangement of blobs, respectively. A $3 \times 3$ unit cell is included in each STM image. 


\subsection{Paper VI}

In this paper, a combination of $\mathrm{Sn}$ and $\mathrm{Ag}$ on the $\mathrm{Si}(111)$ surface was studied. Initially an amount of $1.2 \mathrm{ML}$ of $\mathrm{Ag}$ is evaporated onto the $\mathrm{Si}(111) 7 \times 7$ surface, keeping the substrate at $600{ }^{\circ} \mathrm{C}$ which helps to reduce the amount of $\mathrm{Ag}$ to what is actually needed to form a well-ordered $\mathrm{Ag} / \mathrm{Si111)} \sqrt{3} \times \sqrt{3}$ surface. As a second step, $0.75 \mathrm{ML}$ of $\mathrm{Sn}$ was evaporated onto the $\mathrm{Ag} / \mathrm{Si} 111$ ) $\sqrt{3} \times \sqrt{3}$ surface followed by annealing to $450^{\circ} \mathrm{C}$ for 2 minutes. This procedure resulted in a very well-ordered $\mathrm{Sn} / \mathrm{Ag} / \mathrm{Si}(111) 2 \times 2$ surface alloy, which was verified by LEED and STM. The electronic and atomic structures of the surface were studied in detail by experimental and theoretical methods.

In Fig. 5.11, STM and ARPES results are presented. Figures 5.11(a) and 5.11(b) are the filled and empty state STM images of the $\mathrm{Sn} / \mathrm{Ag} / \mathrm{Si}(111) 2 \times 2$ surface recorded at a sample bias of $-1.0 \mathrm{~V}$ and $+1.0 \mathrm{~V}$, respectively. The image in Fig. 5.11(a) shows three small protrusions per $2 \times 2$ cell while the corresponding empty state image in Fig. 5.11(b) exhibits a contrast reversal. The information from the STM study was used to model the surface atomic structure.

a)

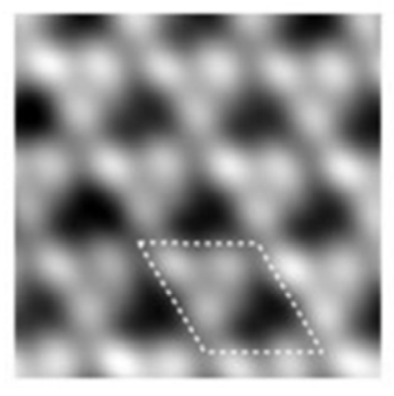

c)

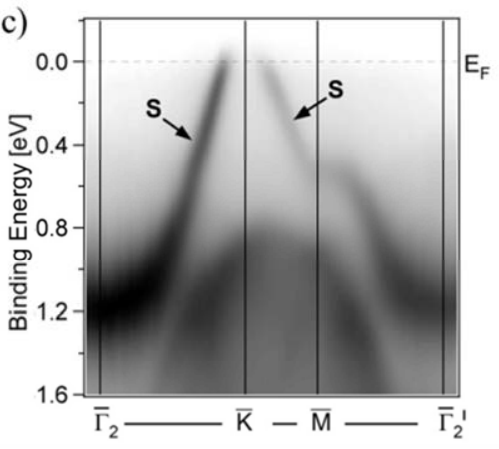

b)

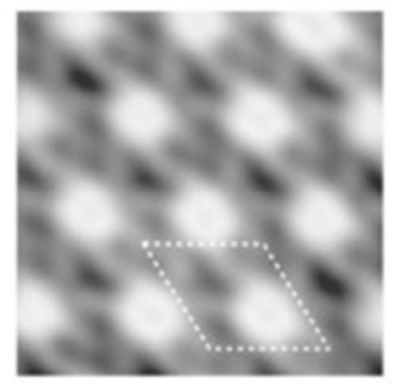

d)

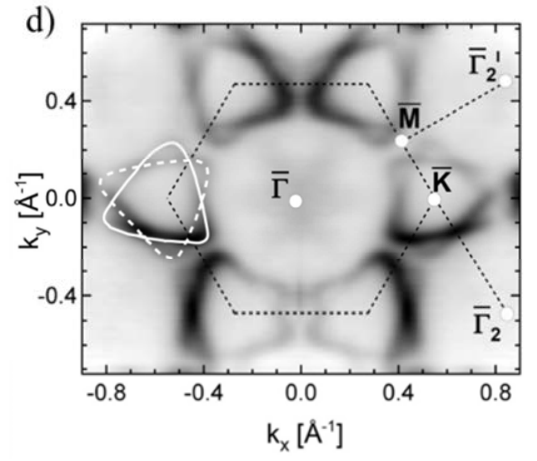

Figure 5.11 (a) and (b) Filled and empty state STM images of the $\mathrm{Sn} / \mathrm{Ag} / \mathrm{Si}(111) 2 \times 2$ surface. The images are obtained in constant current mode $(100 \mathrm{pA})$ with sample biases of -1.0 and $+1.0 \mathrm{~V}$, respectively. The images are obtained at $50 \mathrm{~K}$ and have a size of $7.2 \times 7.2 \mathrm{~nm}^{2}$. (c) Band structure of the surface along the $\bar{\Gamma}_{2}-\bar{K}-\bar{M}-\bar{\Gamma}_{2}^{\prime}$ symmetry lines of the $2 \times 2 \mathrm{SBZ}$, obtained at a photon energy of $52 \mathrm{eV}$, at $100 \mathrm{~K}$. (d) Constant energy contours obtained at 0.4 eV below $\mathrm{E}_{\mathrm{F}}$. 
The model resulted in a structure which consists of three $\mathrm{Sn}$ and four Ag atoms per $2 \times 2$ unit cell which are arranged in the form of $\mathrm{Sn}$ and $\mathrm{Ag}$ trimers while a fourth $\mathrm{Ag}$ atom is located at the corner of the $2 \times 2$ cell. The details of the calculations and the atomic model are described in ref. [24]. Figure 5.11(c) shows the band structure along the $\bar{\Gamma}_{2}-\bar{K}-\bar{M}-\bar{\Gamma}_{2}^{\prime}$ line of the $2 \times 2 \mathrm{SBZ}$. The surface band structure is dominated by a free electron like band $\mathrm{S}$ which crosses the Fermi level near the $\bar{K}$-point. It has a linear upward dispersion from $1.2 \mathrm{eV}$ below $\mathrm{E}_{\mathrm{F}}$ at the $\bar{\Gamma}$-point, see Fig. 5.11(c). The band is unoccupied at the $\bar{K}$-point but it can be shifted down by adding a tiny amount of alkali metals which provides electrons that will fill up the band. In Fig. 5.11(d) constant energy contours at $0.4 \mathrm{eV}$ below $\mathrm{E}_{\mathrm{F}}$ are shown together with a $2 \times 2 \mathrm{SBZ}$ with high symmetry points. The contours reveal two differently rotated triangular contours centered at the $\bar{K}$-points of the $2 \times 2$ SBZ. In addition, the calculated electronic structure based on the proposed model is in agreement with the experimental results verifying the atomic model, see ref. [24] for details. The $2 \times 2$ surface is a perfect example of an ordered binary surface alloy.

\subsection{Paper VII}

In further attempts to form surface alloys, we also investigated other metal adsorbates that form ordered structures on semiconductor surfaces. It was found that also $\mathrm{Pb}$ and $\mathrm{In}$ form ordered surface alloys on $\mathrm{Ge}(111)$. The $\mathrm{In} / \mathrm{Pb} / \mathrm{Ge}(111)$ surface alloy has a $3 \times 3$ periodicity as verified by both LEED and STM. Initially, 1.33 ML of $\mathrm{Pb}$ was evaporated onto a $\mathrm{Ge}(111) \mathrm{c}(2 \times 8)$ surface, followed by annealing to $\approx 200{ }^{\circ} \mathrm{C}$ to prepare a $\mathrm{Pb} / \mathrm{Ge}(111) \sqrt{3} \times \sqrt{3}$ surface. This surface was used as a substrate onto which $0.85 \mathrm{ML}$ of In was added. After annealing at $\approx 200{ }^{\circ} \mathrm{C}$, a well-defined $\mathrm{In} / \mathrm{Pb}$ surface alloy with a $3 \times 3$ periodicity had formed. A detailed investigation of the atomic and electronic structures of this surface alloy was performed.

A LEED pattern obtained at an electron energy of $68 \mathrm{eV}$ shows well-defined $3 \times 3$ spots, see Fig. 5.12.
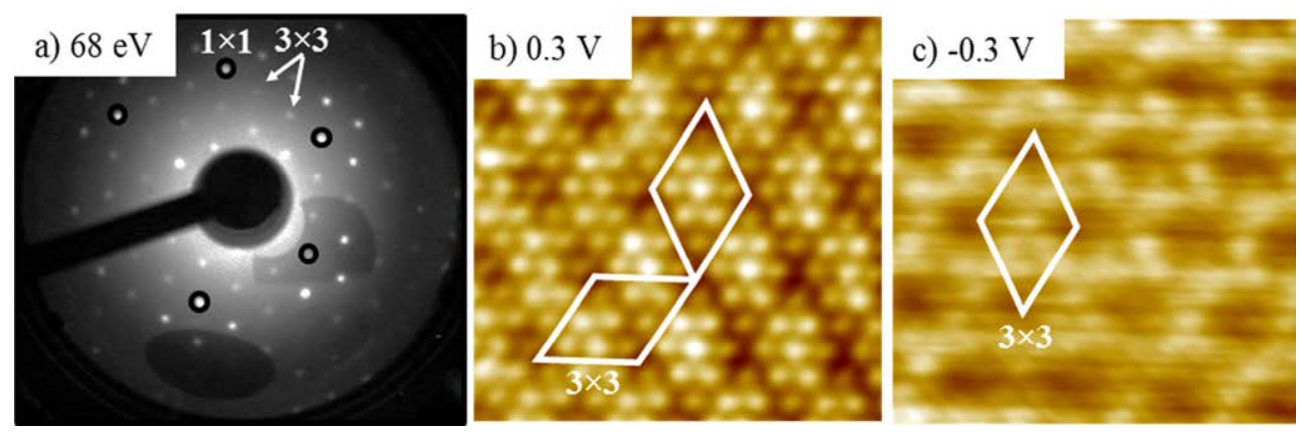

Figure 5.12 (a) LEED pattern of the $\mathrm{In} / \mathrm{Pb} / \mathrm{Ge}(111) 3 \times 3$ surface, obtained at an electron energy of $68 \mathrm{eV} .1 \times 1$ diffraction spots are highlighted by black circles while $3 \times 3$ spots are indicated by arrows. (b) and (c) Empty and filled state STM images $\left(5 \times 5 \mathrm{~nm}^{2}\right)$ obtained at $50 \mathrm{~K}$, respectively. Nine protrusions are identified in each $3 \times 3$ unit cell. 
Empty and filled state STM images are presented in Figs. 5.12(b) and 5.12(c), obtained at $50 \mathrm{~K}$ with sample biases of $\pm 0.3 \mathrm{~V}$, respectively. Nine atomic sized features with a local hexagonal arrangement constitute the structure within the $3 \times 3$ unit cell. Both empty and filled state images show a similar hexagonal structure although the image in Fig. 5.12(c) is less clear.

The electronic structure of the surface alloy was studied by ARPES. A photon energy of $30 \mathrm{eV}$ was used to obtain the band structure along the high symmetry directions of the $3 \times 3 \mathrm{SBZ}$. There are five surface bands identified within the bulk band gap, of which four cross the Fermi level resulting in a metallic character of the surface. Two-dimensional Fermi contours of the metallic bands exhibit interesting features.

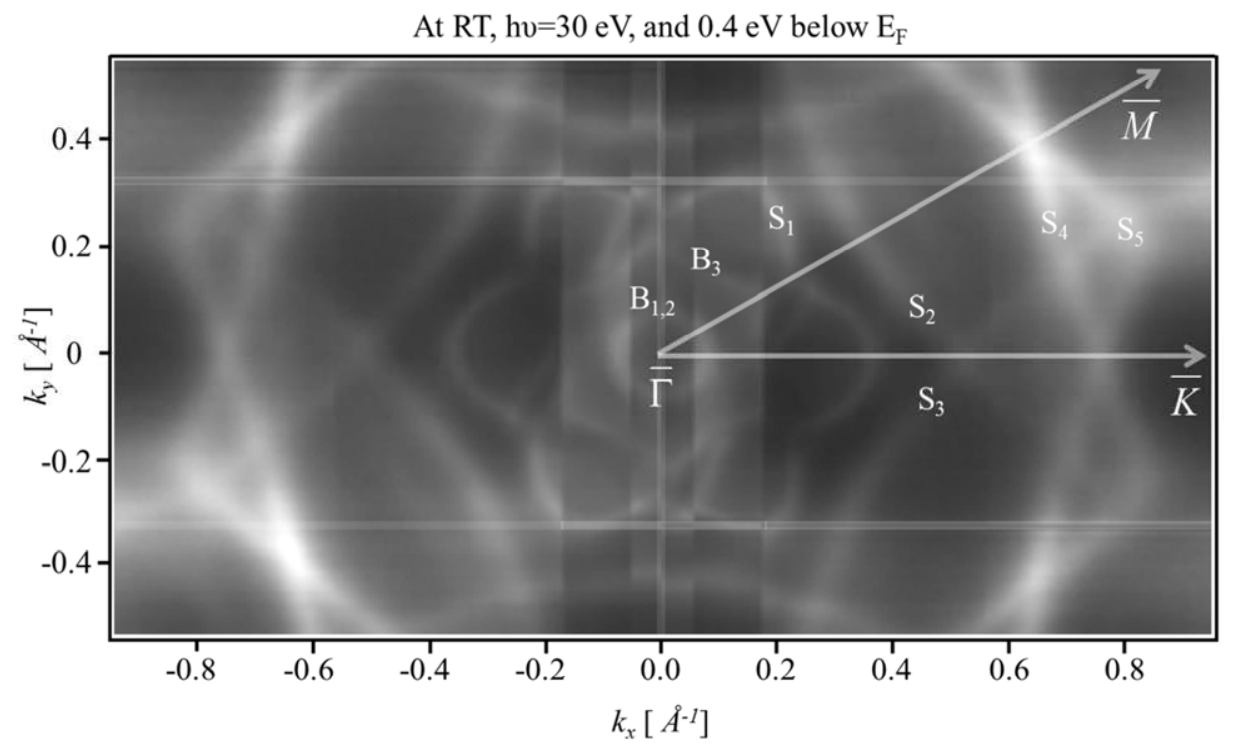

Figure 5.13 Constant energy contours of the $\mathrm{In} / \mathrm{Pb} / \mathrm{Ge}(111) 3 \times 3$ surface obtained by ARPES using a photon energy of $30 \mathrm{eV}$, at RT. The contour data are shown at $0.4 \mathrm{eV}$ below $\mathrm{E}_{\mathrm{F}}$.

In Fig. 5.13, constant energy contours at $0.4 \mathrm{eV}$ below $\mathrm{E}_{\mathrm{F}}$ is shown, which include features from the metallic bands as well as bulk contributions. There are two differently rotated hexagons in the figure. There is a degeneracy of two metallic bands $\mathrm{S}_{4}$ and $\mathrm{S}_{5}$ along the $\bar{\Gamma}-\bar{M}$ and $\bar{\Gamma}-\bar{K}$ directions. In addition, $\mathrm{S}_{2}$ and $\mathrm{S}_{3}$ cross along the $\bar{\Gamma}-\bar{K}$ direction. The flower like contour centered at the $\bar{\Gamma}$-point, is related to contribution from the $S_{1}$ band. Closer to the $\bar{\Gamma}$-point there are contours related to bulk band structures labeled $B_{1,2}$ and $B_{3}$. An interesting feature of the constant energy contours is the existence of the two rotated distorted hexagons which are formed by the $\mathrm{S}_{4}$ and $\mathrm{S}_{5}$ bands. As in the case of the $\mathrm{Sn} / \mathrm{Ag} / \mathrm{Si}(111) 2 \times 2$ surface alloy, one can expect that these distorted and rotated contours provide vital information related to the atomic structure of the $\mathrm{In} / \mathrm{Pb} / \mathrm{Ge}(111) 3 \times 3$ surface alloy. 
Core level spectra of In $4 d, \mathrm{~Pb} 5 d$ and Ge $3 d$ are shown in Fig. 5.14, obtained at RT. The sharp $\mathrm{Pb} 5 d$ spectrum in Fig. 5.14(a) can be fitted by two spin-orbit split components with a Doniach-Šunjić line profile. The In $4 d$ spectrum is fitted by only one spin-orbit split component. The In $4 d$ and $\mathrm{Pb} 5 d$ core level emissions are well-defined with no shifted components, which indicate that the In and $\mathrm{Pb}$ atoms occupy well-defined positions on the $\mathrm{In} / \mathrm{Pb} / \mathrm{Ge}(111) 3 \times 3$ surface. The Ge $3 d$ spectrum in Fig. 5.14(b) is fitted by three components, but it is quite broad and featureless and cannot provide any structural information.

a)

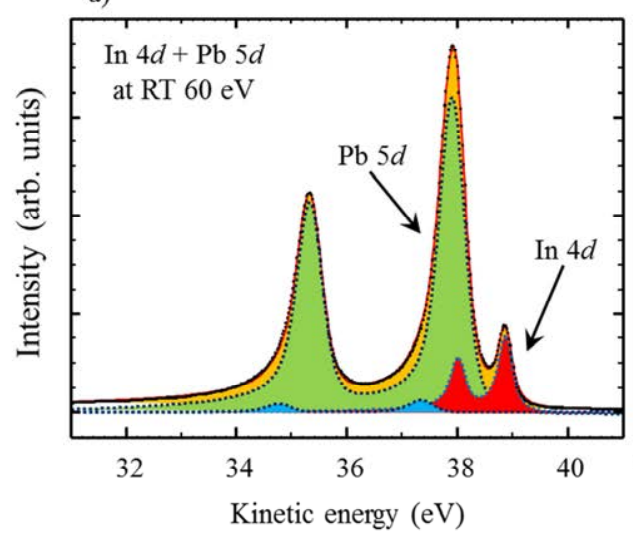

b)

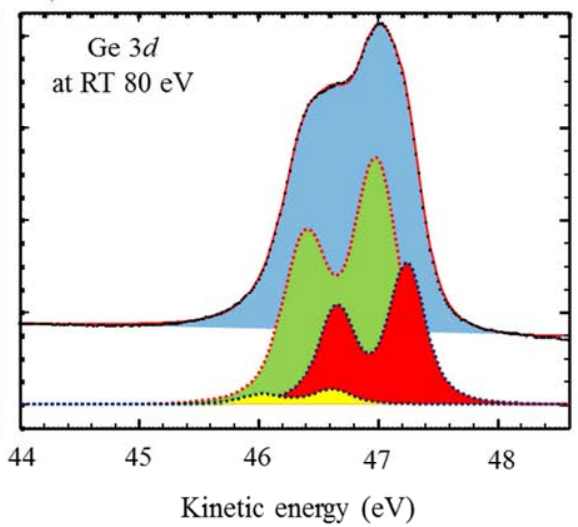

Figure 5.14 (a) Core level spectrum obtained at a photon energy of $60 \mathrm{eV}$ at RT. Emission from both the In $4 d$ and $\mathrm{Pb} 5 d$ levels contribute to the spectrum. (b) Ge $3 d$ core level spectrum obtained at RT using a photon energy of 80 $\mathrm{eV}$.

In conclusion, the $\mathrm{In} / \mathrm{Pb} / \mathrm{Ge}(111) 3 \times 3$ is an exceptionally well-ordered binary surface alloy having metallic character. The results act as inspiration to investigate other possible binary combinations of atomic species which might exhibit interesting properties. 


\section{References}

1. Friedhelm Bechstedt, Principles of Surface Physics, Springer (2003).

2. M. Prutton, Introduction to Surface Physics, Clarendon press, Oxford (1994).

3. P. Bak, Rep. Prog. Phys. 45, 587 (1982).

4. E. Bauer, in Structure and Dynamics on Surfaces 2, edited by W. Schommers and P. von Blanckenhagen (Springer, Berlin, 1987), pp. 115-180.

5. G. Grüner, Density Waves in Solids (Addison-Wesley, Reading, MA, 1994).

6. S. V. Kravchenko, G. V. Kravchenko, J. E. Furneaux, V. M. Pudalov, and M. D’Iorio, Phys. Rev. B 50, 8039 (1994).

7. S. Hasegawa, Y. Nagai, T. Oonishi, N. Kobayashi, T. Miyake, S. Murakami, Y. Ishii, D. Hanawa, and S. Ino, Phase Transitions 53, 87 (1995).

8. H. W. Yeom, S. Takeda, E. Rotenberg, I. Matsuda, K. Horikoshi, J. Schaefer, C. M. Lee, S. D. Kevan, T. Ohta, T. Nagao, and S. Hasegawa, Phys. Rev. Lett. 82, 4898 (1999).

9. M. S. E. Abrahams and S. Kravchenko, Rev. Mod. Phys. 73, 251 (2001).

10. H. M. Zhang, T. Balasubramanian, and R. I. G. Uhrberg, Phys. Rev. B 63, 195402 (2001).

11. H. M. Zhang, Kazuyuki Sakamoto, and R. I. G. Uhrberg, Phys. Rev. B 64, 245421 (2001).

12. H. M. Zhang, T. Balasubramanian, and R. I. G. Uhrberg, Phys. Rev. B 66, 165402 (2002).

13. J. N. Crain, K. N. Altmann, C. Bromberger, and F. J. Himpsel, Phys. Rev. B 66, 205302 (2002).

14. E. Rotenberg, H. Koh, K. Rossnagel, H. W. Yeom, J. Schäfer, B. Krenzer, M. P. Rocha, and S. D. Kevan, Phys. Rev. Lett. 91, 246404 (2003).

15. J. L. McChesney, J. N. Crain, V. Pérez-Dieste, F. Zheng, M. C. Gallagher, M. Bissen, C. Gundelach, and F. J. Himpsel, Phys. Rev. B 70, 195430 (2004).

16. Matsuda, T. Hirahara, M. Konishi, C. Liu, H. Morikawa, M. D'angelo, S. Hasegawa, T. Okuda, and T. Kinoshita, Phys. Rev. B 71, 235315 (2005).

17. R. Cortés, A. Tejeda, J. Lobo, C. Didiot, B. Kierren, D. Malterre, E. G. Michel, and A. Mascaraque, Phys. Rev. Lett. 96, 126103 (2006). 
18. W. H. Choi, H. Koh, E. Rotenberg, and H. W. Yeom, Phys. Rev. B 75, 075329 (2007).

19. W. H. Choi, P. G. Kang, K. D. Ryang, and H. W. Yeom, Phys. Rev. Lett. 100, 126801 (2008).

20. Harumo Morikawa, Iwao Matsuda, and Shuji Hasegawa, Phys. Rev. B 77,193310 (2008).

21. Patrick Han, and Paul S. Weiss, Surf. Sci. Rep. 67, 19-81 (2012).

22. Hafiz M. Sohail, and R. I. G. Uhrberg, Surf. Sci. accepted for publication (2014).

23. Hafiz M. Sohail, J. R. Osiecki, and R. I. G. Uhrberg, Phys. Rev. B 85, 205409 (2012).

24. Jacek R. Osiecki, H. M. Sohail, P. E. J. Eriksson, and R. I. G. Uhrberg, Phys. Rev. Lett. 109, 057601 (2012).

25. C. Kittel, Introduction to Solid State Physics, John Wiley \& Sons, Inc. $7^{\text {th }}$ edition (1996).

26. G. Binnig, H. Rohrer, C. Gerger, and E. Wiebel, Phys. Rev. Lett. 50, 120 (1983).

27. Ernst Meyer, Hans Josef Hug, and Roland Bennewitz, Scanning Probe Microscopy, Springer (2004).

28. J. Tersoff and D. R. Hamann, Phys. Rev. Lett. 50, 1998 (1983).

29. J. Tersoff and D. R. Hamann, Phys. Rev. B 31, 805 (1985).

30. J. Bardeen, Phys. Rev. Lett. 6, 57 (1960).

31. Stefan Hüfner, Photoelectron Spectroscopy - Principles and Applications, Springer, (2003).

32. S. Hagström, C. Nordling, and K. Siegbahn, Phys. Lett. 9, 235 (1964).

33. P. Hohenberg and W. Kohn, Phys. Rev. 136(3B), B864-B871, (1964).

34. R. M. Martin, Electronic Structure, basic theory and practical methods, Cambridge University Press, (2004).

35. W. Kohn and L. J. Sham, Phys. Rev. 140(4A), A1133-A1138, (1965).

36. Peter Blaha, Karlheinz Schwarz, Georg K. H. Madsen, Dieter Kvasnicka, Joachim Luitz, WIEN2k, An Augmented Plane Wave Plus Local Orbitals Program for Calculating Crystal Properties, User's Guide, WIEN2k_10.1, (2010).

37. J. P. Perdew, K. Burke, and M. Ernzerhof, Phys. Rev. Lett. 77, 3865 (1996).

38. P. E. J. Eriksson, Kazuyuki Sakamoto, and R. I. G. Uhrberg, Phys. Rev. B 81, 205422 (2010).

39. P. E. J. Eriksson and R. I. G. Uhrberg, Phys. Rev. B 81, 125443 (2010).

40. M. W. Radny, G. A. Shah, S. R. Schofield, P. V. Smith, and N. J. Curson, Phys. Rev. Lett. 100, 246807 (2008).

41. J. A. Kubby, J. E. Griffith, R. S. Becker, and J. S. Vickers, Phys. Rev. B 36, 6079 (1987).

42. Kazuyuki Sakamoto, Martin Setvin, Kenji Mawatari, P. E. J. Eriksson, Kazushi Miki, and R. I. G. Uhrberg, Phys. Rev. B 79, 045304 (2009).

43. H. E. Farnsworth, R. E. Shlier, and J. A. Dillon, J. Phys. Chem. Solids, 8, 116 (1959).

44. K. Takayanagi, Y. Tanishiro, M. Takahashi, H. Motoyoshi, and K. Yagi, Electron Microsc, 2, 285 (1984).

45. I. K. Robinson, W. K. Waskiewicz, P. H. Foss, J. B. Stark, and P. A. Bennet, Phys. Rev. B 33, 7013 (1986). 
46. S. Y. Tong, H. Huang, C. M. Wei, W. E. Packard, F. K. Men, G. Glander, and M. B. Webb, J. Vac. Sci. Technol., A6, 615 (1988).

47. R. I. G. Uhrberg, T. Kaurila, and Y.-C. Chao, Phys. Rev. B 58, R1730(R) (1998).

48. R. J. Hamers, R. M. Tromp, and J. E. Demuth, Phys. Rev. Lett. 56,1972 (1986).

49. T. Yokotsuka, S. Kono, S. Suzuki, and T. Sagawa, Jpn. J. Appl. Phys. 23, L69 (1984).

50. R. S. Becker, B. S. Swartzentruber, J. S. Vickers, and T. Klitsner, Phys. Rev. B 39, 1633 (1981).

51. E. S. Hirschorn, D. S. Lin, F. M. Leibsle, A. Samsavar, and T. C. Chiang, Phys. Rev. B 44, 1403 (1991).

52. I. Razado-Colambo, Jiangping He, H. M. Zhang, G. V. Hansson, and R. I. G. Uhrberg, Phys. Rev. B 79, 205410 (2009).

53. L. S. O. Johansson, E. Landemark, C. J. Karlsson, and R. I. G. Uhrberg, Phys. Rev. Lett. 63, 2092 (1989).

54. Y. G. Ding, C. T. Chan, and K. M. Ho, Phys. Rev. Lett. 67, 1454 (1991).

55. G. Le Lay, V. Yu. Aristov et al., Surf. Sci. 307-309, 280 (1993).

56. H. Huang, H. Over, J. Quinn, F. Jona, and S. Y. Tong, Phys. Rev. B 49, 13483 (1994).

57. H. H. Weitering, and J. M. Carpinelli, Surf. Sci. 384, 240 (1997).

58. D. J. Spence, S. P. Tear, Surf. Sci. 398, 91 (1998).

59. D. Grozea, E. Bengu, L. D. Marks, Surf. Sci. 461, 23 (2000).

60. H. Aizawa, M. Tsukada, N. Sato, and S. Hasegawa, Surf. Sci. 429, L509 (1999).

61. N. Sato, T. Nagao, and S. Hasegawa, Surf. Sci. 442, 65 (1999).

62. Norio Sato, Tadaaki Nagao, and Shuji Hasegawa, Phys. Rev. B 60, 16083 (1999).

63. Xiao Tong, Satoru Ohuchi, Norio Sato, Takehiro Tanikawa, Tadaaki Nagao, Iwao Matsuda, Yoshinobu Aoyagi, and Shuji Hasegawa, Phys. Rev. B 64, 205316 (2001).

64. R. I. G. Uhrberg, H. M. Zhang, T. Balasubramanian, E. Landemark, and H. W. Yeom, Phys. Rev. B 65, 081305(R) (2002), and references therein.

65. H. M Zhang, T Balasubramanian, R. I. G Uhrberg, Appl. Surf. Sci. 175-176, 237 (2001).

66. H. M. Zhang, Kazuyuki Sakamoto, and R. I. G. Uhrberg, Surf. Sci. 532-535, 934 (2003).

67. H. M. Zhang, R. I. G. Uhrberg, Surf. Sci. 546, L789 (2003).

68. L.-W. Chou, H. C. Wu, Y.-R. Lee, J.-C. Jiang, C. Su, and J.-C. Lin, J. Chem. Phys. 131, 224705 (2009).

69. S. Watanabe, M. Aono, and M. Tsukada, Phys. Rev. B 44, 8330 (1991).

70. S. Watanabe, Y. Kondo, Y. Nakamura, and J. Nakamura, Sci. and Tech. of Adv. Mat. 1, 167-172 (2000).

71. Lan Chen, H. J. Xiang, Bin Li, Aidi Zhao, Xudong Xiao, Jinlong Yang, J. G. Hou, and Qingshi Zhu, Phys. Rev. B 70, 245431 (2004).

72. Hiroko Kaji, Kiminori Kakitani, Surf. Sci. 601, 2491-2497 (2007).

73. H. M. Zhang, R. I. G. Uhrberg, Appl. Surf. Sci. 212-213, 353 (2003). 


\section{Part II}

Included papers 



\section{Papers}

The articles associated with this thesis have been removed for copyright reasons. For more details about these see:

http://urn.kb.se/resolve?urn=urn:nbn:se:liu:diva-105223 